FERNANDO MATTIUCCI MARQUES

\title{
INFLUÊNCIA DO ÍON ZINCO NA REATIVIDADE QUÍMICA DA MIOGLOBINA
}

SÃO CARLOS, 2019 


\section{UNIVERSIDADE DE SÃO PAULO \\ INSTITUTO DE QUÍMICA DE SÃO CARLOS \\ PROGRAMA DE PÓS-GRADUAÇÃO EM QUÍMICA}

Fernando Mattiucci Marques

\section{INFLUÊNCIA DO ÍON ZINCO NA REATIVIDADE QUÍMICA DA MIOGLOBINA}

Tese apresentada ao Instituto de Química de São Carlos da Universidade de São Paulo como parte dos requisitos para a obtenção de título de Doutor em Ciências

Prof. Dr. Daniel R. Cardoso (orientador) 


\section{RESUMO}

Estudo da reatividade de heme-proteínas é de relevância para processos redox no sistema biológico e na digestão de alimentos. A mioglobina (Mb) é a ferro-heme proteína majoritária do músculo esquelético de mamíferos, e tem como principal função biológica suprir a demanda mitocondrial de oxigênio no músculo. Na carne, a Mb é o principal pigmento responsável pela coloração do produto; porém durante sua digestão, esta pode ser ativada por peróxidos à espécies hipervalentes que promovem estresse oxidativo no trato digestivo. $\mathrm{O}$ íon zinco $\left(\mathrm{Zn}^{\mathrm{II}}\right)$ se apresenta como um componente estrutural e/ou funcional de várias metaloenzimas e metaloproteínas, participando de muitas reações do metabolismo celular e de processos fisiológicos. Desta forma, a estrutura e a reatividade da $\mathrm{Mb}$ foi investigada frente a íons de $\mathrm{Zn}{ }^{\mathrm{II}}$. Os dados de espectroscopia de absorção eletrônica sugerem uma alteração conformacional da proteína, e consequentemente uma distorção do anel porfirínico. A intensidade de emissão de fluorescência intrínseca do triptofano (Trp) é aumentada com o aumento da concentração de íons $\mathrm{Zn}^{\mathrm{II}}$. O máximo de emissão não é deslocada no espectro de fluorescência, indicando, desta forma, que o ambiente químico do Trp permanece hidrofóbico. De acordo com dados obtidos por Dicroismo Circular (CD), observa-se um aumento do valor absoluto do sinal de elipticidade molar sugerindo mudanças conformacionais significativas ao longo do tempo. A deconvolução dos espectros de CD revela um decréscimo da estrutura secundária do tipo $\alpha$-hélice e aumento da estrutura secundária de folha- $\beta$ com estrutura randômica. Através dos dados de titulação isotérmica microcalorimétrica (ITC) para a interação entre a $\mathrm{Mb}$ e os íons de $\mathrm{Zn}{ }^{\mathrm{II}}$ foram determinados os parâmetros entálpicos $(\Delta \mathrm{H}=-88,07 \pm 0,50 \mathrm{~kJ}$ $\left.\mathrm{mol}^{-1}\right)$, entrópicos $\left(\Delta \mathrm{S}=-208,78 \pm 0,30 \mathrm{~J} \mathrm{~mol}^{-1} \mathrm{~K}^{-1}\right)$ e a variação de energia livre de Gibbs $(\Delta \mathrm{G}=$ $\left.-25,85 \pm 0,50 \mathrm{~kJ} \mathrm{~mol}^{-1}\right)$ a $298 \mathrm{~K}$. Também foi possível determinar a constante de equilíbrio a 298 $\mathrm{K}\left(\mathrm{K}_{\mathrm{A}}=(3,22 \pm 0,2) \times 10^{4} \mathrm{~L} \mathrm{~mol}^{-1}\right)$ com estequiometria $=1: 1$. A redução da espécie ferrilmioglobina $\left(\mathrm{MbFe}^{\mathrm{IV}}=\mathrm{O}\right)$ pela cisteína produz a metamioglobina $\left(\mathrm{MbFe}^{\mathrm{III}}\right)$ e sulfomioglobina (SulfMbFe ${ }^{\mathrm{II}}$ ), na ausência e presença de íons de $\mathrm{Zn}^{\mathrm{II}}$, a constante de velocidade de segunda ordem para a formação da espécie SulfMbFe ${ }^{\mathrm{II}}$ a $298 \mathrm{~K}$ foi de $\mathrm{k}_{2}=1,39 \pm 0,16 \mathrm{~L} \mathrm{~mol}^{-1} \mathrm{~s}^{-1} \mathrm{e} \mathrm{k}_{2} \approx 3,25 \pm$ $0,18 \mathrm{~L} \mathrm{~mol}^{-1} \mathrm{~s}^{-1}$ respectivamente. Os estudos de espectroscopia de absorção de transientes mostraram que a $\mathrm{Mb}$ apresenta uma afinidade maior pelo ligante $\left(\mathrm{O}_{2}\right.$ e $\left.\mathrm{CO}\right)$ com íons de $\mathrm{Zn}^{\mathrm{II}}$ no meio reacional. A espécie perferrilMb foi gerada através da irradiação $(355 \mathrm{~nm})$ da espécie ferrilMb. $\mathrm{O}$ estudo da $\mathrm{Zn}$-perferrilMb frente ao redutor $\mathrm{CO}$, indica a formação da espécie $\mathrm{CO}_{2}$ resultando em uma redução via 2 elétrons formando a espécie metamioglobina. 


\begin{abstract}
Study of the reactivity of heme-proteins is relevant for the redox processes in the biological system and in the digestion of food. Myoglobin $(\mathrm{Mb})$ is the major iron-heme protein of mammalian skeletal muscle and has as main biological function to supply the mitochondrial demand of oxygen in the muscle. In meat the $\mathrm{Mb}$ is the main pigment responsible for the color of the product, however during its digestion it can be activated by peroxides to hypervalent species that promote oxidative stress in the digestive tract. The zinc ion $\left(\mathrm{Zn}^{\mathrm{II}}\right)$ presents as a structural and / or functional component of several metalloenzymes and metalloproteins, participating in many reactions of cellular metabolism and physiological processes. Thus, the structure and reactivity of $\mathrm{Mb}$ was investigated compared to zinc ions. Absorption spectroscopy data suggests a conformational change of the protein consequently, a distortion of the porphyrin ring. An intrinsic fluorescence emission intensity of tryptophan (Trp) is increased with increasing concentration of zincII ions. The emission is not shifted in the fluorescence spectrum, indicating, in this way, the chemical environment of the Trp will remain hydrophobic. According to the Circular Dichroism (CD) data, there is an increase in the absolute value of the ellipticity signal, suggesting conformational changes over time. The deconvolution of the CD spectra reveals a decrease of the $\alpha$-helical secondary structure and increase of the $\beta$-sheet structure with random structure. Through the microcalorimetric isothermal titration (ITC) data was determined the interaction between $\mathrm{Mb}$ and the zinc ions, the enthalpy parameters $\left(\Delta \mathrm{H}=-88,07 \pm 0,50 \mathrm{~kJ} \mathrm{~mol}^{-1}\right)$, entropic parameters $\left(\Delta \mathrm{S}=-208,78 \pm 0,30 \mathrm{~J} \mathrm{~mol}^{-1} \mathrm{~K}^{-1}\right)$ and a Gibbs free energy variation $\left(\Delta \mathrm{G}=-25,85 \pm 0,50 \mathrm{~kJ} \mathrm{~mol}^{-1}\right)$ at $298 \mathrm{~K}$. It was also possible to determine the equilibrium constant at $298 \mathrm{~K}\left(\mathrm{~K}_{\mathrm{A}}=(3.22 \pm 0.2) \times 10^{4} \mathrm{~L} \mathrm{~mol}^{-1}\right)$ with stoichiometry $=1: 1$. The reduction of the ferrilmioglobin $(\mathrm{MbFeIV}=\mathrm{O})$ by cysteine produces metamioglobin (MbFeIII) and sulfomioglobin (SulfMbFeII), in the absence and presence of zinc ions II, the second order rate constant for the formation of the SulfMbFeII species at $298 \mathrm{~K}$ was $1.39 \pm 0.16 \mathrm{~L} \mathrm{mol-1}$ $\mathrm{s}-1$ and $\mathrm{k}^{\prime} 2 \approx 3.25 \pm 0.18 \mathrm{~L}$ mol-1 s-1 respectively. Transient absorption spectroscopy studies showed that $\mathrm{Mb}$ has a higher affinity for the ligand $\left(\mathrm{O}_{2}\right.$ and $\left.\mathrm{CO}\right)$ with zincin II ions in the reaction medium. The perferrilMb species was generated by the irradiation $(355 \mathrm{~nm})$ of the ferrilMb species. The study of $\mathrm{Zn}$-perferrilMb versus the $\mathrm{CO}$ indicates the formation of the $\mathrm{CO}_{2}$ resulting in a reduction by 2 electrons forming the metamioglobin species.
\end{abstract}




\section{LISTA DE FIGURAS}

Figura 1. (A) Representação dos cinco orbitais d (B) Aproximação de seis ligantes ao redor de um íon metálico (C) Desdobramento dos cinco orbitais d em um campo octaédrico.

Figura 2. Absorção da luz em complexos octaédricos resultando da transição metal-metal (d-d), transferência de carga do ligante para o metal (LMCT), transferência de carga do metal para o ligante (MLCT) e transição ligante-ligante (L-L).

Figura 3. Espectro de absorção eletrônica e as atribuições de bandas para uma dada espécie ferro-heme.

Figura 4. (A) Ilustração da estrutura tridimensional da mioglobina com destaque a ferroporfirina e as His64 e His93 situado no bolso hidrofóbico da globina (oito $\alpha$-hélices de A a H). (B) Estrutura química da protoporfirina IX constituinte do grupo prostético da mioglobina, onde $\mathrm{L}=\mathrm{O}_{2}, \mathrm{CO}, \mathrm{NO}$.

Figura 5. Os diferentes estados redox da mioglobina e suas interconversões: deoxymioglobina, oximioglobina e metamioglobina.

Figura 6. Representação do ferro heme e da histidina distal, favorecendo estabilidade à ligação $\mathrm{Fe}-\mathrm{O}_{2}$ pela formação de uma ligação de hidrogênio entre o $\mathrm{NH}$ do imidazol e o oxigênio molecular.

Figura 7. Espectro de absorção eletrônica de $10 \mu \mathrm{M}$ das espécies: deoximioglobina (- - -), oximioglobina ( - ) e metamioglobina ( - - . ) em tampão Tris/HCl $\left(1,0 \times 10^{-2} \mathrm{mMol} \mathrm{L}^{-1}\right) \mathrm{pH} 8,0$ a $25^{\circ} \mathrm{C}$.

Figura 8. Dependência entre constantes de velocidade de segunda ordem e o $\mathrm{pH}$ à $30^{\circ} \mathrm{C}$ para reação de auto-oxidação da mioglobina de músculo bovino ( $2 \mathrm{~h}$ post morten). Amostras do músculo psoas major $(\Delta)$ e longissimus lumborum $(\square)$.

Figura 9. Ciclo da atividade de pseudoperoxidase da mioglobina. HA representa espécie redutora qualquer.

Figura 10. Mecanismo de transferência de elétrons entre doadores e aceptores de elétrons pela interação direta com os doadores (a) MB/ET (Metal-Binding/Electron-Transfer) ou com os íons radicais formados pela oxidação dos doadores de elétrons (b) (ET/MB, Electron-Transfer/MetalBinding).

Figura 11. Estrutura química da cisteína e do monóxido de carbono.

Figura 12. (A) Espectro de absorção eletrônico e (B) Estruturas químicas dos aminoácidos Trp, Tyr e Phe em $\mathrm{pH} 7$.

Figura 13. Espectros típicos de CD na zona do UV-longínquo. O espectro típico de uma $\alpha$-hélice está representado a verde, o de uma folha- $\beta$ a azul e o da estrutura randômica a vermelho.......... 29

Figura 14. Ilustração do processo de fotodissociação do ligante $\mathrm{L}=\mathrm{O}_{2}$ na oximioglobina. ........ 30

Figura 15. Equipamento de Fotólise de Laser Pulsado simplificado. ............................................ 31

Figura 16. Interior de um microscópio eletrônico de transmissão. ................................................ 32 
Figura 17. Espectro de absorção UV-vis da mioglobina $\left(1,0 \times 10^{-5} \mathrm{~mol} \mathrm{~L}^{-1}\right)$ na presença de acetato de $\mathrm{Zn}^{\mathrm{II}}\left(5,0 \times 10^{-3} \mathrm{~mol} \mathrm{~L}^{-1}\right)$ adquiridos em diferentes tempos após a adição do íon $\mathrm{Zn}{ }^{\mathrm{II}}$. (a) Espectro de absorção na janela espectral de $250 \mathrm{~nm}-450 \mathrm{~nm}$; (b) Espectro de absorção na janela espectral de $450 \mathrm{~nm}-700 \mathrm{~nm}$. Tampão acetato $0,16 \mathrm{~mol} \mathrm{~L}^{-1} \mathrm{pH}=5,8(\mathrm{~T}=298 \mathrm{~K})$.

Figura 18. Espectro de absorção vibracional no infravermelho da $\mathrm{MbFe}^{\mathrm{II}} \mathrm{O}_{2}\left(0,01 \mathrm{~mol} \mathrm{~L}^{-1}\right)$ em tampão acetato (pH 5,7) a $298 \mathrm{~K}$, nas concentrações de $\mathrm{Zn}^{\mathrm{II}}$ indicadas... 40

Figura 19. (A) Espectro de emissão de fluorescência da metamioglobina $\left(\mathrm{MbFe}^{\mathrm{III}} \mathrm{H}_{2} \mathrm{O}\right)$ em diferentes concentrações de acetato de zinco $\left(\left[\mathrm{Zn}^{\mathrm{II}}\right]=0 \rightarrow 3 \times 10^{-2} \mathrm{~mol} \mathrm{~L}^{-1}\right)$; espectros adquiridos 1 min após adição de $\mathrm{Zn}^{\mathrm{II}}$. (B) Curva de intensidade vs tempo para o sistema $\mathrm{Mb}\left(1,0 \times 10^{-5} \mathrm{~mol} \mathrm{~L}^{-}\right.$ $\left.{ }^{1}\right)+\mathrm{Zn}^{\mathrm{II}}$. Tampão acetato $0,16 \mathrm{~mol} \mathrm{~L}^{-1} \mathrm{pH}=5,8(\mathrm{~T}=297 \mathrm{~K})$.

Figura 20. Espectros de $\mathrm{CD}$ da metamioglobina na presença de íons $\mathrm{Zn}^{\mathrm{II}}$, em tampão acetato $\left(1,0 \times 10^{-2} \mathrm{~mol} \mathrm{~L}^{-1}\right), \mathrm{pH} 5,8$ e força iônica de $0,16 \mathrm{~mol} \mathrm{~L}^{-1}$ ajustado com $\mathrm{NaCl}$, coletado a cada 5 minutos. Os espectros foram registrados à temperaturas de $293 \mathrm{~K}(\mathrm{~A}), 298 \mathrm{~K}(\mathrm{~B}), 303 \mathrm{~K}(\mathrm{C}) \mathrm{e}$ $308 \mathrm{~K}$ (D) e a concentração de metamioglobina e acetato de zinco foi de $1,0 \times 10^{-5} \mathrm{~mol} \mathrm{~L}^{-1} \mathrm{e}$ $1,6 \times 10^{-2} \mathrm{~mol} \mathrm{~L}^{-1}$ respectivamente. A cubeta utilizada possui um caminho óptico de $0,1 \mathrm{~mm}$. Para cada espectro, foram acumulados 8 varrimentos.

Figura 21. (A) Efeito da temperatura na estrutura da metamiogobina. Sistema químico de MbFeIIIH2O $\left(1,0 \times 10^{-5} \mathrm{~mol} \mathrm{~L}^{-1}\right)+\mathrm{Zn}^{\mathrm{II}}\left(1,60 \times 10^{-2} \mathrm{~mol} \mathrm{~L}^{-1}\right)$. Tampão acetato $1,0 \times 10^{-2} \mathrm{~mol} \mathrm{~L}^{-1}, \mathrm{pH}$ $=5,8$ e força iônica de $0,16 \mathrm{~mol} \mathrm{~L}^{-1}$ ajustado com $\mathrm{NaCl}$. (B) Ajuste linear da equação de Van't Hoff.......

Figura 22. Titulação microcalorimétrica de uma solução de metamioglobina $\left(1,16 \times 10^{-4} \mathrm{~mol} \mathrm{~L}^{-1}\right)$ com uma solução de íons de $\mathrm{Zn}^{\mathrm{II}}\left(1,74 \times 10^{-3} \mathrm{~mol} \mathrm{~L}^{-1}\right)$ em tampão acetato $\left(0,16 \mathrm{~mol} \mathrm{~L}^{-1}\right) \mathrm{pH} 5,7.46$

Figura 23. Valores de raio hidrodinâmico aparente de amostras de $\mathrm{Zn}^{\mathrm{II}}$ e $\mathrm{MbFe}^{\mathrm{III}} \mathrm{H}_{2} \mathrm{O}\left(5,0 \times 10^{-4}\right.$ mol L $\left.{ }^{-1}\right)$ em função do tempo em solução tampão acetato $\left(0,16 \mathrm{~mol} \mathrm{~L}^{-1}\right) \mathrm{com}$ pH 5,7 a $298 \mathrm{~K}$... 47

Figura 24. Imagens de MET da metamioglobina após o período de incubação de 24 horas. As escalas de aumento estão indicadas nas figuras. $\left[\mathrm{MbFe}^{\mathrm{III}} \mathrm{H}_{2} \mathrm{O}\right]=5,0 \times 10^{-4} \mathrm{~mol} \mathrm{~L}^{-1}$

Figura 25. Imagens de MET para o sistema Zn-Mb após o período de incubação de 24 horas. As escalas de aumento estão indicadas nas figuras. $\left[\mathrm{MbFe}^{\mathrm{III}} \mathrm{H}_{2} \mathrm{O}\right]=5,0 \times 10^{-4} \mathrm{~mol} \mathrm{~L}^{-1} \mathrm{e}\left[\mathrm{Zn}^{\mathrm{II}}\right]=$ $1,0 \times 10^{-2} \mathrm{~mol} \mathrm{~L}^{-1}$.

Figura 26. (A) Evolução espectral da oximioglobina $\left(\left[\mathrm{MbFe}^{\mathrm{II}} \mathrm{O}_{2}\right]=3,62 \times 10^{-5} \mathrm{~mol} \mathrm{~L}^{-1}\right)$ em intervalos de 30 minutos. (B). Gráfico da cinética de primeira ordem da auto-oxidação (absorção em $544 \mathrm{~nm})$. Solução em tampão acetato $\left(0,16 \mathrm{~mol} \mathrm{~L}^{-1}\right), \mathrm{pH}=5.8$ e T = $298 \mathrm{~K}$.

Figura 27. Constantes de velocidade da reação auto-oxidação da oximioglobina em função da concentração de íons de $\mathrm{Zn}^{\mathrm{II}}$. [ $\left[\mathrm{MbFe}^{\mathrm{II}} \mathrm{O}_{2}\right]=3,62 \times 10^{-5} \mathrm{~mol} \mathrm{~L}^{-1}$ em solução tampão acetato $(0,16$ mol L'-1), $\mathrm{pH}=5,8$ e $\mathrm{T}=298 \mathrm{~K}$.

Figura 28. Espectro de diferença de absorção do transiente no tempo da oximioglobina (A) e carboximioglobina (B) em solução tampão acetato pH 5,7 (Força iônica ajustada $0,16 \mathrm{~mol} \mathrm{~L}^{-1}$ ) a $298 \mathrm{~K}$. O pulso de laser em $532 \mathrm{~nm}(8 \mathrm{~ns})$ e intensidade de $10 \mathrm{~mJ} . \mathrm{cm}^{2}$, solução contendo $3,1 \times 10^{-6}$ mol L ${ }^{-1}$ de $\mathrm{Mb}$.

Figura 29. (A) Curva cinética de transiente da oximioglobina (curva em vermelho) e deoximioglobina (curve em preto). (B) Curva cinética de transiente da carboximioglobina (curva 
em vermelho) e deoximioglobina (curva em preto). Solução tampão acetato pH 5,7 (Força iônica ajustada $0,16 \mathrm{~mol} \mathrm{~L}^{-1}$ ) a $298 \mathrm{~K}$. [MbFe $\left.{ }^{\mathrm{II}} \mathrm{L}\right]=3,1 \times 10^{-6} \mathrm{~mol} \mathrm{~L}^{-1}$. (pulso de laser em $532 \mathrm{~nm}$ com energia de $10 \mathrm{~mJ} \mathrm{~cm}^{-2}$ )

Figura 30. Efeito da presença de concentrações crescentes de íons de $\mathrm{Zn}^{\mathrm{II}}$ na cinética de recombinação da $\mathrm{MbFe}^{\mathrm{II}}$ com os ligantes $\mathrm{O}_{2}$. (A) e com $\mathrm{CO}(\mathrm{C})$. Gráfico de $\mathrm{k}_{\text {obs }}$ vs concentração de $\mathrm{Zn}^{\mathrm{II}}$ para os ligantes $\mathrm{O}_{2}(\mathrm{~B})$ e $\mathrm{CO}(\mathrm{D})$. [MbFeIIL] $=3,1 \times 10^{-6} \mathrm{~mol} \mathrm{~L}^{-1}$, Solução tampão $\mathrm{pH}=$ 5,7 (Força iônica $\left.0,16 \mathrm{~mol} \mathrm{~L}^{-1}\right)$ à $298 \mathrm{~K}$. Pulso de laser em $532 \mathrm{~nm}\left(10 \mathrm{~mJ} \mathrm{~cm}{ }^{-2}\right.$ e duração de 8 $\mathrm{ns})$.

Figura 31. Variação de absorção do processo de auto-redução da espécie ferrilmioglobina $\left(5,0 \times 10^{-5} \mathrm{~mol} \mathrm{~L}^{-1}\right)$ em função do tempo na presença de diferentes concentrações de íons $\mathrm{ZnII}$. Tampão acetato $\mathrm{pH} 5,7$ a $298 \mathrm{~K}$.

Figura 32. Espectros de $\mathrm{CD}$ da ferrilmioglobina $\left(1,2 \times 10^{-5} \mathrm{~mol} \mathrm{~L}^{-1}\right)$ na presença de íons $\mathrm{Zn}$, em tampão acetato $\left(1,0 \times 10^{-2} \mathrm{~mol} \mathrm{~L}^{-1}\right), \mathrm{pH} 5,8$ e força iônica de $0,16 \mathrm{~mol} \mathrm{~L}^{-1}$ ajustado com $\mathrm{NaCl}$. A cubeta utilizada possui um percurso óptico de $0,1 \mathrm{~mm}$. Para cada espectro, foram acumulados 8 varrimentos a $298 \mathrm{~K}$.

Figura 33. Espectros de absorção eletrônica coletados a cada $5 \mathrm{~s}$ da reação entre a espécie $\mathrm{MbFe}^{\mathrm{IV}}=\mathrm{O}\left(5 \times 10^{-5} \mathrm{~mol} \mathrm{~L}^{-1}\right)$ e a cisteína $\left(2,5 \times 10^{-3} \mathrm{~mol} \mathrm{~L}^{-1}\right)$. Tampão acetato $0,16 \mathrm{~mol} \mathrm{~L}^{-1}(\mathrm{pH} 5,7)$ a $298 \mathrm{~K}$.

Figura 34. Dependência linear da constante de velocidade com a concentração de cisteína em condições de pseudo-primeira ordem em solução tampão acetato (pH 5,7) e força iônica de 0,16 $\mathrm{mol} \mathrm{L}^{-1}$ a $298 \mathrm{~K}\left(\left[\mathrm{MbFe}^{\mathrm{IV}}=\mathrm{O}\right]=5 \times 10^{-5} \mathrm{~mol} \mathrm{~L}^{-1}\right)$. Em $625 \mathrm{~nm}$ referente a espécie SulfMbFe ${ }^{\mathrm{II}}(\mathrm{A})$ e em $580 \mathrm{~nm}$ referente a espécie $\mathrm{MbFe}^{\mathrm{IV}}=\mathrm{O}(\mathrm{B})$. A direita, correlação linear entre kobs e concentração de total de cisteína a fim de se obter as constantes de segunda ordem através do coeficiente angular do ajuste linear da reta.

Figura 35. Constante de segunda ordem (k2) do processo de redução da espécie ferrilmioglobina pela cisteína em função da concentração de íons $\mathrm{Zn}^{\mathrm{II}}\left(\left[\mathrm{MbFe}^{\mathrm{IV}}=\mathrm{O}\right]=5 \times 10^{-5} \mathrm{~mol} \mathrm{~L}^{-1}\right)$. Em $580 \mathrm{~nm}$ referente a espécie $\mathrm{MbFe}^{\mathrm{IV}}=\mathrm{O}(\mathrm{A})$ e em $625 \mathrm{~nm}$ referente a espécie $\operatorname{SulfMbFe}^{\mathrm{II}}$ (B). Tampão acetato à temperatura de $298 \mathrm{~K}$.

Figura 36. Espectro de diferença de absorção do transiente no tempo da reação de redução da perferrilmioglobina pelo $\mathrm{CO}(\mathrm{A})$ e na presença de $1 \times 10^{-3} \mathrm{~mol} \mathrm{~L}^{-1}$ de $\mathrm{Zn}^{\mathrm{II}}$ (B) em solução tampão acetato pH 5,7 (Força iônica ajustada $0,16 \mathrm{~mol} \mathrm{~L}^{-1}$ ) a $298 \mathrm{~K}$. O pulso de laser em $355 \mathrm{~nm}(8 \mathrm{~ns}) \mathrm{e}$ intensidade de $10 \mathrm{~mJ} . \mathrm{cm}^{2}$, solução contendo $3,1 \times 10^{-6} \mathrm{~mol} \mathrm{~L}^{-1}$ de $\mathrm{Mb}$ e $0,7 \times 10^{-3} \mathrm{~mol} \mathrm{~L}^{-1}$ de CO. 64

Figura 37. (A) Curva de decaimento da espécie perferrilmioglobina $\left(3 \times 10^{-5} \mathrm{~mol} \mathrm{~L}^{-1}\right) \mathrm{em}$ diferentes concentrações de $\mathrm{Zn}^{\mathrm{II}}$ utilizando $\mathrm{CO}$ como redutor. em solução tampão acetato pH 5,7 (Força iônica ajustada $0,16 \mathrm{~mol} \mathrm{~L}^{-1}$ ) a $298 \mathrm{~K}$. O pulso de laser em $355 \mathrm{~nm}$ (8 ns) e intensidade de $10 \mathrm{~mJ} . \mathrm{cm}^{2}$. (B) Gráfico de kobs versus concentração de acetato de zinco. A partir do ajuste não linear do gráfico (equação 18) calculou-se os valores e k2 e KLigação ......................................... 65

Figura 38. Espectro de FTIR da fase gasosa em tampão acetato pH 5,7 e 298 K. Solução ferrilmioglobina e CO (curva em preto). Após 2 minutos de irradiação $(355 \mathrm{~nm})$, reação e equilíbrio da fase gasosa e líquida (curva em vermelho). $\left[\mathrm{MbFe}^{\mathrm{IV}}=\mathrm{O}\right]=1 \times 10^{-4} \mathrm{~mol} \mathrm{~L}^{-1}$; $[\mathrm{CO}]=$ $7 \times 10^{-4} \mathrm{~mol} \mathrm{~L}^{-1}$ 
Figura 39. Espectros de absorção eletrônica da mistura ferrilmioglobina e CO (curva em preto) e após 2 minutos de irradiação (curva em vermelho). Solução tampão acetato pH 5,8 a $298 \mathrm{~K}$. $\lambda_{\mathrm{ex}}$ $=355 \mathrm{~nm} .\left[\mathrm{MbFe}^{\mathrm{IV}}=\mathrm{O}\right]=4,15 \times 10^{-5} \mathrm{~mol} \mathrm{~L}^{-1} ;[\mathrm{CO}]=7,0 \times 10^{-4} \mathrm{~mol} \mathrm{~L}^{-1}$.

Figura 40. (A) Curvas de decaimento em $440 \mathrm{~nm}$ da perferrilmioglobina $\left(\left[\mathrm{MbFe}^{\mathrm{IV}}=\mathrm{O} \bullet+\right]=\right.$ $3,1 \times 10^{-5} \mathrm{~mol} \mathrm{~L}^{-1}$ ) em diferentes concentrações de $\mathrm{CO}$ a $298 \mathrm{~K}$. Solução tampão acetato força iônica ajustada 0,16 Mol L-1 (pulso de laser em $355 \mathrm{~nm}$ com energia de $30 \mathrm{~mJ} . \mathrm{cm}^{2}$ ). (B) Constantes de primeira ordem $\mathrm{em} \mathrm{s}^{-1}$ para a reação da perferrilmioglobina em função da concentração de monóxido de carbono. 


\section{LISTA DE TABELA}

Tabela 1. Possíveis valores de spin para os sistemas químicos de ferro

Tabela 2. Parâmetros de absorção e fluorescência dos aminoácidos aromáticos em solução aquosa, pH 7. Os comprimentos de onda máximos de absorção e de emissão estão denotados por $\lambda \mathrm{a}$ e $\lambda \mathrm{F}$, respectivamente. $\varepsilon$ é o coeficiente de absorção molar e o rendimento quântico de fluorescência é denotado por $\phi \mathrm{F}$. 28

Tabela 3. Reagentes e solventes utilizados e gases especiais

Tabela 4. Propriedades estruturais e espectroscópicas da metamioglobina em diferentes temperaturas (A) $293 \mathrm{~K}$; (B) $298 \mathrm{~K}$; (C) $303 \mathrm{~K}$ e (D) $308 \mathrm{~K}$, quando na presença de $16 \times 10-3$ mol L-1 de íons ZnII.

Tabela 5. Valores das constantes de associação, dissociação e equilíbrio para a reação de recombinação da $\mathrm{Mb}$ com os ligantes O2 e CO. Solução tampão acetato, pH 5,8 a $298 \mathrm{~K}$. $[\mathrm{MbFeII}]=3,6 \times 10-6 \mathrm{~mol} \mathrm{~L}-1 ;[\mathrm{ZnII}]=0,008 \mathrm{~mol} \mathrm{~L}-1$.

Tabela 6. Propriedades estruturais e espectroscópicas da ferrilmioglobina $(1.2 \times 10-5$ mol L-1) em diferentes concentrações de íons ZnII a $298 \mathrm{~K}$. 


\section{LISTA DE ESQUEMA}

Esquema 1. Ligação reversível e irreversível da molécula de oxigênio ao íon ferroso. ............. 29

Esquema 2. Esquema reacional da auto-oxidação da oxiMb na presença de íons ZnII.............. 50 


\section{SUMÁRIO}

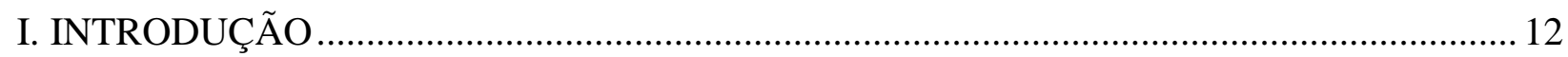

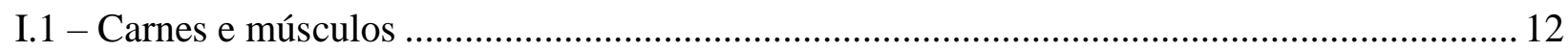

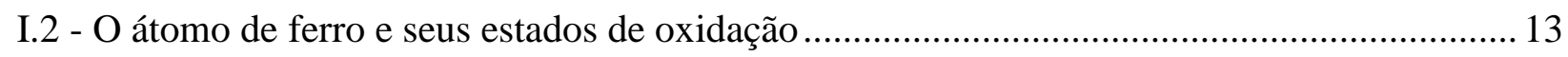

I.3 - Espectroscopia de absorção eletrônica no UV-vis ............................................................. 14

I.3.1 - Espectro eletrônico de absorção de porfirinas livres e ferro-porfirinas ............................... 15

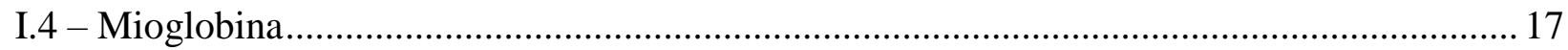

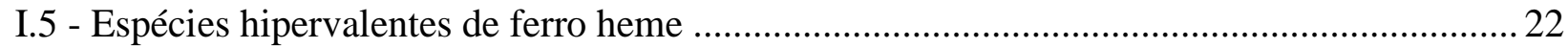

I.6 - Aspectos químicos, bioquímicos e mediador redox do Zinco ................................................. 24

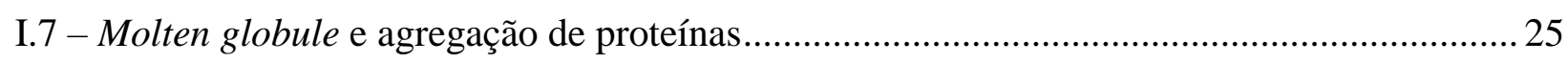

I.8 - Importância da cisteína e do monóxido de carbono em processos oxidativos em meios

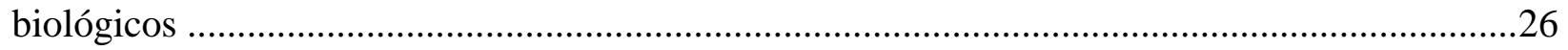

I.9 - Estudo conformacional da proteína por emissão de fluorescência molecular.........................2 27

I.10 - Dicroismo Circular no UV-longínquo (CD UV) ............................................................... 28

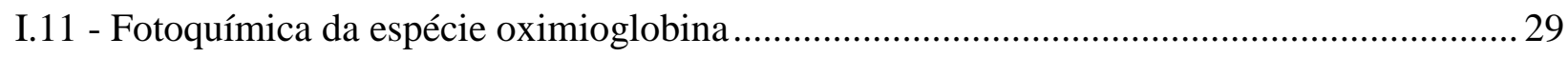

I.12. Fotólise de Laser Pulsado com absorção transiente (LFP) ……………………………......... 30

I. 13 - Microscopia Eletrônica de Transmissão (MET) ……………………………………..... 32

I.14 - Espalhamento de luz dinâmico (DLS)........................................................................... 33

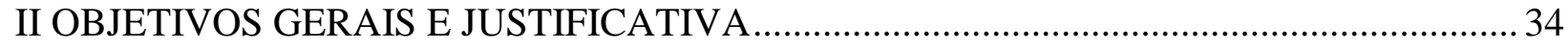

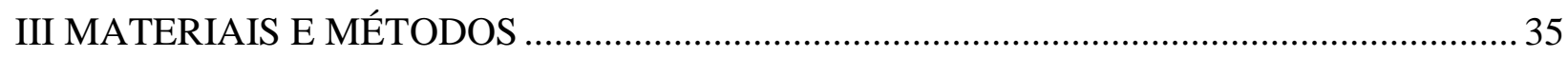

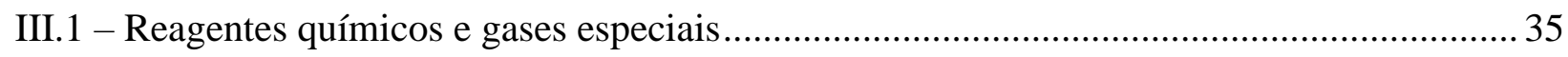

III.2 - Preparo das soluções de mioglobina e sais metálicos .......................................................... 35

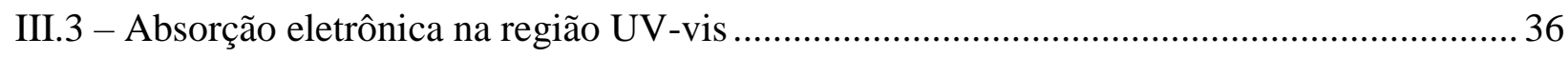

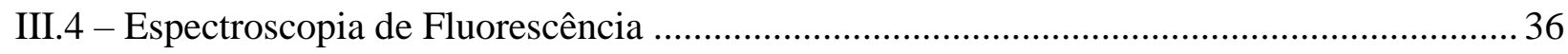

III.5 - Dicroísmo Circular (CD) ………………………..................................................... 37

III.6 - Titulação isotérmica microcalorimétrica (ITC) ………………………………………........ 37

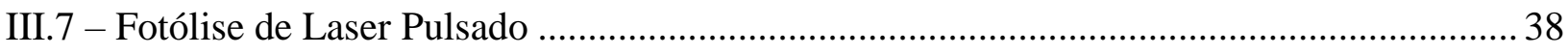

III.8 - Microscopia Eletrônica de Transmissão (MET) ………………………………………..... 38

III.9 - Espectroscopia vibracional na região do infravermelho (FTIR)........................................ 38

III.10 - Espalhamento de luz dinâmico (DLS) …………….................................................... 38

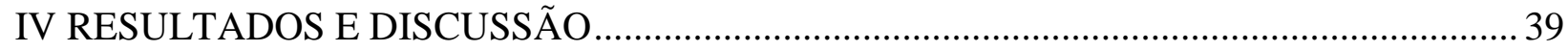

IV.1 - Estudo de absorção UV-Vis e FTIR para o sistema $\mathrm{Mb} / \mathrm{Zn}^{\mathrm{II}}$............................................ 39

IV.2 - Estudo de emissão de fluorescência para o sistema $\mathrm{Mb} / \mathrm{Zn}^{\mathrm{II}}$............................................ 41 
IV.3 - Análise da estrutura secundária da metamioglobina por Dicroísmo Circular UV-vis ...... 42

IV.4 - Análise por titulação isocalorimétrica da interação entre a mioglobina e íons de $\mathrm{Zn}^{\mathrm{II}}$..... 45

IV.5 - Espalhamento dinâmico de Luz (DLS) .................................................................... 47

IV.6 - Microscopia eletrônica de transmissão (MET) ......................................................... 48

IV.7 - Estudo da reação de auto-oxidação da espécie Oxymioglobina $\left(\mathrm{MbFe}^{\mathrm{II}} \mathrm{O}_{2}\right)$...................50

IV.8 - Estudo de transientes das espécies MbFe ${ }^{\mathrm{II}} \mathrm{L}$............................................................... 53

IV.8.1 - Fotólise da deoximioglobina na presença de íons de $\mathrm{Zn}^{\mathrm{II}}$........................................55

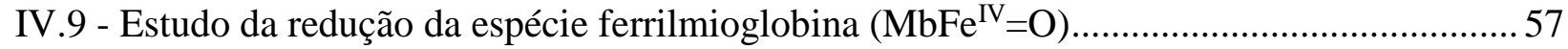

IV.9.1- Estudo da auto-redução da espécie ferrilmioglobina na presença de íons $\mathrm{Zn}{ }^{\mathrm{II}}$...............57

IV.9.2 - Análise da estrutura secundária da ferrilmioglobina por Dicroísmo Circular UV-vis .... 58

IV.9.3 - Estudo da reatividade da ferrilmioglobina pela cisteína na presença de íons $\mathrm{Zn}{ }^{\mathrm{II}}$.........60

IV 9.4 - Estudo da influência de íons $\mathrm{Zn}^{\text {II }}$ na oxidação do monóxido de carbono mediada pela

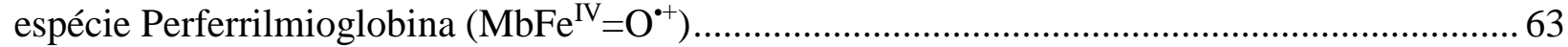

IV 9.5 - Cinética de oxidação monóxido de carbono mediada pela Perferrilmioglobina

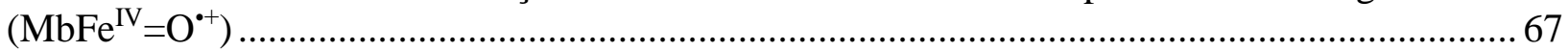

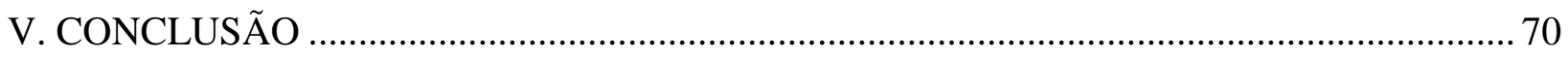

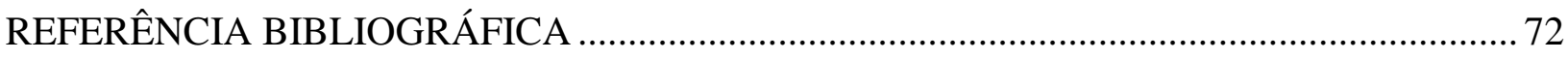

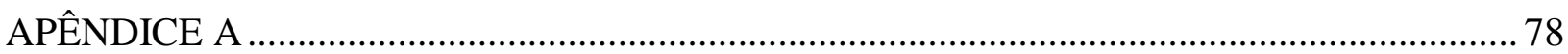

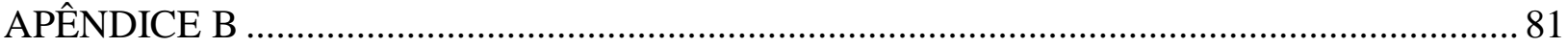

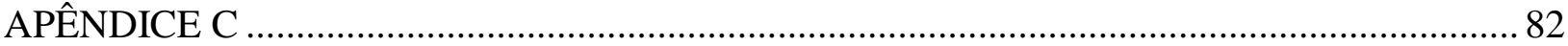




\section{INTRODUÇÃO}

\section{I.1 - Carnes e músculos}

O produto "carne" vendido ao consumidor ou em estado de corte nos frigoríficos provem de diversas transformações químicas e biológicas, principalmente os eventos bioquímicos causados pelo condicionamento físico e químico do produto. O condicionamento do material a baixas ou altas temperaturas, em diferentes valores de $\mathrm{pH}$ e na presença de conservantes, são alguns estudos já demonstrados na literatura (JAMES, JAMES, 2002; MOTTRAM, 1998).

O produto "carne" possui grande destaque na alimentação humana, ocupando a posição de prato principal nas diferentes refeições ao longo do dia (TEICHMANN, 2000). Isso de seve ao fato de a carne possuir alto valor proteico, possuindo uma relevante importância do metabolismo de diferentes organismos vivos, e podendo ainda atuar como uma importante fonte de energia (KINTON; CESERANI; FOSKETT, 1999).

A cor da carne provem de diferentes fatores, tais como espécie do animal, idade, concentração e as três formas da mioglobina $(\mathrm{Mb})$ - maiores contribuintes para os desclocamentos e as diferentes transienções eletrônicas no espectro do visível (BECKER, et al. 2012). As possíveis colorações para a carne são:

- Vermelho Púrpura - Mioglobina Reduzida (Mb);

- Vermelho Brilhante - Mioglobina Oxigenada ou Oximioglobina (MbO2);

- Vermelho Marrom Mioglobina Oxidada ou Metamioglobina (MetMb).

Nos músculos vivos, a mioglobina $(\mathrm{Mb})$ é uma das espécies bioquímicas que armazena e transporta o oxigênio. Nas carnes em geral, a Mb atua como principal fonte de pigmento, conferindo assim a cor vermelha que observamos nos frigoríficos (SUMAN, JOSEPH, 2013).

A "carne", como produto de consumo, possui algumas características importantes. Por exemplo: o Laboratório Nacional de Referência Animal (LANARA) considera apenas "carne" o produto que possuir um intervalo de $\mathrm{pH}$ entre 5,8 a 6,2 (BRASIL, 1981). Após o cozimento da carne, o pigmento observado é de coloração marrom, apresentando a parte protéica (globina) desnaturada e o estado de oxidação do íon ferro igual a $+3\left(\mathrm{Fe}^{\mathrm{III}}\right)$. Assim, em razão dos diferentes fatores que influenciam a característica física e química do produto "carne", um melhor entendimento dos processos bioquímicos, dos métodos de processamento, e confinamento dos produtos são de grande relevância do ponto de vista tecnológico, comercial e de saúde pública. 


\section{I.2 - O átomo de ferro e seus estados de oxidação}

$\mathrm{O}$ átomo de ferro $(\mathrm{Fe})$ com estado de oxidação igual a zero possui a seguinte configuração eletrônica $1 s^{2} 2 s^{2} 2 p^{6} 3 s^{2} 3 p^{6} 4 s^{2} 3 d^{6}$. Em estruturas porfirínicas e/ou mioglobinas, os possíveis íons ferro são observados com estado de oxidação $+3\left(\mathrm{Fe}^{\mathrm{III}}\right)$, estado de oxidação $+2\left(\mathrm{Fe}^{\mathrm{II}}\right)$ e estado hipervalente de $+4\left(\mathrm{Fe}^{\mathrm{IV}}\right)$, com as seguintes e correspondentes configurações eletrônicas $3 \mathrm{~d}^{5}, 3 \mathrm{~d}^{6} \mathrm{e}$ $3 \mathrm{~d}^{4}$. A Tabela 1 ilustra os diferentes valores de spin de um sistema químico contendo ferro.

Tabela 1. Possíveis valores de spin para os sistemas químicos de ferro.

\begin{tabular}{ccc}
\hline $\begin{array}{c}\text { Número de elétrons na camada d / } \\
\text { estado de oxidação }\left(\mathbf{F e}^{\mathbf{n}+}\right)\end{array}$ & Spin alto & Spin baixo \\
\hline $\mathbf{d}^{3} / \mathbf{F e}^{\mathbf{V}}$ & $\mathrm{S}=3 / 2$ & $\mathrm{~S}=1 / 2$ \\
\hline $\mathbf{d}^{4} / \mathbf{F e}^{\mathrm{IV}}$ & $\mathrm{S}=2$ & $\mathrm{~S}=0$ \\
\hline $\mathbf{d}^{5} / \mathbf{F e} \mathbf{I I I}^{\mathrm{III}}$ & $\mathrm{S}=5 / 2$ & $\mathrm{~S}=1 / 2$ \\
\hline $\mathbf{d}^{6} / \mathbf{F e}$ & $\mathrm{S}=2$ & $\mathrm{~S}=0$ \\
\hline
\end{tabular}

Fonte: Huheey, Keiter e Keiter (1993).

Em relação ao anel profirínico, a simetria da molécula e/ou dos orbitais moleculares é influenciado pela presença ou ausência de íons ferro, para os diferentes estados de oxidação do metal (MOREIRA, 2004). O tipo de transição eletrônica pode ser predito a partir da absortividade molar e da região espectral onde se observa as bandas (MONDAL et al., 2016). Os deslocamentos de bandas podem fornecer informações a respeito do ambiente químico, devido a interação do meio com os diferentes momentos de dipolo do estado excitado e do fundamental da porfirina (SHRIVER; ATKINS, 2009).

Em relação ao íon de ferro, a energia dos cinco orbitais $d\left(\mathrm{dx}^{2}-\mathrm{y}^{2}, \mathrm{dz}^{2}, \mathrm{dxy}, \mathrm{dxz}\right.$ e dyz) no estado fundamental se mostra pentadegenerado $\left(\mathrm{E}_{\mathrm{dx} 2-\mathrm{y} 2}=\mathrm{E}_{\mathrm{dxy}}=\mathrm{E}_{\mathrm{dz} z}=\mathrm{E}_{\mathrm{dxz}}=\mathrm{E}_{\mathrm{dyz}}\right)$. O campo cristalino deste sistema também é fortemente influenciado pelas características químicas do ligante (exemplo: doador/aceptor de elétrons).

De acordo com a literatura, as possíveis geometrias de um complexo metálico, como o octaédrica e o tetragonal, mostram claramente que o efeito dos ligantes pode não ser o mesmo sobre todos os orbitais d, uma consequência disso é uma possível a mudança de degenerescência dos orbiatais d (Figura 1). 
Figura 1. (A) Representação dos cinco orbitais d (B) Aproximação de seis ligantes ao redor de um íon metálico (C) Desdobramento dos cinco orbitais d em um campo octaédrico.

(A)

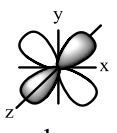

$\mathrm{dxy}$

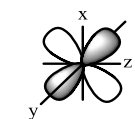

$\mathrm{dxz}$
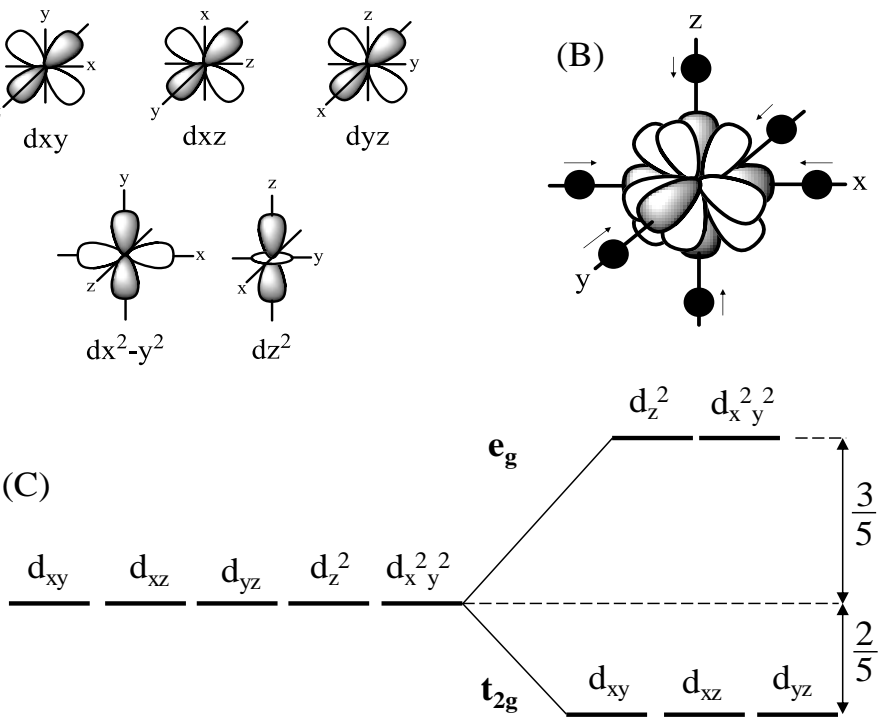

Fonte: Adaptado de Huheey, Keiter e Keiter (1993).

\section{I.3 - Espectroscopia de absorção eletrônica no UV-vis}

A interação luz e matéria compreende o fenômeno de absorção da luz pela matéria. Um exemplo clássico é a absorção eletrônica de corantes na região ultravioleta e visível. A transição eletrônica de porfirinas, por exemplo, um quantum de energia é utilizado para elevar um elétron do estado fundamental até o estado de maior energia (estado excitado).

De acordo com o princípio de Frank-Condon, a probabilididade de uma transição eletrônica é condicionada pela disposição em fase dos orbitais que compõem os estados fundamental e excitado, não sendo considerado as mudanças nas coordenadas nucleares. De fato, muitos pesquisadores não fotoquímicos ou não fotofísicos tem muita dificuldade em compreender perfeitamente a amplitude do princípio de Frank-condon, pois de fato este princípio já prediz muitas das diretrizes da frágil regra de seleção.

A fragilidade da regra de seleção por spin retrata que uma transição só é possível se a multiplicidade de spin permanecer a mesma após a transição eletrônica. Entretanto, a regra de ElSayed retrata que esta transição é possível e a absortividade molar para uma transição eletrônica entre diferentes estados de diferentes multiplicidades pode assumir valores entre $10^{-1}$ até $10^{-4} \mathrm{~L}$ $\mathrm{mol}^{-1} \mathrm{~cm}^{-1}$. 
A dependência da simetria dos orbitais também é evidenciada na regra de El-Sayed, que difere as probabilidades dos eventos de uma transição de diferente multiplicidade, como por exemplo a transição $\pi-\pi^{*} \rightarrow \mathrm{n}-\pi^{*}$. A maior absortividade molar para este tipo de transição eletrônica provém da sobreposição favorável dos orbitais no estado singlete excitado com os orbitais no estado triplete.

As transições eletrônicas não são restritas para um sistema orgânico com transições do tipo $\pi-\pi^{*}$ e $n-\pi^{*}$. Para um complexo metálico, as possíveis transições eletrônicas possíveis são: $\pi-\pi^{*} \mathrm{e}$ $\mathrm{n}-\pi^{*}$ para o ligante $(\mathrm{L} \rightarrow \mathrm{L})$, transferência de carga do metal para ligante (MLCT) e ligante para o metal (LMCT) e de transições do tipo d-d $\left(\mathrm{t}_{2 \mathrm{~g}} \rightarrow \mathrm{e}_{\mathrm{g}}\right)$ (SHRIVER; ATKINS, 2009; HUHEEY; KEITER; KEITER, 1993). As possíveis transições eletrônicas podem ser observadas na Figura 2.

Figura 2. Absorção da luz em complexos octaédricos resultando da transição metal-metal (d-d), transferência de carga do ligante para o metal (LMCT), transferência de carga do metal para o ligante (MLCT) e transição ligante-ligante (L-L).

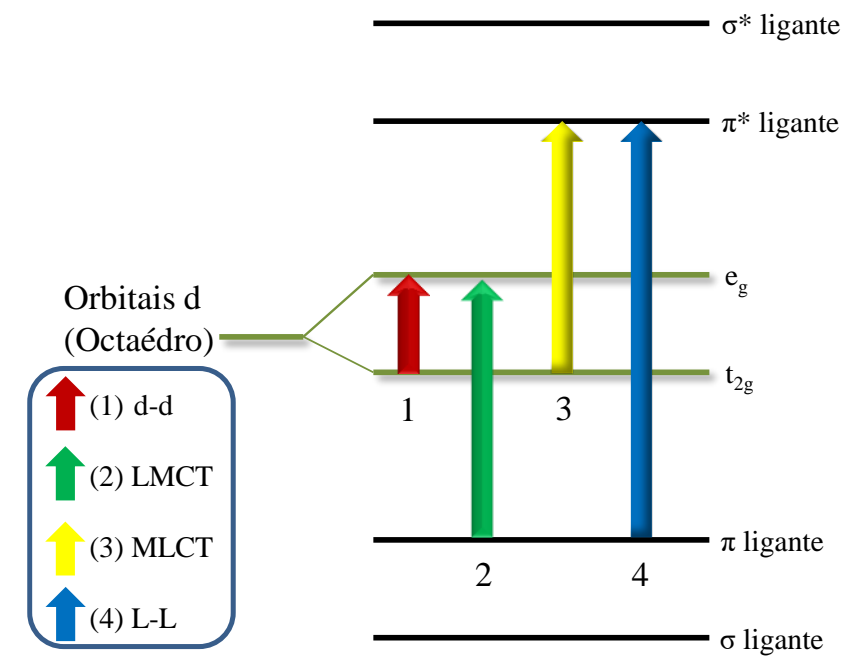

Fonte: Adaptado de Shriver e Atkins (2009).

\section{I.3.1 - Espectro eletrônico de absorção de porfirinas livres e ferro-porfirinas}

As porfirinas podem ser divididas em duas vertentes, considerando-se os espectros de absorção (a e b). A primeira vertente diz respeito as (a) porfirinas regulares, em que o espectro de absorção permacence praticamente o mesmo com a inserção do íon de ferro. A segunda vertente são as (b) as porfirinas irregulares, em que mudanças significativas são observadas no espectro eletrônico de absorção (GOUTERMAN, 1978). 
As porfirinas irregulares são classificadas em dois tipos: (a) Hypso e (b) Hyper (AJLOO et al., 2002). As do tipo Hypso possuem deslocamentos espectrais para a região do azul (de maior energia). Normalmente, estes espectros deslocados são observados para porfirinas com íons de metais de transição $\mathrm{d}_{6}$ ou de maior $n$.

As porfirinas tipo Hyper apresentam bandas electronicas em menores regiões de energia ( $\lambda$ $>320 \mathrm{~nm}$ ). Normalmente, os espectros observados para este tipo de porfirina são com íons de metais de transição com $\mathrm{n}<6$, como é observado para as porfirinas de $\mathrm{Fe}^{\mathrm{II}}\left(\mathrm{d}^{6}, \mathrm{~S} \neq 0\right)$ e $\mathrm{Fe}^{\mathrm{III}}\left(\mathrm{d}^{5}, \mathrm{~S}\right.$ $=5 / 2)($ AJLOO et al., 2002).

Nas porfirinas de base livre, o espectro de absorção eletrônica é observado com quatro bandas na região do visível, denominadas banda Q e máximo de absorção entre $500 \mathrm{~nm}$ e $700 \mathrm{~nm}\left(\varepsilon \cong 10^{4}\right.$ $\left.\mathrm{L} \mathrm{mol}^{-1} \mathrm{~cm}^{-1}\right)$. Uma outra banda de maior intensidade é observada em aproximadamente $400 \mathrm{~nm}$ ( $\varepsilon$ $\cong 10^{5} \mathrm{~L} \mathrm{~mol}^{-1} \mathrm{~cm}^{-1}$ ), denominada banda Soret (ou banda B) (MONDAL et al., 2016).

Quando o íon metálico está coordenado na cavidade interna da porfirina, participando do anel, os dois hidrogênios pirrólicos da porfirina base livre são perdidos. Nesta nova molécula, a simetria molecular $\mathrm{D}_{2 \mathrm{~h}}$ é agora alterada para uma simetria quadrada $\mathrm{D}_{4 \mathrm{~h}}$.

Nesta nova simetria $\left(\mathrm{D}_{4 \mathrm{~h}}\right)$, apenas duas bandas são observadas na região do visível $\left(\varepsilon \cong 10^{4} \mathrm{~L}\right.$ $\mathrm{mol}^{-1} \mathrm{~cm}^{-1}$ ). De fato, a posição espectral destas duas bandas é alterada com o estado de spin do metal, com o estado de oxidação do centro metálico e com o caráter ácido/básico do ligante L. Para esta nova estrutura química, a banda Soret ou banda B pode então apresentar uma nova banda de baixa intensidade e menor energia $\mathrm{B}(1,0)$, sendo esta atribuída a um acoplamento vibrônico entre a banda Soret e a vibração $\mathrm{a}_{1}\left(\mathrm{a}_{1 \mathrm{u}} \rightarrow \mathrm{e}_{\mathrm{g}}{ }^{*}\right)$.

As duas bandas $\mathrm{Q}\left(\mathrm{a}_{\mathrm{u} 2} \rightarrow \mathrm{e}_{\mathrm{g}}{ }^{*}\right)$ no espectro eletrônico de absorção de porfirinas metaladas correspondem à duas transições específicas: (a) a primeira é referente ao nível vibracional de menor energia do estado fundamental singlete para o primeiro nível vibracional do estado eletrônico excitado singlete $\mathrm{Q}(0,0)$ ou $\mathrm{Q}_{\mathrm{o}}$ ou simplesmente transição $\alpha$; (b) a outra é referente a população do primeiro nível vibracional dexcitado do estado excitado singlete, $\mathrm{Q}(1,0)$ ou $\mathrm{Q}_{\mathrm{v}}$ ou simplesmente transição $\beta$ (WHITTEN; LOPP; WILDES, 1968; DOLPHIN, 1978).

É interessante ressaltar que as ferro-porfirinas de baixo spin apresentam bandas Soret e Q deslocadas para o vermelho em relação as porfirinas de base livre. No caso das ferro-porfirinas de alto spin, as bandas Soret e Q são deslocadas para o azul. Assim, a partir do espectro de absorção 
eletrônica, as espécies de ferro-porfirina de baixo e alto spins podem ser facilmente descriminadas. A Figura 3 ilustra o espectro eletrônico de absorção e as atribuições das bandas.

Figura 3. Espectro de absorção eletrônica e as atribuições de bandas para uma dada espécie ferroheme.

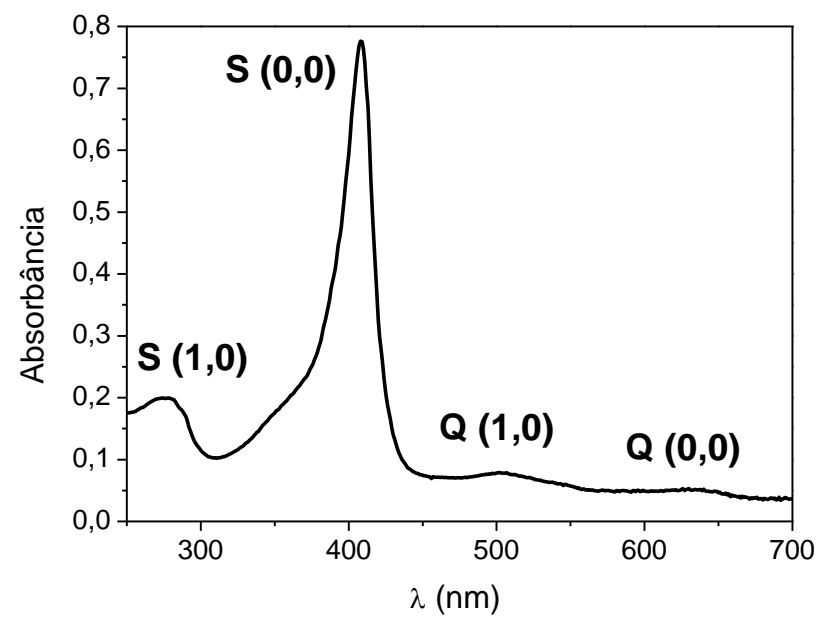

Fonte: Autoria própria.

\section{I.4 - Mioglobina}

A mioglobina $(\mathrm{Mb})(\mathrm{Mr}=17,641 \mathrm{kDa})$ é constituída por uma estrutura de forma esférica globular proteica denominada globina e um grupo postético heme no interior da globina localizado dentro de um bolsão (fenda) hidrofóbico. A estrutura globular proteica é constituída por uma única cadeia polipeptídica com 153 resíduos de aminoácidos sendo composta por oito seções de $\alpha$-hélices nomeadas de A a H (MØLLER, 2002). O grupo prostético heme é um ligante macrocíclico composto por quatro anéis pirrólicos unidos que estão coordenados a um íon de ferro localizado em bolsão hidrofóbico da globina conhecida como protoporfirina IX (PEGG; SHAHIDI, 1997). O íon metálico de ferro possui seis sítios de coordenação, sendo que quatro deles estão ocupados no plano equatorial por átomos de nitrogênio do anel tetrapirrólico e na quinta posição axial está ligada um resíduo de histidina (His93 proximal) da globina (Figura 4). O sexto sítio de coordenação está disponível para ligar-se a um ligante exógeno, podendo alterar o estado de spin do centro de coordenação e até mesmo favorecer a modificação do estado de oxidação do metal (MOREIRA; RIBELATTO; IMASATO, 2004). 
Figura 4. (A) Ilustração da estrutura tridimensional da mioglobina com destaque a ferro-porfirina e as His64 e His93 situado no bolso hidrofóbico da globina (oito $\alpha$-hélices de A a H). (B) Estrutura química da protoporfirina IX constituinte do grupo prostético da mioglobina, onde $\mathrm{L}=\mathrm{O}_{2}, \mathrm{CO}$, NO.

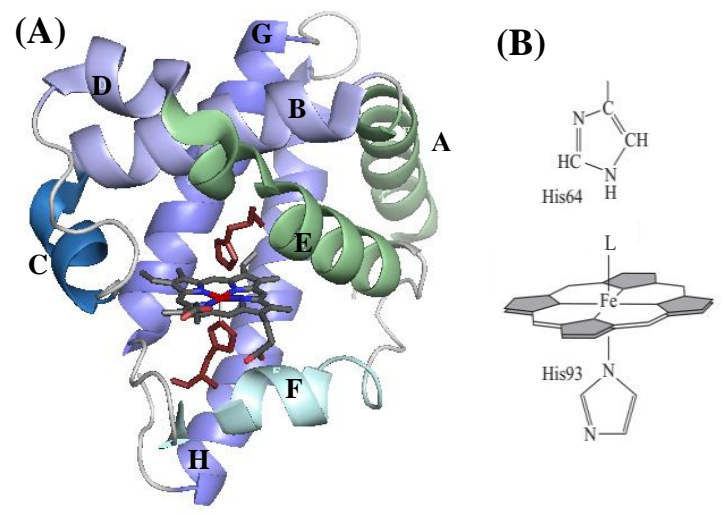

Fonte: Barends et al., 2015. Número de identificação 5D5R no protein data bank.

A mioglobina é o principal componente responsável pela coloração de produtos cárneos representando de 70 a $90 \%$ da concentração total de heme proteínas no tecido muscular, podendo existir em diferentes estados de oxidação: deoximioglobina $\left(\mathrm{MbFe}^{\mathrm{II}}\right)$, oximioglobina $\left(\mathrm{MbFe}^{\mathrm{II}} \mathrm{O}_{2}\right)$ e metamioglobina (MbFe $\left.{ }^{\mathrm{III}} \mathrm{H}_{2} \mathrm{O}\right)$ (SUMAN; JOSEPH, 2013), como ilustrado na Figura 5.

A espécie deoximioglobina $\left(\mathrm{MbFe}^{\mathrm{II}}\right)$ ocorre quando o ferro heme pentacoordenado está no estado ferroso (2+), resultando em uma coloração violeta. A exposição da espécie $\mathrm{MbFe}^{\mathrm{II}}$ ao oxigênio ocorre a formação da espécie $\mathrm{MbFe}^{\mathrm{II}} \mathrm{O}_{2}$, onde o sexto sítio de coordenação está ocupado por uma molécula de oxigênio diatômica característico de uma coloração vermelho brilhante como o observado em transformação de músculo em carne. Ambas as espécies $\mathrm{MbFe}^{\mathrm{II}}$ e $\mathrm{MbFe}^{\mathrm{II}} \mathrm{O}_{2}$ podem sofrer oxidação formando a espécie metamioglobina $\left(\mathrm{MbFe}^{\mathrm{III}}\right)$, na qual o ferro heme encontra-se no estado férrico (3+) e o sexto sítio de coordenação é ocupado por uma molécula de $\mathrm{H}_{2} \mathrm{O}, \mathrm{pKa}=$ 8,9 (Figura 5). A espécie $\mathrm{MbFe}^{\mathrm{III}} \mathrm{H}_{2} \mathrm{O}$ é caracterizada pela coloração marrom, típica de carne oxidada (CALSEN; SKOVGAARD; SKIBSTED, 2003). 
Figura 5. Os diferentes estados redox da mioglobina e suas interconversões: deoxymioglobina, oximioglobina e metamioglobina.

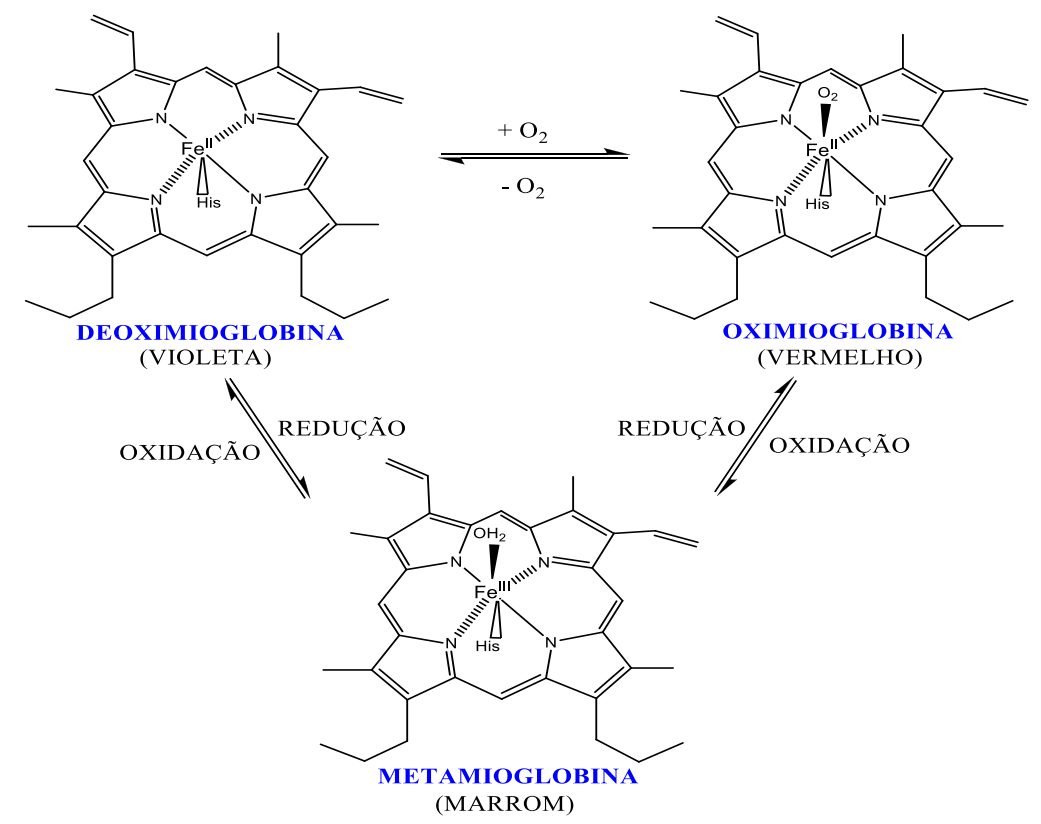

Fonte: Adaptado de Calsen, Skovgaard e Skibsted (2003).

Próxima a sexta posição de coordenação do ferro, localiza-se o grupo NH do imidazol da histidina distal ou His64 que estabiliza a ligação $\mathrm{Fe}-\mathrm{O}_{2}$ através da formação de uma ligação de hidrogênio com o oxigênio molecular, como pode ser observado na Figura 6. O oxigênio molecular coordenado ao centro ferroso forma ligação de hidrogênio com o próton oriundo da histidina distal, reforçando as propriedades eletrônicas do ligante $\mathrm{O}_{2}$. Este caráter ácido do ligante é devido ao efeito indutivo da ligação de hidrogênio entre o hidrogênio da histidina e o oxigênio molecular, que então retirará densidade eletrônica do centro de coordenação ferro-porfirina.

Nesta estrutura molecular, o próton proveniente da histidina distal forma ligação de hidrogênio com o oxigênio molecular coordenado ao centro ferroso, acentuando as propriedades eletrônicas do ligante $\mathrm{O}_{2}$. 
Figura 6. Representação do ferro heme e da histidina distal, favorecendo estabilidade à ligação Fe$\mathrm{O}_{2}$ pela formação de uma ligação de hidrogênio entre o $\mathrm{NH}$ do imidazol e o oxigênio molecular.

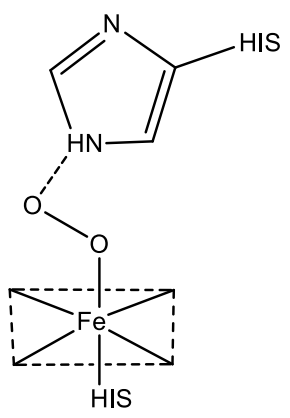

Fonte: Adaptado de Olson (1988); Shriver, Atkins (2009).

Modificações na estrutura das porfirinas como a formação de complexo com metais, protonação dos átomos do nitrogênio do anel ou a substituição de grupos periféricos podem causar sensíveis alterações na intensidade e na posição das bandas de absorção (SANNA et al., 2005), como pode ser observado no espectro de absorção da Figura 7, para as espécies: deoximioglobina $\left(\mathrm{MbFe}^{\mathrm{II}}\right)$, oximioglobina $\left(\mathrm{MbFe}^{\mathrm{II}} \mathrm{O}_{2}\right)$ e metamioglobina $\left(\mathrm{MbFe}^{\mathrm{III}} \mathrm{H}_{2} \mathrm{O}\right)$.

Figura 7. Espectro de absorção eletrônica de $10 \mu \mathrm{M}$ das espécies: deoximioglobina (- - -), oximioglobina $(-)$ e metamioglobina $(-\cdot-\cdot)$ em tampão Tris/ $\mathrm{HCl}\left(1,0 \times 10^{-2} \mathrm{mMol} \mathrm{L}^{-1}\right) \mathrm{pH} 8,0$ a $25^{\circ} \mathrm{C}$.

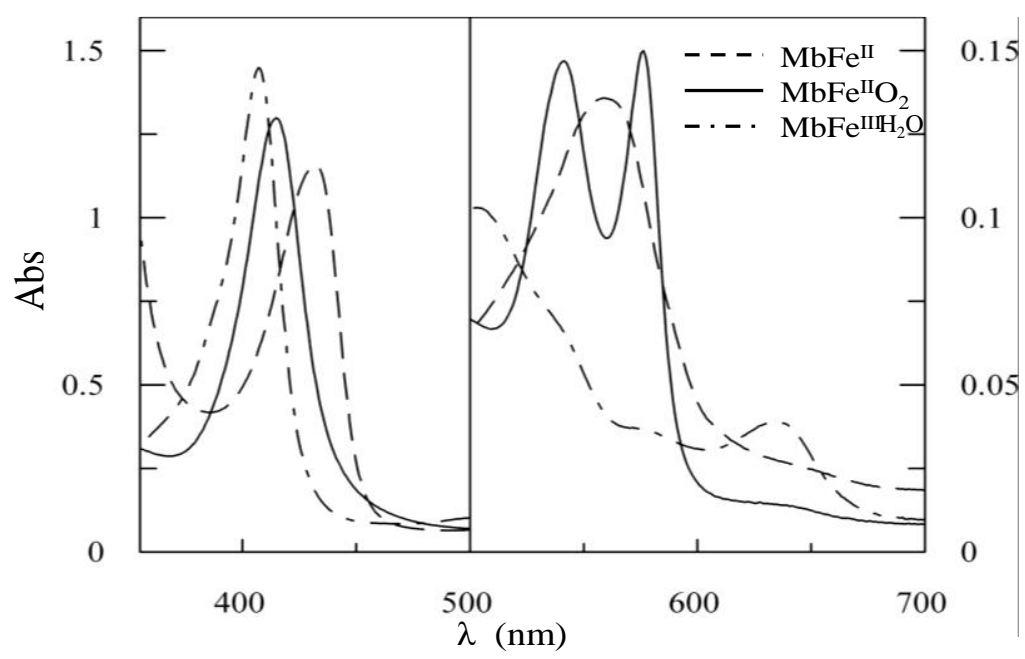

Fonte: Adaptado de Sanna et al. (2005). 
A reação de auto-oxidação de hemproteínas (em geral) e de mioglobinas (em especial) é de grande relevância para a estabilização da molécula de oxigênio com o ferro, pois torna o centro de coordenação do ferro heme incapaz de se ligar à molécula de oxigênio; isto é, faz com que a mioglobina perca sua função. Detalhes do mecanismo desta reação de auto-oxidação são de interesse químico e clínico, e têm sido estudados por muitos autores (SHIKAMA, 1998; ZHANG; LEVY; RIFKIND, 1991). Alguns fatores como pH, pressão de oxigênio, presença de ligantes e dissociação da proteína podem influenciar na velocidade desse processo (SHIKAMA, 1998; ZHANG; LEVY; RIFKIND, 1991). Três possíveis mecanismos para a reação de auto-oxidação das heme-proteínas são elucidados por Gonzalez et al. (1998).

\section{1 - Dissociação do superóxido protonado a partir do oxi-heme}

Este mecanismo de auto-oxidação é altamente dependente do $\mathrm{pH}$ em condições saturadas de oxigênio (Figura 8). O ligante $\mathrm{O}_{2}$ do oxi-heme é protonado seguido da dissociação como ânion superóxido. A velocidade da auto-oxidação, por sua vez, aumenta com a diminuição do pH.

$$
\begin{gathered}
\mathrm{Fe}^{\mathrm{II}}+\mathrm{O}_{2} \rightleftharpoons \mathrm{Fe}^{\mathrm{II}} \mathrm{O}_{2} \\
\mathrm{Fe}^{\mathrm{II}} \mathrm{O}_{2}+\mathrm{H}^{+} \longrightarrow \mathrm{Fe}^{\mathrm{II}} \mathrm{O}_{2} \mathrm{H}^{+} \rightarrow \mathrm{Fe}^{\mathrm{III}}+\mathrm{HO}_{2}
\end{gathered}
$$

Figura 8. Dependência entre constantes de velocidade de segunda ordem e o pH à $30{ }^{\circ} \mathrm{C}$ para reação de auto-oxidação da mioglobina de músculo bovino ( $2 \mathrm{~h}$ post morten). Amostras do músculo psoas major $(\Delta)$ e longissimus lumborum $(\square)$.

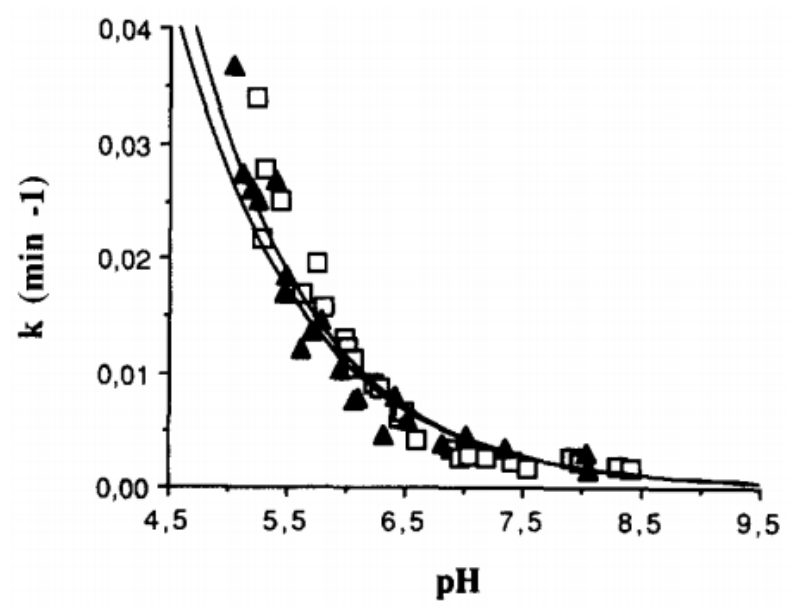

Fonte: Renerre, Anton e Gatellier (1991). 


\section{2 - Transferência de elétron por esfera externa do intermediário pentacoordenado desoxi-heme}

A reação de transferência de elétron por esfera externa ocorre a partir do complexo deoxiheme; isto é, do complexo pentacoordenado ferroso. Este mecanismo de transferência de elétron por esfera externa não depende do $\mathrm{pH}$.

$$
\mathrm{Fe}^{\mathrm{II}} \mathrm{O}_{2} \rightleftharpoons \mathrm{Fe}^{\mathrm{II}}+\mathrm{O}_{2} \rightarrow \mathrm{Fe}^{\mathrm{III}}+\mathrm{O}_{2}^{-}
$$

3 - Transferência de elétron por esfera externa do intermediário desoxiheme hexacoordenado

O mecanismo de transferência de elétrons mediado por ligantes ocorre em duas etapas. Primeiro, um nucleófilo $(\mathrm{Nu})$ se liga à deoximioglobina, em seguida, o heme ferroso hexacoordenado transfere um elétron para o oxigênio através do mecanismo de esfera externa.

$$
\begin{aligned}
\mathrm{Nu}+\mathrm{Fe}^{\mathrm{II}} & \rightleftharpoons \mathrm{Fe}^{\mathrm{II}} \mathrm{Nu} \\
\mathrm{Fe}^{\mathrm{II}} \mathrm{Nu}+\mathrm{O}_{2} & \longrightarrow \mathrm{Fe}^{\mathrm{III}} \mathrm{Nu}+\mathrm{O}_{2}^{-}
\end{aligned}
$$

\section{I.5 - Espécies hipervalentes de ferro heme}

Heme-proteínas podem reagir in vivo com hidroperóxidos orgânicos ou peróxido de hidrogênio produzido nas células em vários processos metabólicos formando espécies hipervalentes de ferro heme (KELMAN et al., 1994; DEGRAY et al., 1997). As espécies hipervalentes de mioglobina perferrilmioglobina, $\bullet \mathrm{MbFe}^{\mathrm{IV}}=\mathrm{O}$ e a ferrilmioglobina, $\mathrm{MbFe} \mathrm{IV}^{\mathrm{IV}}=\mathrm{O}$ tem como característica o centro metálico de Fe no estado de oxidação 4+ com seu sexto sítio de coordenação ocupado por um grupo oxo e para a espécie $\mathrm{MbFe}^{\mathrm{IV}}=\mathrm{O}^{+} \bullet$, a qual é uma espécie com um estado de oxidação superior a ferrilmioglobina (formalmente $\mathrm{Fe}^{\mathrm{v}}$ ), o segundo equivalente de oxidação está presente como um cátion radical localizado no fragmento da globina.

A perferrilmioglobina e a ferrilmioglobina são similares aos compostos I e II das enzimas peroxidase, respectivamente. A diferença de função biológica entre a mioglobina e as peroxidases (armazenamento de dioxigênio vs. catálise de reações redox) é decorrente da interação das proteínas com o grupo heme e com potenciais substratos (DUNFORD, 1999).

No mecanismo de atividade de pseudoperoxidase da mioglobina (Figura 9), inicialmente a espécie metamioglobina $\left(\mathrm{MbFe}^{\mathrm{III}} \mathrm{H}_{2} \mathrm{O}\right)$ é oxidada via dois elétrons levando à formação da espécie reativa perferrilmioglobina $\left(\mathrm{MbFe}^{\mathrm{IV}}=\mathrm{O}^{\bullet+}, \tau \sim 10^{-6} \mathrm{~s}\right)$. Ainda na espécie perferrilmioglobina, $\mathrm{o}$ 
cátion radical localizado no anel porfirínico recebe a transferência de um elétron dos aminoácios triptofano ou tirosina, na qual induz, na presença de oxigênio, a formação do radical peroxila no resíduo de aminoácido Trp14 (TrpOO*). Por sua vez, a espécie perferrilmioglobina $\left(\bullet \mathrm{MbFe}{ }^{\mathrm{IV}}=\mathrm{O}, \tau\right.$ $\sim 1 \mathrm{~s}$ ), a qual sofre processo de auto-redução ou então pode ser reduzida por uma molécula de proteína ou lipídeo, forma a espécie reativa ferrilmioglobina $\left(\mathrm{MbFe}^{\mathrm{IV}}=\mathrm{O}, \tau \sim 1 \mathrm{~s}\right)$. Finalmente, a $\mathrm{MbFe}^{\mathrm{IV}}=\mathrm{O}$ reage com uma segunda molécula redutora e é convertida à espécie inicial $\mathrm{MbFe}^{\mathrm{III}} \mathrm{H}_{2} \mathrm{O}$ (RAO et al., 1994; JØRGENSEN; ANDERSEN; SKIBSTED, 1997; CARLSEN, C. U.; MØLLER, J. K. S.; SKIBSTED L. H., 2005). Vale ressaltar que ambas as espécies hipervalentes de ferro heme podem passar lentamente por um processo de auto-redução pela oxidação da cadeia lateral de resíduos de aminoácidos da proteína (Figura 9).

Figura 9. Ciclo da atividade de pseudoperoxidase da mioglobina. HA representa espécie redutora qualquer.

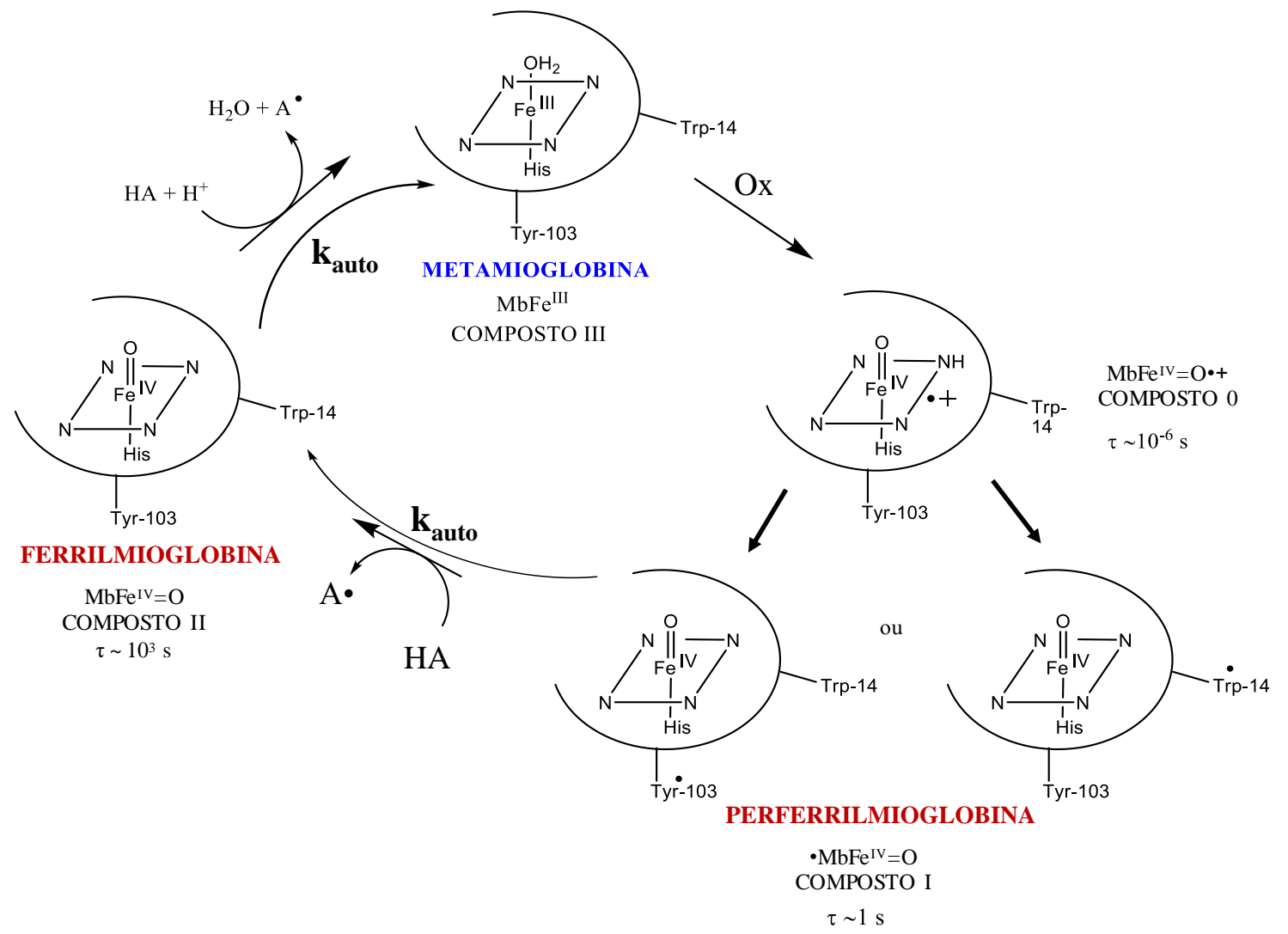

Fonte: Adaptado de Calsen, Skovgaard e Skibsted (2003); Kelman et al. (1994).

Exemplos da importância desta reação consiste no fato de que as espécies hipervalentes de $\mathrm{Mb}$ indica ser o fator determinante nas lesões provenientes da isquemia cardíaca (RONCONE et 
al., 2004). A presença de Mb no sistema circulatório pode provocar lesões no músculo cardíaco, que por sua vez podem induzir ao enfarte do miocárdio (ZHANG et al., 2005). Devido ao papel fundamental que estas proteínas desempenham na vida animal, a sua detecção é de extrema importância, levando à investigação e a evolução de vários métodos. Assim, naturalmente estas hemeproteínas continuam a ser intensivamente alvo de inúmeros estudos por parte de vários investigadores (KELMAN et al., 1994; CALSEN; SKOVGAARD; SKIBSTED, 2003; DEGRAY et al., 1997).

\section{I.6 - Aspectos químicos, bioquímicos e mediador redox do Zinco}

O íon zinco é um metal com o nível d completo $\left(3 \mathrm{~d}^{10}\right)$, não disponível, desta forma, para a participação em reações redox, mas agindo apenas como ácido de Lewis aceitando um par de elétrons e tornando-se um íon estável. O íon zinco $\left(\mathrm{Zn}^{\mathrm{II}}\right)$ se apresenta como um componente estrutural e/ou funcional de várias metaloenzimas e metaloproteínas, participando de muitas reações do metabolismo celular, incluindo processos fisiológicos, tais como função imune, defesa antioxidante, crescimento e desenvolvimento. O conteúdo de zinco no organismo varia de 1,5 a 2 g, distribuído em cerca de $85 \%$ nos músculos e ossos, com o restante no sangue, sendo $80 \%$ nos

eritrócitos e 16\% no plasma (VALLE; FALCHUK, 1993). Com relação ao seu metabolismo, o zinco é absorvido no segmento proximal do intestino delgado, sendo este processo dependente da sua concentração no lúmen (CHUNG; STOOKEY; DARE, 2008).

Diversos eventos biológicos se processam através das reações de transferência de elétrons (ET), sendo as conversões químicas das espécies metabólicas, mediadas por íons metálicos livres ou associados a sítios enzimáticos (STADTMAN; OLIVIER, 1991). Íons metálicos com caráter de ácidos de Lewis podem regular reações de transferência de elétrons entre doadores e aceptores de elétrons pela interação e/ou complexação do ácido com o aceptor de elétrons, ou também com os íons radicais formados pela redução dos aceptores de elétrons - Figura 10 (FUKUZUMI; OHKUBOA; MORIMOTO, 2012). O processo de transferência de elétrons entre centros iônicos é conhecido como metal ion-coupled electron-transfer (MCET) (FUKUZUMI, 2009). 
Figura 10. Mecanismo de transferência de elétrons entre doadores e aceptores de elétrons pela interação direta com os doadores (a) MB/ET (Metal-Binding/Electron-Transfer) ou com os íons radicais formados pela oxidação dos doadores de elétrons (b) (ET/MB, Electron-Transfer/MetalBinding).

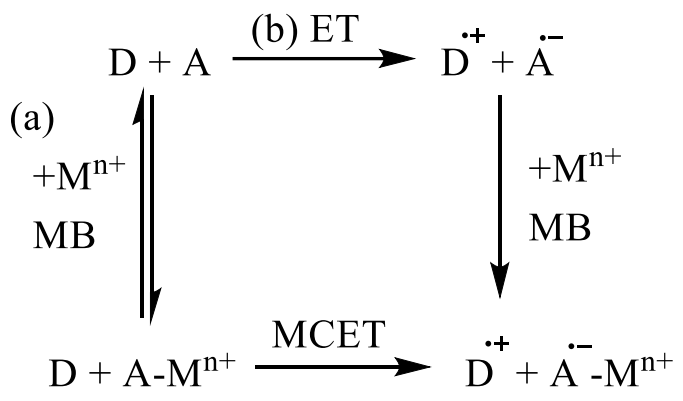

Fonte: Fukuzumi, Ohkuboa e Morimoto (2012).

\section{I.7 - Molten globule e agregação de proteínas}

As proteínas, em geral, oferecem vários tipos de sítios de coordenação para os íons metálicos, duros ou moles. As cadeias laterais ligantes mais importantes são o grupo SH da Cys, o imidazol da His, o carboxilato do Asp e Glu e o fenolato da Tyr. Ligantes menos frequentes são a hidroxila da Ser/Thr, o tioéter da Met, a carboxamida da Gln/Asn e a guarnidina da Arg (LIPPARD; BERG, 1994). Íons metálicos podem promover a dimerização de moléculas de proteínas e, consequentemente, pode induzir a uma mudança da estrutura conformacional da proteína. A principal justificativa é a capacidade dos íons metálicos de atuar como pontes entre duas proteínas, bem como fornecer uma regulação "screening" na força eletrostática entre os grupos laterais carregados negativamente das proteínas (BRYANT; MCCLEMENTS, 1998; HONGSPRABHAS; BARBUT, 1998; REMONDETTO; SUBIRADE, 2003; IYER; PRZYBYCIEN, 1996). A energia potencial de repulsão pode ser reduzida a ponto de eliminar a barreira de energia, de modo que as partículas podem se aproximar sem que haja repulsão entre as proteínas (REMONDETTO; SUBIRADE, 2003).

Em estudos de enovelamento de proteínas, foi mostrado que as estruturas parcialmente enoveladas eram compactas e parte da estrutura secundária presente no estado nativo, porém apresentam estrutura terciária flutuante (PTITSYN, 1991). A esta estrutura foi atribuído o nome de "molten globule", ou seja, glóbulo fundido (OHGUSHI; WADA, 1983). Os molten globule são um dos intermediários na via de enovelamento das proteínas. Estes intermediários são compactos, com elevada estrutura secundária nativa, mas com pouca ou nenhuma estrutura terciária, contendo zonas 
hidrofóbicas expostas (YON, 1997). Foi demonstrado que este tipo de intermediários pode potencializar a agregação na neurodegeneração (MAHLEY; HUANG, 2006; UVERSKY; LI; FINK, 2001; SKORA; BECKER; ZWECKSTETTER, 2010). Como exemplo, a ligação do cobre e ferro à $\alpha$ sinucleina leva à formação de um molten globule, o que resulta num aumento da cinética de agregação e na doença neurodegenerativa (UVERSKY; LI; FINK, 2001).

\section{I.8 - Importância da cisteína e do monóxido de carbono em processos oxidativos em meios biológicos}

O aminoácido cisteína é um tiol presente em uma grande variedade de proteínas atuando em diversos processos celulares como manutenção da estabilidade e da atividade redutora em meio biológico. Sua atividade antioxidante é exibida tanto em sua forma livre, como quando está incorporada na cadeia polipeptídica de proteínas. Os tióis e o $\mathrm{H}_{2} \mathrm{~S}$ são conhecidos por reagir com $\mathrm{MbFe}^{\mathrm{IV}}=\mathrm{O}$ para formar sulfomioglobina (sulfMb) (ROMERO et al., 1992). A SulfMb, assim como a mioglobina, pode existir em sua forma reduzida (SulfMbFe ${ }^{\mathrm{II}}$ ) ou oxidada (SulfMbFe ${ }^{\mathrm{III}}$ ) (CHATFIELD; LAMAR; KAUTEN, 1987).

A química do monóxido de carbono (CO) tornou-se uma importante área de estudos em processos redox em meio biológico, visto que o $\mathrm{CO}$ pode também exibir importante função na desativação dos pigmentos heme hipervalentes no sistema biológico e em produtos cárneos (FUKUTO et al., 2012). O CO é produzido endogenamente como resultado da degradação de heme proteínas pela enzima heme oxygenase nas células reticuloendoteliais do fígado e do baço (MAINES, 1997). Desta forma, diversos trabalhos reportaram o papel do CO no organismo, suas atividades de sinalização celular, vasodilatação do sistema cardiovascular e ação anti-inflamatória principalmente no trato gastrointestinal (GIBBONS et al., 2013; GIBBONS; FARRUGIA, 2004; BERNE et al., 2012). Tais estruturas são mostradas na Figura 11.

Figura 11. Estrutura química da cisteína e do monóxido de carbono.

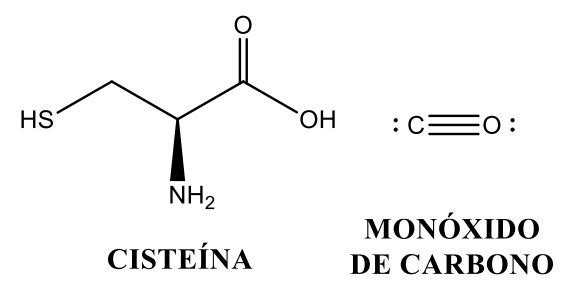

Fonte: Autoria própria. 


\section{I.9 - Estudo conformacional da proteína por emissão de fluorescência molecular}

Para medidas de fluorescência de macromoléculas são utilizados dois tipos de fluoróforos - fluoróforos intrínsecos (contidos nas macromoléculas) e fluoróforos extrínsecos (adicionados ao sistema, normalmente ligados a um de seus componentes).

Há três fluoróforos intrínsecos em proteínas - triptofano, tirosina e fenilalanina (em ordem de maior para menor rendimento quântico). É possível distinguir os três fluoróforos pela excitação e observação em comprimentos de onda apropriados. A fluorescência do triptofano é a mais utilizada na prática selecionando-o em compromentos de onda maiores do que $295 \mathrm{~nm}$. A fenilalanina tem um rendimento quântico muito baixo e a fluorescência da tirosina é frequentemente muito baixa devido à supressão. A tirosina apresenta uma fluorescência praticamente suprimida se ela estiver ionizada ou próxima de um grupo amino, um grupo carboxil, ou um triptofano. Em situações especiais, no entanto, é possível detectá-la com excitação em 280 nm (WETLAUFER, 1963).

A fluorescência tanto do triptofano quanto da tirosina dependem fortemente do seu ambiente (solvente, $\mathrm{pH}$, a presença de um inibidor, uma molécula pequena ou um grupo vizinho na proteína). Por isso, o estudo de fluorescência intrínseca de proteínas permite informações sobre sua conformação. A Figura 12 apresenta os espectros de absorção eletrônica do triptofano, tirosina e fenilalanina em $\mathrm{pH} 7$.

Figura 12. (A) Espectro de absorção eletrônico e (B) Estruturas químicas dos aminoácidos Trp, Tyr e Phe em pH 7.

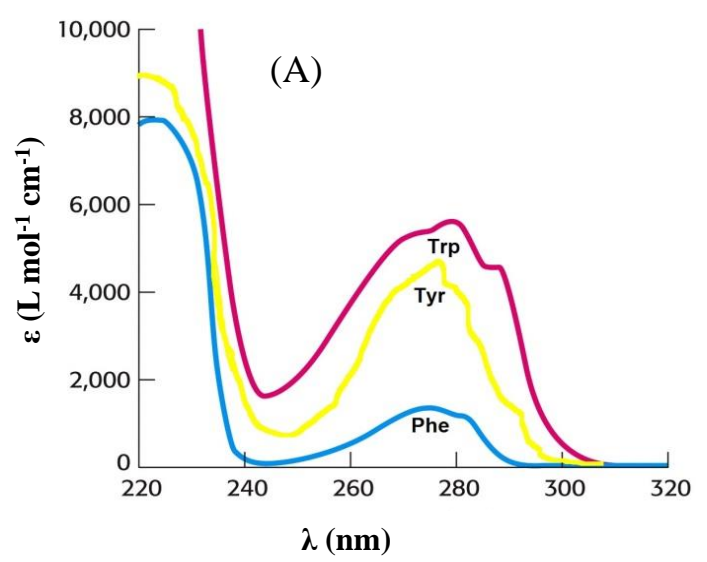

(B)
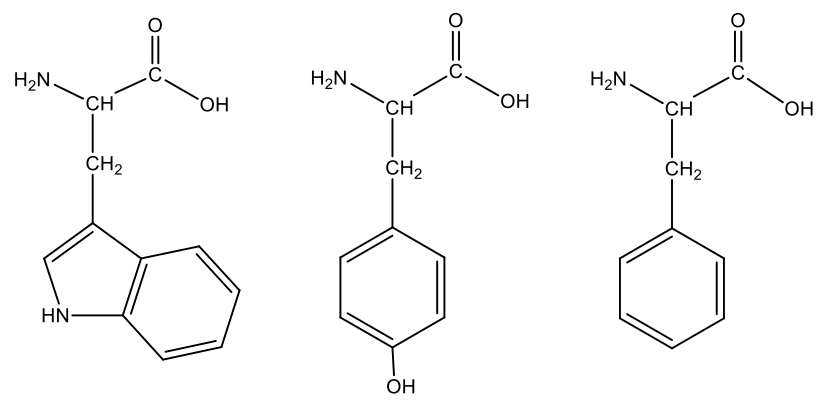

TRIPTOFANO (Trp)

TIROSINA (Tyr)

FENILALANiNA (Phen)

Fonte: (A) Adaptado de Wetlaufer (1963); (B) Autoria própria. 
Em seguida, a Tabela 2 apresenta, com mais detalhes, as propriedades de absorção e emissão dos três fluoróforos intrínsecos.

Tabela 2. Parâmetros de absorção e fluorescência dos aminoácidos aromáticos em solução aquosa, pH 7. Os comprimentos de onda máximos de absorção e de emissão estão denotados por $\lambda_{\mathrm{a}}$ e $\lambda_{\mathrm{F}}$, respectivamente. $\varepsilon$ é o coeficiente de absorção molar e o rendimento quântico de fluorescência é denotado por $\phi \mathrm{F}$.

\begin{tabular}{lccccc}
\hline & Tempo de vida $(\mathbf{n s})$ & $\boldsymbol{\varepsilon}\left(\mathbf{L ~ m o l}^{-\mathbf{1}} \mathbf{c m}^{-\mathbf{1}}\right)$ & $\lambda_{\mathbf{a}}(\mathbf{n m})$ & $\lambda_{\mathbf{F}}(\mathbf{n m})$ & $\Phi_{\mathbf{F}}$ \\
\hline Trp & 2,6 & 5600 & 280 & 348 & 0,20 \\
\hline Tyr & 3,6 & 1400 & 274 & 303 & 0,14 \\
\hline Phe & 6,4 & 200 & 257 & 282 & 0,04 \\
\hline
\end{tabular}

Fonte: Schmid (1997).

\section{I.10 - Dicroismo Circular no UV (CD UV)}

O sinal de CD no UV fornece informação quantitativa sobre o conteúdo de estrutura secundária em proteínas. Os elementos de estrutura secundária (hélice- $\alpha$, folha- $\beta$, volta- $\beta$ e estrutura randômica) têm espectros de CD característicos e bem definidos. $\mathrm{O}$ espectro da estrutura hélice- $\alpha$ (Figura 13) é característico a transições eletrônicas que ocorrem na amida da ligação peptídica; ou seja, a banda intensa e positiva a $190 \mathrm{~nm}$ e a banda negativa a $208 \mathrm{~nm}$ são resultantes da transição $\pi \rightarrow \pi^{*}$, enquanto que a outra banda negativa localizada a $220 \mathrm{~nm}$ surge a partir de uma transição $\mathrm{n} \rightarrow \pi^{*}$ (BULHELLER; RODGER; HIRST, 2007).

O espectro de CD da folha- $\beta$ apresenta uma uma banda positiva próximo de $195 \mathrm{~nm}$ devido a uma transição $\pi \rightarrow \pi^{*}$ e banda negativa à volta dos $217 \mathrm{~nm}$ devida a uma transição $\mathrm{n} \rightarrow \pi^{*}$. Proteínas que possuem estrutura desordenada têm um espectro de CD característico com uma banda fraca positiva causada por uma transição $n \rightarrow \pi^{*}$ e uma banda negativa intensa próxima dos 195-200 nm originada por uma transição $\pi \rightarrow \pi^{*}$ (NAKANISHI; BEROVA; WOOD, 1994), conforme observado na Figura 13. Desta forma, através da deconvolução do espectro de CD-UV é possível determinar as contribuições individuais das estruturas de hélice- $\alpha$, folha- $\beta$, volta- $\beta$ e estrutura randômica e assim monitorar alterações na estrutura secundária da proteína. 
Figura 13. Espectros típicos de CD na região do UV. O espectro típico de uma $\alpha$-hélice está representado a preto, o de uma folha- $\beta$ a azul e o da estrutura randômica a vermelho.

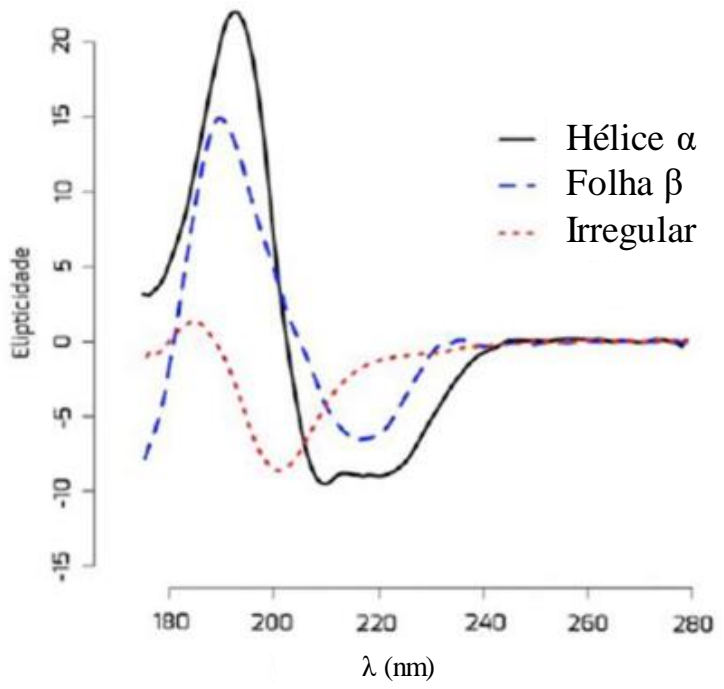

Fonte: Adaptado de Ruggeri et al. (2016).

\section{I.11 - Fotoquímica da espécie oximioglobina}

$\mathrm{Na}$ ausência de luz, o processo de dissociação da espécie oximioglobina formando a deoximioglobina é reversível $\left(\mathrm{Fe}^{\mathrm{II}} \mathrm{O}_{2} \leftrightarrow \mathrm{Fe}^{\mathrm{II}}+\mathrm{O}_{2}\right)$. Já a dissociação espontânea do oxigênio (autooxidação), na forma do ânion superóxido formando a espécie metamioglobina ( $\mathrm{MbFe}{ }^{\mathrm{III}}$ ), é irreversível. Nesta etapa, a presença de um redutor leva a formação da espécie deoximioglobina, como ilustrado no Esquema 1.

Esquema 1. Ligação reversível e irreversível da molécula de oxigênio ao íon ferroso.

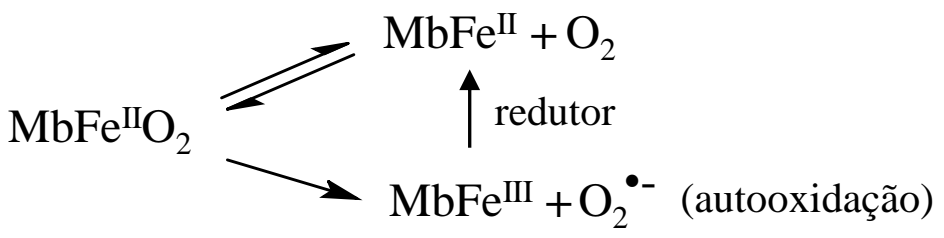

Fonte: Autoria própria.

A utilização de outros ligantes como o CO, possibilita apenas a formação da oximioglobina $\left(\mathrm{MbFe}^{\mathrm{II}}\right)$, evitando assim a formação do ânion superóxido. O monitoramento de transientes através da técnica de Fotólise deLaser Pulsado (FLP) é uma das técnicas mais eficazes para a detecção direta ou indireta de dissociação de ligantes, da influência de ligantes axiais, tais como o $\mathrm{O}_{2}, \mathrm{CO}$ 
ou NO na estrutura conformacional da proteína (FUKUTO et al., 2012). Após o pulso de laser, ou na presença de contínua radiação luminosa, o processo de fotodissociação unimolecular da oximioglobina é confirmado com a liberação do ligante $\mathrm{O}_{2}$, como ilustrado na Figura 14.

Figura 14. Ilustração do processo de fotodissociação do ligante $\mathrm{L}=\mathrm{O}_{2}$ na oximioglobina.

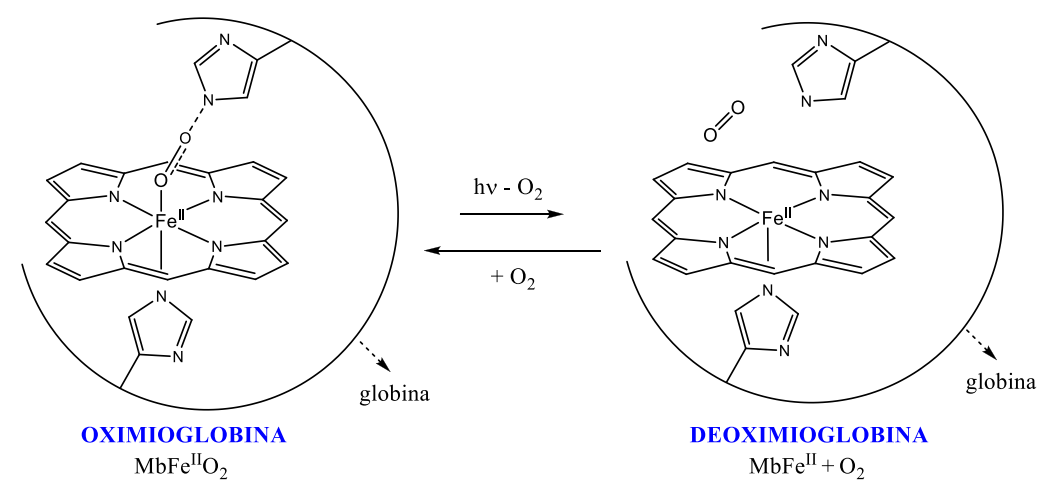

Fonte: Autoria própria.

A técnica de FLP permite a quebra da ligação ferro-ligante (Figura 14), e isto dá origem ao ligante livre dentro do pocket $\left(\mathrm{k}_{\text {diss }}\right)$. Após o pulso de laser, imediatamente ocorre a formação da espécie desoxi-Mb e o ligante pode, então, recombinar com o ferro-heme (geminadamente) de dentro do pocket (bolsa distal).

A oxidação do centro ferroso do grupo heme para o estado trivalente leva à formação da espécie denominada metamioglobina $\left(\mathrm{MbFe}^{\mathrm{III}}\right)$. Após esta oxidação, o íon de ferro não pode mais formar o complexo com o oxigênio, pois o ligante oxigênio não tem afinidade pelo íon férrico. Este fenômeno ocorre também "in vivo" e é responsável pela presença de aproximadamente $0,5 \%$ de metamioglobina nas células vermelhas do sangue (ANTONINI; ROSSI-BERNARD; CHIANCONE, 1981).

\section{I.12. Fotólise de Laser Pulsado com absorção transiente (LFP)}

A técnica de LFP utiliza o princípio de bombardeio da amostra (pump-probe) através de um intenso e curto pulso de laser, na região de absorção eletrônica da amostra como ilustrado na Figura 15. 
Figura 15. Equipamento de Fotólise de Laser Pulsado simplificado.

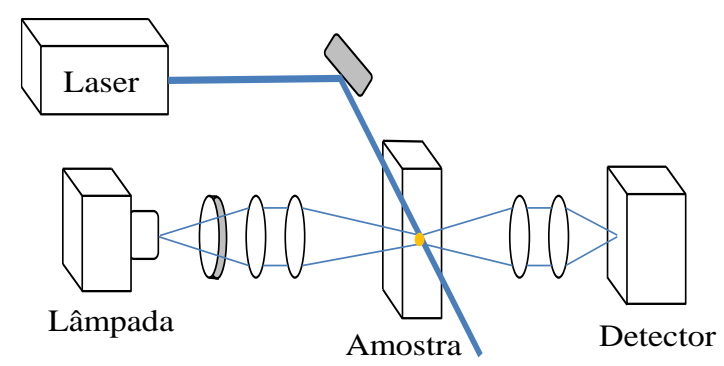

Fonte: Autoria própria.

Após a excitação, o sistema é perturbado promovendo um grande número de moléculas para o estado excitado singlete, que pode emitir fluorescência ou ser desativado por via nãoradiativa (ex. reagir quimicamente, dissipar energia na forma de calor, entre outros). Uma luz branca e contínua (também denotada como luz de análise) incide sobre a amostra, a qual irá monitorar as mudanças na absorção enquanto a amostra ainda se encontra no estado transiente.

Uma vez que o espectro de absorção de um transiente, por exemplo do estado triplete (T) ou de um radical $\left(\mathrm{R}^{\bullet}\right)$, é estabelecido a cinética de decaimento de $T$ ou $\mathrm{R}^{\bullet}$ que pode ser obtida através das medidas de absorção em diferentes tempos de aquisição. A técnica ainda permite determinar espectros, tempos de vida dos transientes, rendimentos quânticos e as energias dos estados excitados.

Em um sistema químico contendo um doador de elétrons (D) e um aceptor de elétrons (A), o processo de transferência de elétrons pode ser acompanhado pela dinâmica do estado transiente (ex. estado triplete do doador, ${ }^{3} \mathrm{D}$ ). No caso de um sistema químico de $\mathrm{Fe}^{\mathrm{II}}$-porfirina atuando como doador de elétrons, a constante de velocidade de transferência de elétrons pode ser facilmente obtida pela diferença de tempo de decaimento do transiente na presença e ausência do aceptor. $\mathrm{O}$ mecanismo químico abaixo (Equação 1) ilustra um processo de transferência de elétrons para o sistema $\mathrm{Fe}^{\mathrm{II}}$-porfirina na presença de um aceptor de elétrons (A).

$$
{ }^{3}\left[\mathrm{Fe}^{\mathrm{II}} \text {-porfirina }\right]+\mathrm{A} \rightarrow\left[\mathrm{Fe}^{\mathrm{III}}-\text { porfirina }\right]_{0}+\mathrm{A}^{\bullet-}
$$

Equação 1 


\section{13 - Microscopia Eletrônica de Transmissão (MET)}

A microscopia eletrônica de transmissão (MET) constitui uma ferramenta muito importante para diferenciar morfologicamente espécies intervenientes em processos de agregação de proteínas em solução, por exemplo. Os métodos de microscopia eletrônica baseiam-se na interacção de feixes de elétrons com a amostra. O fluxo de elétrons, num microscópio eletrônico típico, é formado por uma fonte (por exemplo, um filamento de tungstênio) que é acelerado por um potencial elétrico positivo de várias dezenas de kilovolts na direção da amostra. Os feixes eletrônicos, após serem dispersos por estruturas diferentes da amostra, podem ser focados através de lentes eletromagnéticas e detectados para se produzir uma imagem bidimensional imensamente ampliada da amostra numa película fotográfica ou, mais recentemente, sob a forma digital (Figura 16) (REIMER; KOHL, 2008). A principal vantagem em usar um feixe de elétrons é que há um grande aumento no poder de resolução. Este aumento deve-se ao fato de o comprimento de onda do feixe de elétrons ser muito pequeno e, quanto menor o comprimento de onda, maior a resolução obtida (relação de Broglie).

Figura 16. Interior de um microscópio eletrônico de transmissão.

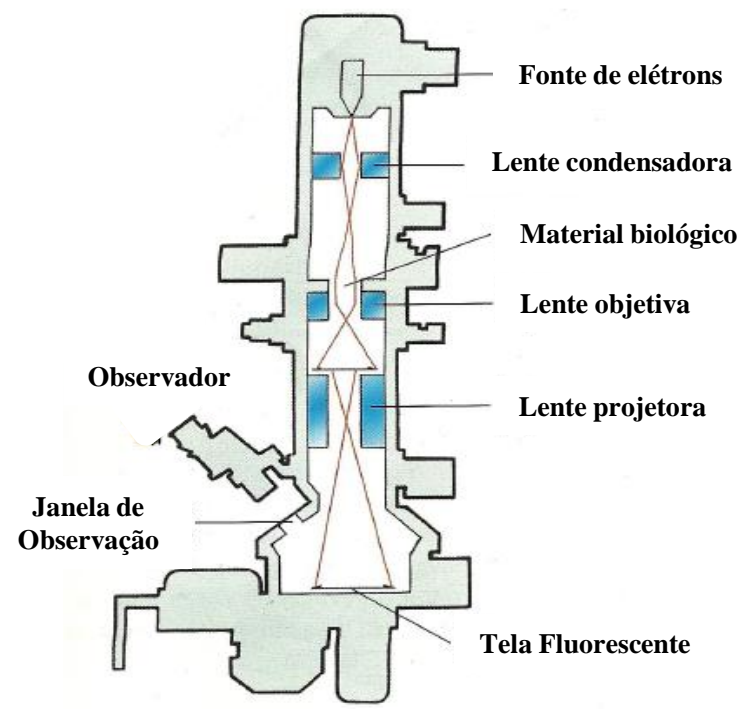

Fonte: Adaptado de Yang et al. (2012). 


\section{I.14 - Espalhamento de luz dinâmico (DLS)}

O espalhamento de luz dinâmico é uma técnica que permite determinar o raio hidrodinâmico de uma partícula pelo espalhamento de luz decorrido do movimento Browniano da partícula. Como as partículas pequenas movem-se mais rapidamente quando comparadas as partículas maiores, o espalhamento de luz será dependente do tamanho da partícula e de acordo com a velocidade do movimento browniano. A equação de Stokes-Einstein (Equação 2) demonstra a relação entre a velocidade da pertícula e seu tamanho devido ao movimento browniano:

$$
\mathrm{R}_{\mathrm{h}}=\mathrm{k}_{\mathrm{B}} \mathrm{T} / 6 \pi \eta_{\mathrm{o}} \mathrm{Do}_{\mathrm{o}}
$$

Sendo $\mathrm{k}_{\mathrm{B}}$ a constante de Boltzmann, $\mathrm{T}$ a temperatura, $\eta_{\mathrm{o}}$ a viscosidade do solvente, e Do o coeficiente de difusão translacional. A técnica de DLS é sensível a impurezas como poeira, fibras e partículas que pode desviar a luz, prejudicando as medidas de espalhamento de luz. 


\section{OBJETIVOS GERAIS E JUSTIFICATIVA}

A influência de íons zinco $\left(\mathrm{Zn}^{\mathrm{II}}\right)$ na estrutura e/ou reatividade de proteínas é de extrema relevância biológica. No caso do sistema químico composto por mioglobina e íons $\mathrm{Zn}{ }^{\mathrm{II}}$, é relevante uma vez que ambos estão presentes na dieta alimentar e no músculo esquelético. Neste sentido, os estudos aqui propostos contribuem para a elucidação do mecanismo de interação e/ou reatividade entre íons $\mathrm{Zn}^{\mathrm{II}}$ e sistemas ferro-porfirinas de proteínas e, também, da influência na estrutura protéica da $\mathrm{Mb}$ (hélice- $\alpha$, folha- $\beta$ e randômica).

Os objetivos deste trabalho foram divididos nos seguintes tópicos:

I. Estudos fotofísicos e fotoquímicos da mioglobina na presença de íons de $\mathrm{Zn}$, visando compreender o mecanismo de interação destes íons metálicos redox inativos com a estrutura das proteínas e o efeito desta interação nas propriedades da heme-proteína. Nesta etapa, as mudanças estruturais da proteína (mioglobina) foram acompanhadas por UV-vis, dicroísmo circular e fluorescência.

II. Investigar a interação dos íons de $\mathrm{Zn}$ II com a mioglobina e o comportamento morfológico da mesma através das técnicas de ITC e microscopia eletrônica de trasmissão.

III. Correlacionar o efeito da mudança de conformação com a reatividade das espécies ferroporfirina. Nesta etapa, pretende-se excitar o grupo ferro-porfirina da mioglobina, na região das bandas Soret ou banda $\mathrm{Q}$, e investigar a reatividade do ligante axial $-\mathrm{O}_{2}$ da ferro-porfirina $\left(\mathrm{MbFe}^{\mathrm{II}} \mathrm{O}_{2}\right)$ na presença e ausência de íons de $\mathrm{Zn}{ }^{\mathrm{II}}$. Para isso, a técnica de Fotólise de Laser Pulsado (ou LFP) foi utilizada para o monitoramento das espécies transientes de ferro-porfirinas.

IV. Investigar a reatividade das espécies de $\mathrm{Mb}$ hipervalentes (ferrilmioglobina e perferrilmioglobina) frente a moléculas de interesse biológicos (monóxido de carbono e cisteína) na presença e ausência de íons de $\mathrm{Zn}$ II , utilizando a técnica de UV-vis e LFP. 


\section{MATERIAIS E MÉTODOS}

\section{III.1 - Reagentes químicos e gases especiais}

Os reagentes utilizados para realizar os experimentos estão descritos na Tabela 3.

Tabela 3. Reagentes e solventes utilizados e gases especiais.

\begin{tabular}{ll}
\hline Reagentes/Solventes & Procedência \\
\hline Acetato de sódio (99\%) & Aldrich \\
\hline Acetato de zinco (99\%) & Aldrich \\
\hline Ácido 2-N-morfolinoetanossulfônico (MES) & Aldrich \\
\hline Ácido acético (HPLC) & Tedia \\
\hline Água deionizada (18 M $\Omega$. cm a $\left.25^{\circ} \mathrm{C}\right)$ & Sistema Milli-Q (Milipore) \\
\hline Catalase de fígado bovino & Aldrich \\
\hline L-Cisteína & Aldrich \\
\hline Cloreto de sódio (99,7\%) & J. T. Baker \\
\hline Ditionito de sódio (99,5\%) & Aldrich \\
\hline Mioglobina de coração de cavalo $(>90 \%)$ & Aldrich \\
\hline Monóxido de carbono & White Martins \\
\hline Oxigênio & White Martins \\
\hline Peróxido de hidrogênio & Merck \\
\hline Sephadex G25 & Aldrich \\
\hline Sulfato de sódio (99\%) & Aldrich \\
\hline TRIS (hidroximetilaminometano) & Aldrich \\
\hline
\end{tabular}

Fonte: Autoria própria

\section{III.2 - Preparo das soluções de mioglobina e sais metálicos}

Para a obtenção da metamioglobina, a proteína mioglobina obtida comercialmente foi dissolvida em tampão acetato $0,16 \mathrm{~mol} \mathrm{~L}^{-1} \mathrm{com} \mathrm{pH}$ ajustado para 5,7 e purificada por meio de filtração em uma coluna Sephadex G-25 como descrito na literatura (CARLSEN et al., 2005). Sua concentração foi determinada através da espectroscopia de UV-vis utilizando um coeficiente de 
absortividade molar de $\varepsilon_{525}=7700 \mathrm{~L} \mathrm{~mol}^{-1} \mathrm{~cm}^{-1} \mathrm{em} 525 \mathrm{~nm}$ (LEE et al., 2003). Para a preparação da oximioglobina, $2 \mathrm{~mL}$ da solução de mioglobina (cerca de $5 \mathrm{mg}$ a cada $\mathrm{mL}$ de tampão acetato $0,16 \mathrm{~mol} \mathrm{~L}^{-1} \mathrm{com} \mathrm{pH}$ ajustando para 5,7) foram reduzidos pela adição de $2 \mathrm{mg}$ de ditionito de sódio $\left(\mathrm{Na}_{2} \mathrm{~S}_{2} \mathrm{O}_{4}\right)$. A solução foi imediatamente purificada em uma coluna Sephadex G-25 para a retenção do ditionito residual (LUND et al., 2008). Sua concentração foi determinada através da espectroscopia de UV-vis utilizando um coeficiente de absortividade molar de $\varepsilon_{544}=14300 \mathrm{~L} \mathrm{~mol}^{-}$ ${ }^{1} \mathrm{~cm}^{-1} \mathrm{em} 544 \mathrm{~nm}$ (BOWEN et al., 1969). Solução estoque de acetato de zinco na concentração de $1 \mathrm{~mol} \mathrm{~L}^{-1}$ foi preparada com tampão acetato $\left(0,16 \mathrm{~mol} \mathrm{~L}^{-1}\right)$, ajustando-se o $\mathrm{pH}$ em 5,8. A espécie reativa ferrilmioglobina foi preparada a partir da reação entre uma solução de metamioglobina de concentração apropriada com peróxido de hidrogênio em duas vezes de excesso molar com relação à concentração de mioglobina. Após 3 minutos de reação, o excesso de $\mathrm{H}_{2} \mathrm{O}_{2}$ foi removido a partir da adição de $13 \mu \mathrm{L}$ de uma solução de catalase $(9.4 \mathrm{mg} / \mathrm{mL})$ em $1 \mathrm{~mL}$ da solução reacional. A solução de ferrilmioglobina foi mantida por 5 minutos à temperatura ambiente para assegurar total consumo do peróxido de hidrogênio.

\section{III.3 - Absorção eletrônica na região UV-vis}

As medidas de absorção eletrônica na região UV-vis foram realizadas em um espectrofotômetro de arranjo de diodos Multiskan GO Microplate Spectrophotometer (ThermoScientific, Bremen, Alemanha). Os experimentos foram termostatizados à temperatura de $298,0 \pm 0,1 \mathrm{~K}$.

\section{III.4 - Espectroscopia de Fluorescência}

Os espectros de fluorescência foram obtidos com o fluorímetro Hitachi (FL4500), utilizando-se fendas de absorção e emissão de $5 \mathrm{~nm}$ a 298,0 \pm 0,2 K. As amostras de mioglobina foram excitadas em $295 \mathrm{~nm}$, onde apenas o triptofano possui absorção eletrônica.

As cinéticas de emissão foram realizadas no modo signal in time, em que o comprimento de excitação e a emissão de fluorescência ( $\lambda_{\mathrm{em}}=425 \mathrm{~nm}$ ) são mantidos fixos e a intensidade de fluorescência é medida em diferentes tempos. 


\section{III.5 - Dicroísmo Circular (CD)}

Os experimentos foram realizados no espectropolarímetro J-815 (Jasco Inc.). A cubeta utilizada possui um caminho óptico de $0,1 \mathrm{~mm}$ e para cada espectro, foram acumulados 8 varrimentos a diferentes temperaturas $(293,0 ; 298,0 ; 303,0$ e 308,0) $\pm 0,1 \mathrm{~K}$. Os resultados de CD podem ser apresentados como: diferença de absorção $(\Delta \mathrm{A})$, elipticidade dicróica $(\theta \lambda)$ ou elipticidade molar $(\theta \lambda, \mathrm{m})$. A Equação 3 mostra a dependência da elipticidade molar com a elipticidade dicróica, em que, m é a concentração molar e d é o caminho óptico da cubeta. A predição da estrutura secundária da proteína foi realizada a partir do programa CDNN Deconvolution.

$$
[\theta]=\frac{100 \times \theta}{m \times d}
$$

Equação 3

\section{III.6 - Titulação isotérmica microcalorimétrica (ITC)}

Os experimentos de titulação isotérmica microcalorimétrica foram realizados em um microcalorímetro iTC200 (GE Healthcare Lifesciences). O equipamento foi lavado previamente à realização dos ensaios e uma titulação teste de água contra água foi realizada, a fim de verificar a presença de possíveis contaminantes na seringa de titulação e/ou celas experimental e de referência. As amostras de metamioglobina, de referência e do ligante, foram degaseificadas para a retirada de eventuais bolhas de ar que poderiam interferir nas medidas.

O ligante foi titulado com 18 injeções de $2 \mu \mathrm{L}$ até se obter a saturação das curvas com o intervalo entre as injeções de 120 segundos a 298,0 \pm 0,1 K. Os experimentos foram realizados em tampão acetato $0,16 \mathrm{~mol} \mathrm{~L}^{-1}$ ( $\mathrm{pH} 5,7$ ), onde a cela continha uma solução de $1,16.10^{-4} \mathrm{~mol} \mathrm{~L}^{-1}$ de metamioglobina e titulada (seringa) com solução de $\mathrm{Zn}^{\mathrm{II}}=1,74.10^{-3} \mathrm{~mol} \mathrm{~L}^{-1}$. Uma injeção inicial de $0,2 \mu \mathrm{L}$ foi realizada e posteriormente descartada. Os resultados obtidos foram analisados pelo software Microcal Origin, fornecido pela fabricante, sendo utilizado o modelo de um sítio de ligação para ajuste da curva, permitindo assim a obtenção do coeficiente estequiométrico, da constante de associação $\left(\mathrm{K}_{\mathrm{A}}\right)$, e de parâmetros termodinâmicos $(\Delta \mathrm{H}$ e $\Delta \mathrm{S})$. 


\section{III.7 - Fotólise de Laser Pulsado (FLP)}

Os experimentos de fotólise de laser pulsado resolvida no tempo foram obtidos por um espectrômetro LFP-112 ns da Luzchem (Ottawa, Canadá), bombeado com um laser de $N d: Y A G$ Oscillator Laser (Brilliant-B, LesUlis, France). O harmônico $2 \omega(532 \mathrm{~nm})$ foi utilizado para excitar a amostra, de acordo com o sistema químico estudado. As medidas foram realizadas em cubeta de quartzo de volume reduzido (1,0cm excitação x 0,5cm monitoramento) a 298,0 $\pm 0,3 \mathrm{~K}$.

\section{III.8 - Microscopia Eletrônica de Transmissão (MET)}

Os ensaios de microscopia eletrônica de transmissão (MET) foi realizado com a finalidade de verificar a morfologia da proteína na presença de íons de $\mathrm{Zn}$ II . Inicialmente colocou-se amostras

de $5 \mu \mathrm{L}$ de metamioglobina $\left(\mathrm{MbFe}^{\mathrm{III}}\right.$ ) e amostras de metamioglobina e $\mathrm{Zn}^{\mathrm{II}}$ a pH 5,7 (tampão acetato), numa grelha de cobre com uma malha de 400 quadrados, coberta com um filme polimérico de formvar, com o período de incubação de 24 horas. Estes ensaios foram realizados no Departamento de Engenharia dos Materiais, da Universidade do Estado de Santa Catarina (UDESC - CCT). As imagens das amostras observadas foram obtidas através de um microscópio JEOL modelo JEM-2100, com um canhão filamento de tungsténio, operando até $200 \mathrm{kV}$, e com uma câmera acoplada CCD da Orius Gatan.

\section{III.9 - Espectroscopia vibracional na região do infravermelho (FTIR)}

O espectro vibracional foi obtido utilizando-se o espectrofotômetro da marca Bruker modelo Vertex 70V, fonte globar, detector $\mathrm{HgCdTe}$ (MCT), abertura de fenda 1,5 mm, velocidade de escaneamento $160 \mathrm{~Hz}$. As medidas foram realizadas na região de 4000 a $600 \mathrm{~cm}^{-1}$ com resolução de $8 \mathrm{~cm}^{-1}$ e 256 acumulações.

\section{III.10 - Espalhamento de luz dinâmico (DLS)}

A distribuição de tamanhos da proteína na presença de íons de $\mathrm{Zn}{ }^{\mathrm{II}}$ foi obtida por medidas de DLS realizadas a $298 \mathrm{~K}$ em triplicata utilizando o equipamento Malvern spectrometer Nano-ZS (Malvern Instruments, UK) pertencente a Embrapa, São Carlos. Todas as amostras foram medidas em tampão acetato pH 5,7 e força iônica de $0,16 \mathrm{~mol} \mathrm{~L}^{-1}$. 


\section{RESULTADOS E DISCUSSÃO}

\section{IV.1 - Estudo de absorção UV-Vis e FTIR para o sistema Mb/ZñI}

As Figuras 17A e 17B mostra o espectro da mioglobina $\left(10 \times 10^{-5} \mathrm{~mol} \mathrm{~L}^{-1}\right)$ em tampão acetato $\left(0,16 \mathrm{~mol} \mathrm{~L}^{-1} ; \mathrm{pH}=5,7\right)$ na presença e ausência de acetato de zinco $\left(5 \times 10^{-3} \mathrm{~mol} \mathrm{~L}^{-1}\right)$. Após a adição do sal de $\mathrm{Zn}^{\mathrm{II}}$ na solução de mioglobina, os espectros de absorção eletrônica foram adquiridos com diferentes tempos de interação ( 0 min $\rightarrow 60 \mathrm{~min} ; \Delta t=1 \mathrm{~min})$.

Figura 17. Espectro de absorção UV-vis da mioglobina $\left(1,0 \times 10^{-5} \mathrm{~mol} \mathrm{~L}^{-1}\right)$ na presença de acetato de $\mathrm{Zn}^{\mathrm{II}}\left(5,0 \times 10^{-3} \mathrm{~mol} \mathrm{~L}^{-1}\right)$ adquiridos em diferentes tempos após a adição do íon $\mathrm{Zn}^{\mathrm{II}}$. (a) Espectro de absorção na janela espectral de $250 \mathrm{~nm}-450 \mathrm{~nm}$; (b) Espectro de absorção na janela espectral de $450 \mathrm{~nm}-700 \mathrm{~nm}$. Tampão acetato $0,16 \mathrm{~mol} \mathrm{~L}^{-1} \mathrm{pH}=5,8(\mathrm{~T}=298 \mathrm{~K})$.
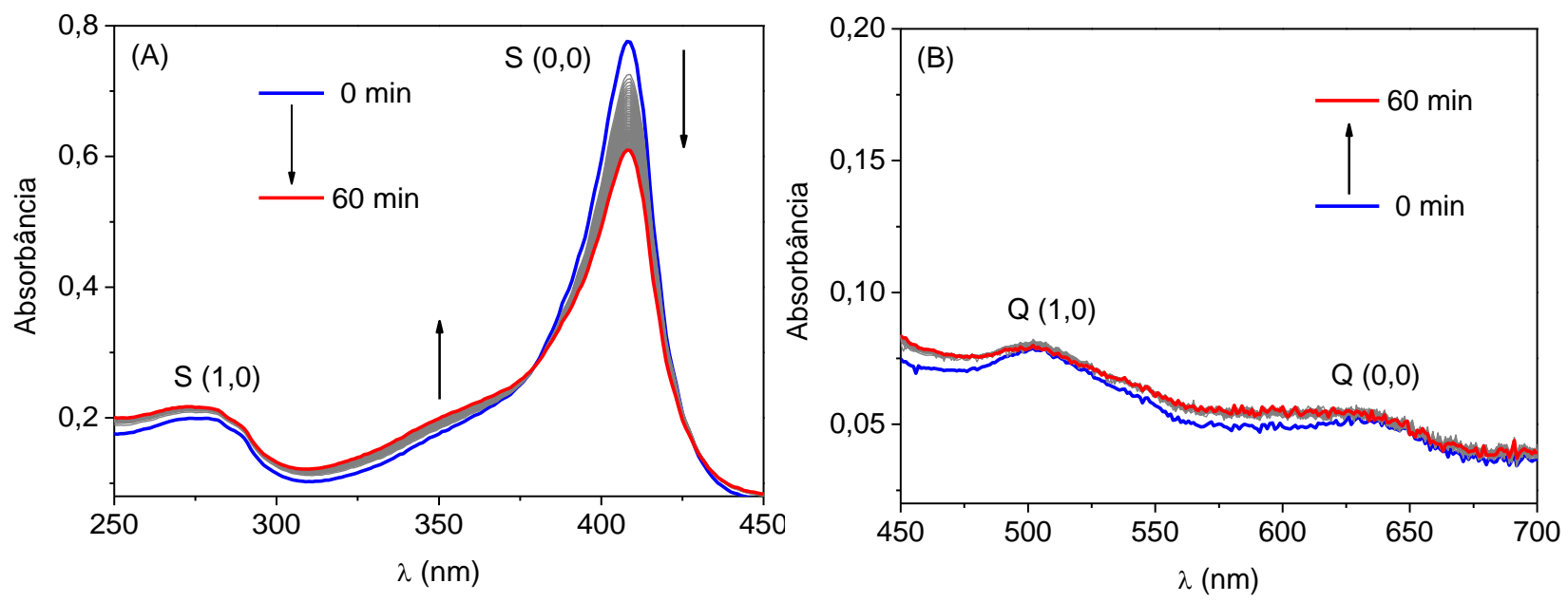

Fonte: Autoria própria

A Figura 17A contém o espectro de absorção UV-vis da mioglobina registrado em diferentes tempos após a adição de acetato de zinco. Pode-se observar na Figura 17A que a banda Soret em $\lambda=410 \mathrm{~nm}(0,0)$ diminui ao longo do tempo de interação entre as espécies com o concomitante aumento da banda Soret $(1,0)$ em $355 \mathrm{~nm}$. A ausência de deslocamento do máximo de absorção das bandas Soret $(0,0$ e 1,0) e das bandas Q (Figura 17B) indicam que não existe processo redox ocorrendo na metaloporfirina na presença de $\mathrm{Zn}^{\mathrm{II}}$. Neste sentido, o estado de spin do metal continua o mesmo após a adição de íons de $\mathrm{Zn}^{\mathrm{II}}$, mantendo-se hexa-coordenado e com configuração de spin alto (TOFANI et al., 2004). 
A diminuição de absorção na banda Soret $(0,0)$ pode ser então atribuída à mudança de conformação da mioglobina, como reportado na literatura (AJLOO et al., 2002; MONDAL et al., 2016). Na investigação de Ajloo et al. (2002), os autores encontram fortes indícios da participação de surfactantes catiônicos na diminuição da quantidade de hélice- $\alpha$, que por consequência diminui a intensidade de absorção da banda Soret $(0,0)$. Neste sentido, o comportamento de absorção da banda Soret na Figura 17A pode estar relacionada à uma mudança de conformação da proteína, induzindo uma perturbação nos orbitais $\pi$ do anel porfirínico, que então favorece um maior acoplamento eletrônico-vibracional e, por consequência, o aumento da absortividade molar da banda Soret $(1,0)$.

Com o propósito de avaliar o efeito dos íons de $\mathrm{Zn}^{\mathrm{II}}$ no ambiente ferro-heme da $\mathrm{Mb}$, a técnica de espectroscopia de absorção vibracional com reflexão total atenuada (FTIR-ATR) foi utilizada de forma comparativa (Figura 18) na ausência e presença de diferentes concentrações de íons de $\mathrm{Zn}^{\mathrm{II}}$.

Figura 18. Espectro de absorção vibracional no infravermelho da $\mathrm{MbFe}^{\mathrm{II}} \mathrm{O}_{2}\left(0,01 \mathrm{~mol} \mathrm{~L}{ }^{-1}\right)$ em tampão acetato (pH 5,7) a $298 \mathrm{~K}$, nas concentrações de $\mathrm{Zn}^{\mathrm{II}}$ indicadas.

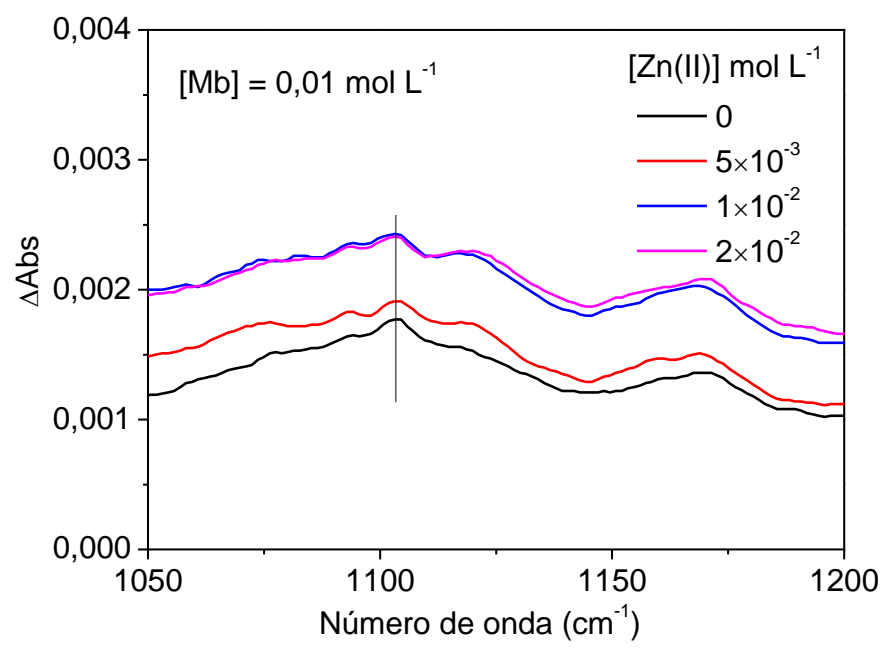

Fonte: Autoria própria

A Figura 18 mostra o espectro de absorção vibracional na janela espectral de 1050 a 1200 $\mathrm{cm}^{-1}$, região associada a vibrações da ligação Fe-O, banda em torno de $1104 \mathrm{~cm}^{-1}$ (POTTER et al., 1987). Observa-se que as frequências relativas ao estiramento da ligação Fe-O não foram alteradas 
na presença de íons de $\mathrm{Zn}{ }^{\mathrm{II}}$, sugerindo que não há interação do íon $\mathrm{Zn}^{\mathrm{II}}$ com o ligante $\mathrm{O}_{2}$ da ferroporfirina.

\section{IV.2 - Estudo de emissão de fluorescência para o sistema $\mathrm{Mb} / \mathrm{Zn}^{\mathrm{II}}$}

A mioglobina $(\mathrm{Mb})$ possui dois resíduos de triptofano, duas tirosinas e sete resíduos de fenilalanina (DAUTREVAUX et al., 1969). Os resíduos de triptofano dominam a emissão de fluorescência da mioglobina, devido ao maior valor de rendimento quântico de fluorescência (veja Tabela 2 para os valores de $\Phi_{\mathrm{F}}$ ). Quando a mioglobina é excitada em comprimentos de onda maiores ou igual a $295 \mathrm{~nm}$ apenas o resíduo de triptofano é excitado. A Figura 19A e a Figura 19B contém o espectro de emissão de fluorescência e a curva cinética ( $\mathrm{I}_{\mathrm{F}} v s$. tempo) para o sistema químico $\mathrm{MbFe}^{\mathrm{III}} \mathrm{H}_{2} \mathrm{O}+\mathrm{Zn}^{\mathrm{II}}$, respectivamente.

Figura 19. (A) Espectro de emissão de fluorescência da metamioglobina $\left(\mathrm{MbFe}^{\mathrm{III}} \mathrm{H}_{2} \mathrm{O}\right)$ em diferentes concentrações de acetato de zinco $\left(\left[\mathrm{Zn}^{\mathrm{II}}\right]=0 \rightarrow 3 \times 10^{-2} \mathrm{~mol} \mathrm{~L}^{-1}\right)$; espectros adquiridos 1 min após adição de $\mathrm{Zn}^{\mathrm{II}}$. (B) Curva de intensidade vs tempo para o sistema $\mathrm{Mb}\left(1,0 \times 10^{-5} \mathrm{~mol} \mathrm{~L}^{-1}\right)$ $+\mathrm{Zn}^{\mathrm{II}}$. Tampão acetato $0,16 \mathrm{~mol} \mathrm{~L}{ }^{-1} \mathrm{pH}=5,8(\mathrm{~T}=297 \mathrm{~K})$.
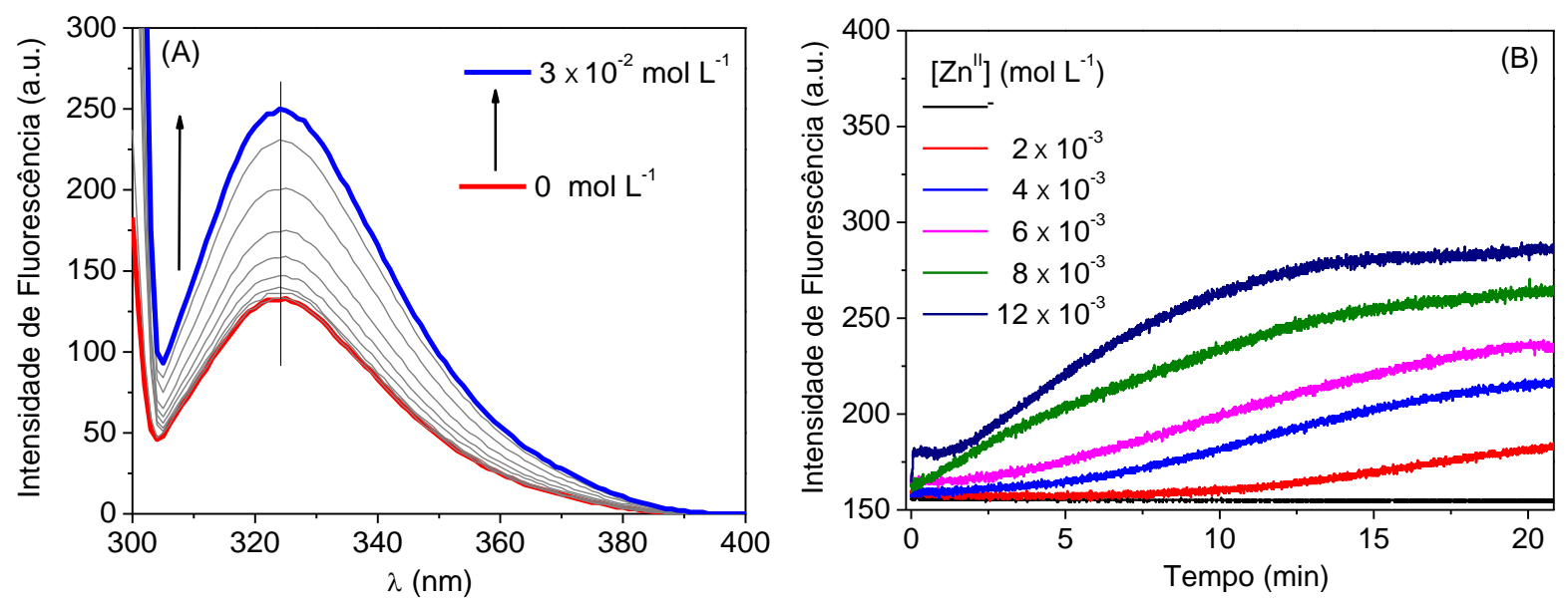

Fonte: Autoria própria

Na presença de íons $\mathrm{Zn}^{\mathrm{II}}$, a intensidade de emissão de fluorescência é aumentada, como pode ser observado na Figura 19A, e nas curvas cinéticas da Figura 19B, para as diferentes concentrações de zinco. O aumento da intensidade é atribuído a um maior distanciamento entre o fluoróforo e o supressor. Após a adição de íons zinco na solução de mioglobina, a posição do máximo de emissão não é deslocada no espectro de fluorescência (Figura 19A), indicando, desta forma, que o ambiente químico do triptofano permanece hidrofóbico. A Figura 19B mostra a evolução temporal da intensidade de fluorescência após a adição de íons zinco ${ }^{\text {II }}$. O aumento da 
intensidade de fluorescência para o sistema mioglobina contendo $\mathrm{Zn}^{\mathrm{II}}\left(8 \times 10^{-3} \mathrm{~mol} \mathrm{~L}^{-1}\right)$ leva a um aumento na intensidade de emissão ao longo do tempo sugerindo uma lenta cinética de interação, que perdura por vários minutos.

\section{IV.3 - Análise da estrutura secundária da metamioglobina por Dicroísmo Circular UV-vis}

A técnica de dicroísmo circular na região do UV-vis foi utilizada neste estudo com a intenção de avaliar as mudanças na estrutura da proteína. Os espectros obtidos estão ilustrados na Figura 20 em diferentes temperaturas e a predição da estrutura secundária foi realizada a partir do programa CDNN Deconvolution. Os valores percentuais determinados para cada estrutura secundária são relatados na Tabela 4.

Figura 20. Espectros de $\mathrm{CD}$ da metamioglobina na presença de íons $\mathrm{Zn}^{\mathrm{II}}$, em tampão acetato $\left(1,0 \times 10^{-2} \mathrm{~mol} \mathrm{~L}^{-1}\right), \mathrm{pH} 5,8$ e força iônica de $0,16 \mathrm{~mol} \mathrm{~L}^{-1}$ ajustado com $\mathrm{NaCl}$, coletado a cada 5 minutos. Os espectros foram registrados à temperaturas de $293 \mathrm{~K}(\mathrm{~A}), 298 \mathrm{~K}(\mathrm{~B}), 303 \mathrm{~K}(\mathrm{C})$ e 308

$\mathrm{K}$ (D) e a concentração de metamioglobina e acetato de zinco foi de $1,0 \times 10^{-5} \mathrm{~mol} \mathrm{~L}^{-1}$ e $1,6 \times 10^{-2}$ mol $\mathrm{L}^{-1}$ respectivamente. A cubeta utilizada possui um caminho óptico de $0,1 \mathrm{~mm}$. Para cada espectro, foram acumulados 8 varrimentos.
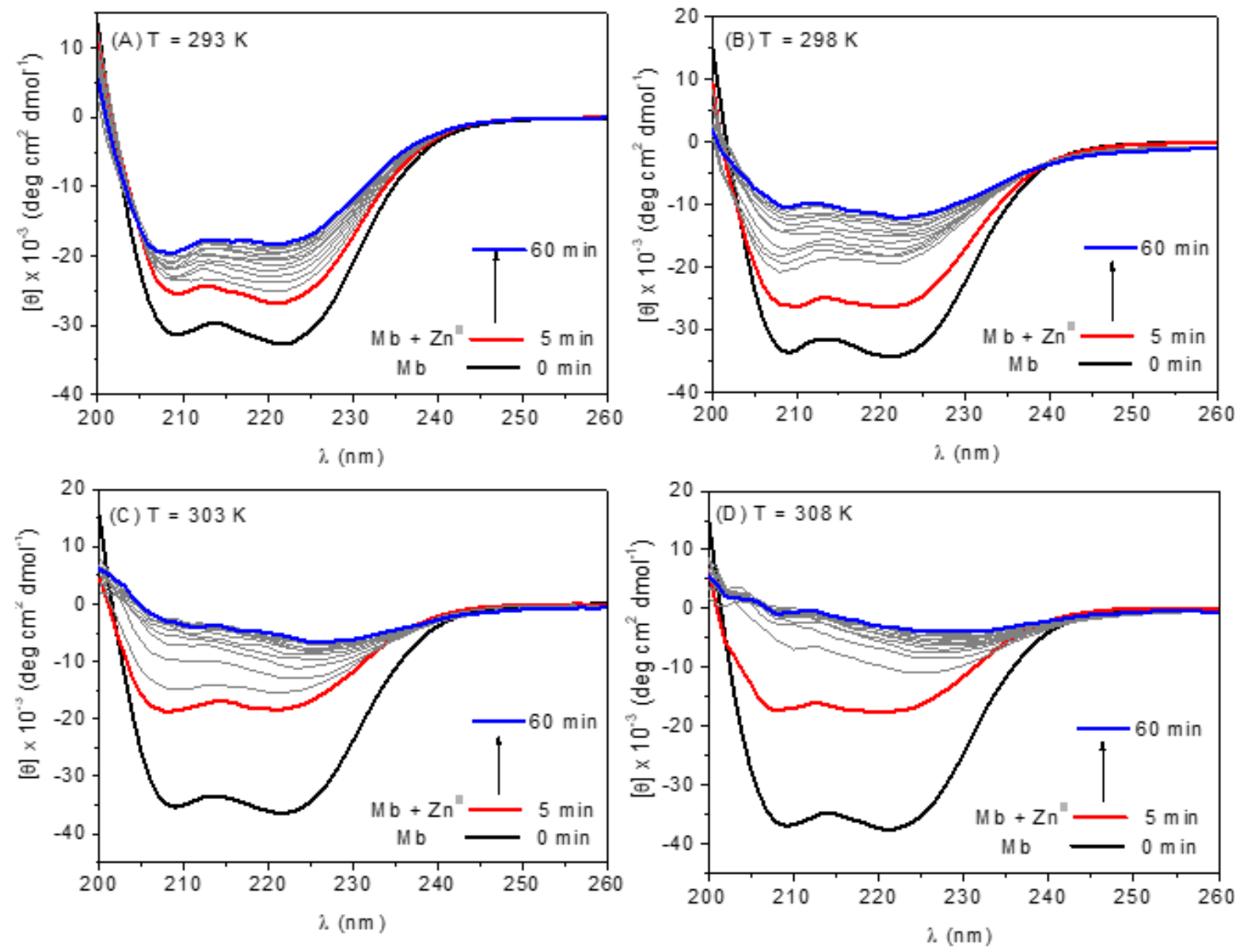
Tabela 4. Propriedades estruturais e espectroscópicas da metamioglobina em diferentes temperaturas (A) $293 \mathrm{~K}$; (B) $298 \mathrm{~K}$; (C) $303 \mathrm{~K}$ e (D) $308 \mathrm{~K}$, quando na presença de $1,60 \times 10^{-3} \mathrm{~mol}$ $\mathrm{L}^{-1}$ de íons $\mathrm{Zn}^{\mathrm{II}}$.

(A) $293 \mathrm{~K}$

\begin{tabular}{|c|c|c|c|c|c|c|c|c|c|}
\hline \multirow{2}{*}{ Conformação } & \multirow{2}{*}{$\begin{array}{l}{ }^{\mathrm{a}} \mathrm{Mb} \\
\text { nativa }\end{array}$} & \multicolumn{8}{|c|}{${ }^{\mathrm{b}}$ Após adição de $\mathrm{Zn}^{\mathrm{II}}$} \\
\hline & & $0 \min$ & $5 \mathrm{~min}$ & $10 \min$ & $20 \min$ & $30 \mathrm{~min}$ & $40 \min$ & $50 \min$ & $60 \mathrm{~min}$ \\
\hline hélice- $\alpha(\%)$ & 84,0 & 81,3 & 79,1 & 75,0 & 69,8 & 67,3 & 63,0 & 60,7 & 60,2 \\
\hline Antiparalela (\%) & 1,0 & 1,5 & 1,8 & 2,1 & 2,6 & 2,8 & 3,3 & 3,6 & 3,7 \\
\hline Paralela (\%) & 1,5 & 1,9 & 2,2 & 2,4 & 2,9 & 3,2 & 3,6 & 3,8 & 3,9 \\
\hline Folha- $\beta(\%)$ & 8,3 & 9,7 & 10,2 & 10,7 & 11,5 & 11,9 & 12,5 & 12,9 & 13,0 \\
\hline Randômica (\%) & 9,0 & 9,4 & 10,0 & 11,7 & 13,4 & 14,2 & 15,6 & 16,2 & 16,8 \\
\hline Total (\%) & 103,8 & 103,7 & 103,4 & 102,0 & 100,2 & 99,5 & 98,1 & 97,2 & 97,6 \\
\hline
\end{tabular}

${ }^{\mathrm{a}}\left[\mathrm{MbFe}^{\mathrm{III}} \mathrm{H}_{2} \mathrm{O}\right]=1,73 \times 10^{-6} \mathrm{~mol} \mathrm{~L}^{-1}$; tampão acetato $\mathrm{pH}=5,8 / \mathrm{NaCl}\left(0,16 \mathrm{~mol} \mathrm{~L}^{-1}\right) ;{ }^{\mathrm{b}}\left[\mathrm{Zn}^{\mathrm{II}}\right]=16 \times 10^{-3} \mathrm{~mol} \mathrm{~L}^{-1}$

(B) $298 \mathrm{~K}$

\begin{tabular}{|c|c|c|c|c|c|c|c|c|c|}
\hline \multirow{2}{*}{ Conformação } & \multirow{2}{*}{$\begin{array}{l}{ }^{\mathrm{a}} \mathrm{Mb} \\
\text { nativa }\end{array}$} & \multicolumn{8}{|c|}{ b Após adição de Zn"II } \\
\hline & & $0 \mathrm{~min}$ & $5 \mathrm{~min}$ & $10 \mathrm{~min}$ & $20 \mathrm{~min}$ & $30 \mathrm{~min}$ & $40 \mathrm{~min}$ & $50 \mathrm{~min}$ & $60 \mathrm{~min}$ \\
\hline hélice- $\alpha(\%)$ & 83,2 & 81,4 & 81,4 & 57,4 & 52,8 & 46,3 & 37,9 & 34,8 & 32,2 \\
\hline Antiparalela (\%) & 1,1 & 1,5 & 1,5 & 4,0 & 4,6 & 5,5 & 7,1 & 7,9 & 8,6 \\
\hline Paralela (\%) & 1,2 & 1,8 & 1,8 & 4,2 & 4,9 & 6,0 & 7,6 & 8,4 & 9,0 \\
\hline Folha- $\beta(\%)$ & 8,1 & 9,8 & 9,8 & 13,4 & 13,8 & 14,6 & 15,9 & 16,3 & 16,8 \\
\hline Randômica (\%) & 8,2 & 8,7 & 8,7 & 17,7 & 20,8 & 25,0 & 29,7 & 32,30 & 33,7 \\
\hline Total (\%) & 101,8 & 103,2 & 103,2 & 96,7 & 96,9 & 97,5 & 98,2 & 99,7 & 100,3 \\
\hline
\end{tabular}

${ }^{\mathrm{a}}\left[\mathrm{MbFe}^{\mathrm{III}} \mathrm{H}_{2} \mathrm{O}\right]=1,73 \times 10^{-6} \mathrm{~mol} \mathrm{~L}-1$; tampão acetato $\mathrm{pH}=5,8 / \mathrm{NaCl}\left(0,16 \mathrm{~mol} \mathrm{~L}^{-1}\right) ;{ }^{\mathrm{b}}\left[\mathrm{Zn}^{\mathrm{II}}\right]=16 \times 10^{-3} \mathrm{~mol} \mathrm{~L}^{-1}$

(C) $303 \mathrm{~K}$

\begin{tabular}{|c|c|c|c|c|c|c|c|c|c|}
\hline \multirow{2}{*}{ Conformação } & \multirow{2}{*}{$\begin{array}{l}{ }^{\mathrm{a}} \mathrm{Mb} \\
\text { nativa }\end{array}$} & \multicolumn{8}{|c|}{${ }^{\text {b }}$ Após adição de $\mathbf{Z n}^{\text {II }}$} \\
\hline & & $0 \mathrm{~min}$ & $5 \min$ & $10 \mathrm{~min}$ & $20 \mathrm{~min}$ & $30 \mathrm{~min}$ & $40 \mathrm{~min}$ & $50 \mathrm{~min}$ & $60 \mathrm{~min}$ \\
\hline hélice- $\alpha(\%)$ & 80,7 & 58.6 & 47,6 & 35,1 & 24,4 & 21,8 & 20,1 & 18,9 & 19,4 \\
\hline Antiparalela (\%) & 2,5 & 3,9 & 5,3 & 7,7 & 11,2 & 12,3 & 13,4 & 14,1 & 13,8 \\
\hline Paralela (\%) & 1,6 & 4,1 & 5,8 & 8,6 & 12,1 & 13,5 & 14,2 & 14,9 & 14,8 \\
\hline Folha- $\beta(\%)$ & 7,7 & 13,2 & 14,5 & 16,2 & 18,2 & 18,7 & 19,3 & 19,6 & 19,5 \\
\hline Randômica (\%) & 9,4 & 17,6 & 23,8 & 33,3 & 42,3 & 45,7 & 46,5 & 48,0 & 47,9 \\
\hline Total (\%) & 101,9 & 97,3 & 97,1 & 100,7 & 108,1 & 112,1 & 113,5 & 115,5 & 115,3 \\
\hline
\end{tabular}

${ }^{\mathrm{a}}\left[\mathrm{MbFe}^{\mathrm{III}} \mathrm{H}_{2} \mathrm{O}\right]=1,73 \times 10^{-6} \mathrm{~mol} \mathrm{~L}^{-1}$; tampão acetato $\mathrm{pH}=5,8 / \mathrm{NaCl}\left(0,16 \mathrm{~mol} \mathrm{~L}^{-1}\right) ;{ }^{\mathrm{b}}\left[\mathrm{Zn}^{\mathrm{II}}\right]=16 \times 10^{-3} \mathrm{~mol} \mathrm{~L}^{-1}$ 
(D) $308 \mathrm{~K}$

\begin{tabular}{|c|c|c|c|c|c|c|c|c|c|}
\hline \multirow{2}{*}{ Conformação } & \multirow{2}{*}{$\begin{array}{c}{ }^{\mathrm{a}} \mathrm{Mb} \\
\text { nativa }\end{array}$} & \multicolumn{8}{|c|}{${ }^{\text {b }}$ Após adição de Zn } \\
\hline & & $0 \min$ & $5 \mathrm{~min}$ & $10 \mathrm{~min}$ & $20 \min$ & $30 \mathrm{~min}$ & $40 \mathrm{~min}$ & $50 \min$ & $60 \mathrm{~min}$ \\
\hline hélice- $\alpha$ (\%) & 80,1 & 55,0 & 26,8 & 20,3 & 17,0 & 16,7 & 14,7 & 14,9 & 15,0 \\
\hline Antiparalela (\%) & 2,4 & 4,3 & 10,0 & 13,0 & 15,2 & 15,6 & 17,2 & 17,2 & 17,2 \\
\hline Paralela (\%) & 1,6 & 4,6 & 11,4 & 14,4 & 16,5 & 16,7 & 18,1 & 17,8 & 17,8 \\
\hline Folha- $\beta(\%)$ & 7,3 & 13,6 & 17,5 & 19,0 & 20,0 & 20,2 & 20,9 & 20,9 & 20,9 \\
\hline Randômica (\%) & 9,9 & 19,7 & 41,5 & 48,0 & $\overline{51,7}$ & $\overline{51,6}$ & 53,9 & 53,1 & $\overline{53,0}$ \\
\hline Total (\%) & 101,3 & 97,1 & 107,1 & 114,6 & 120,3 & 120,7 & 124,8 & 124,0 & 123,9 \\
\hline
\end{tabular}

${ }^{\mathrm{a}}\left[\mathrm{MbFe}^{\mathrm{III}} \mathrm{H}_{2} \mathrm{O}\right]=1,73 \times 10^{-6} \mathrm{~mol} \mathrm{~L}^{-1}$; tampão acetato $\mathrm{pH}=5,8 / \mathrm{NaCl}\left(0,16 \mathrm{~mol} \mathrm{~L}^{-1}\right) ;{ }^{\mathrm{b}}\left[\mathrm{Zn}^{\mathrm{II}}\right]=16 \times 10^{-3} \mathrm{~mol} \mathrm{~L}^{-1}$

De acordo com os dados obtidos da Figura 20 e reportados na Tabela 4, observa-se aumento do valor absoluto do sinal de elipticidade molar indicando mudanças conformacionais significativas ao longo do tempo. A deconvolução dos espectros contidos na Figura 20 sugere que logo após a adição de íons $\mathrm{Zn}^{\mathrm{II}}$ ocorre um decréscimo de estrutura secundária tipo hélice- $\alpha$ com um ganho de estrutura secundária em folha- $\beta$ e de estrutura randômica.

Também pode-se observar um efeito da temperatura na diminuição da porção $\alpha$-hélice e aumento das folha- $\beta$ e randômica. Este efeito da temperatura é melhor observado na Figura 21, em que foi acompanhado a banda centrada em $222 \mathrm{~nm}$, para os diferentes valores de temperatura (293 $\rightarrow 308 \mathrm{~K})$.

Figura 21. (A) Efeito da temperatura na estrutura da metamiogobina. Sistema químico de MbFeIIIH2O $\left(1,0 \times 10^{-5} \mathrm{~mol} \mathrm{~L}^{-1}\right)+\mathrm{Zn}^{\mathrm{II}}\left(1,60 \times 10^{-2} \mathrm{~mol} \mathrm{~L}^{-1}\right)$. Tampão acetato $1,0 \times 10^{-2} \mathrm{~mol} \mathrm{~L}^{-1}, \mathrm{pH}$ $=5,8$ e força iônica de $0,16 \mathrm{~mol} \mathrm{~L}^{-1}$ ajustado com $\mathrm{NaCl}$. (B) Ajuste linear da equação de Van't Hoff.
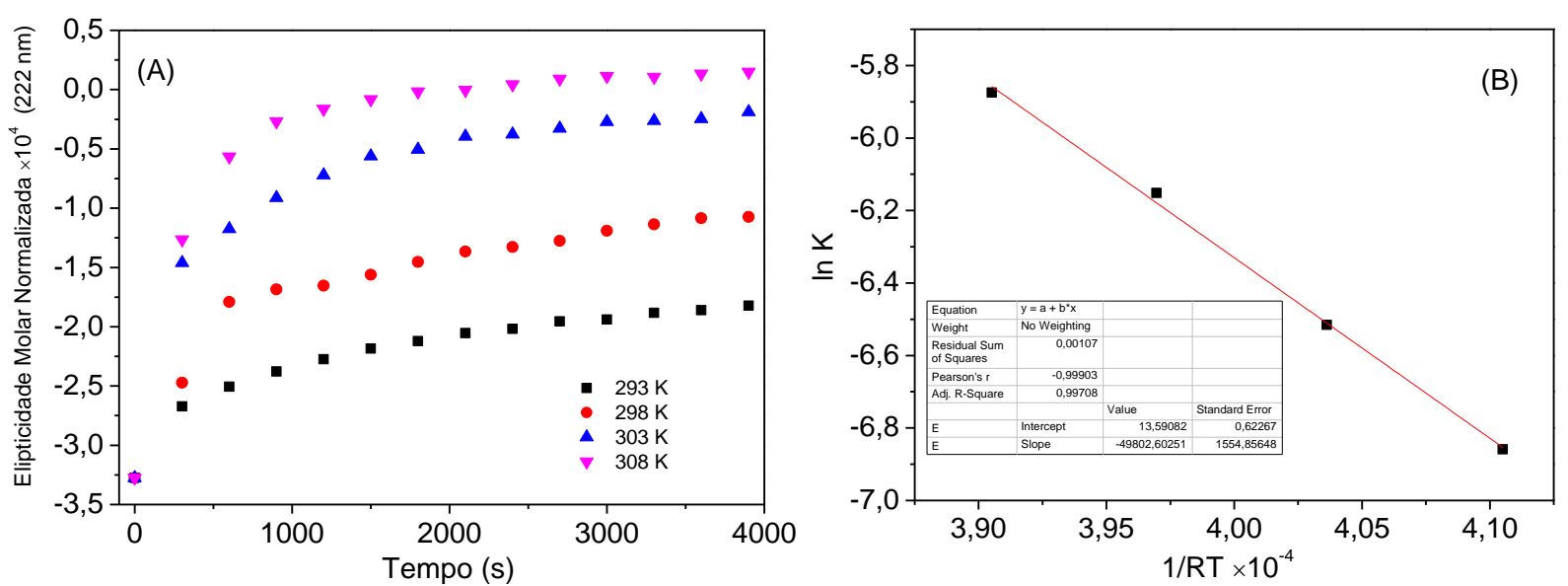

Fonte: Autoria própria 
Os cálculos referentes aos parâmetros termodinâmicos da mudança na estrutura conformacional da proteína foram realizados em acordo com a da equação de Van't Hoff a partir dos dados da Figura 21A. A partir do gráfico da Figura 21B obteve-se os valores de $\Delta \mathrm{H}^{0}=13,59 \pm$ $0,62 \mathrm{~kJ} \mathrm{~mol}^{-1}$ e $\Delta \mathrm{S}^{0}=-49,80 \pm 1,55 \mathrm{~J} \mathrm{~mol}^{-1} \mathrm{~K}^{-1}$.

Estes dados termodinâmicos obtidos demostram que a mudança na estrutura conformacional da $\mathrm{Mb}$ é endotérmica. $\mathrm{O}$ valor de $\Delta \mathrm{S}^{0}$ negativo sugere a formação de uma conformação parcialmente desnaturada do tipo glóbulo fundido compacto com capacidade para agregar ao longo do tempo, também conhecida como molten globule.

\section{IV.4 - Análise por titulação isocalorimétrica da interação entre a mioglobina e íons de $\mathrm{Zn}^{\mathrm{II}}$}

Pela técnica de titulação microcalorimetria isotérmica (ITC) foi possível determinar os parâmetros entálpicos e entrópicos da interação entre mioglobina e íons de $\mathrm{Zn}^{\mathrm{II}}$. A Figura 22 ilustra os resultados de uma típica curva de titulação exotérmica $(\Delta \mathrm{H}<0)$. O equilíbrio químico para o sistema de metamioglobina e íons de $\mathrm{Zn}^{\mathrm{II}}$ é ilustrado na Equação 4, em que $\mathrm{K}_{\mathrm{a}}$ é a constante de equilíbrio para o processo de associação entre a mioglobina e $\mathrm{Zn}^{\mathrm{II}}$.

$$
\mathrm{Zn}^{2+}+\mathrm{MbFe}^{\mathrm{III}} \mathrm{H}_{2} \mathrm{O} \stackrel{\mathrm{K}_{\mathrm{a}}}{\rightleftharpoons}\left[\mathrm{MbFe}^{\mathrm{III}} \mathrm{H}_{2} \mathrm{O} ; \mathrm{Zn}^{2+}\right]+\text { calor }
$$

Equação 4

A partir da curva calorimétrica da Figura 22, os parâmetros entálpicos e entrópicos foram determinados, obtendo-se valores de $\Delta \mathrm{H}^{\mathrm{o}}=-88,07 \pm 0,50 \mathrm{~kJ} \mathrm{~mol}^{-1}$ e $\Delta \mathrm{S}^{\mathrm{o}}=-208,78 \pm 0,30 \mathrm{~J} \mathrm{~mol}^{-}$ ${ }^{1} \mathrm{~K}^{-1}$. Também foi determinada a variação de energia de Gibbs usando-se a Equação 5.

$$
\Delta \mathrm{G}^{\mathrm{o}}=\Delta \mathrm{H}^{\mathrm{o}}-\mathrm{T} \Delta \mathrm{S}^{\mathrm{o}}
$$

Equação 5

$\mathrm{O}$ valor negativo para a variação de energia livre de Gibbs à $298 \mathrm{~K}\left(\Delta \mathrm{G}^{\mathrm{o}}=-25,85 \pm 0,5 \mathrm{~kJ}\right.$ $\mathrm{mol}^{-1}$ ) indica que o processo de interação entre as espécies químicas é espontâneo. Os valores negativos para as variações de entalpia e entropia indicam que o processo de interação é exotérmico e que o produto final possui um menor grau de liberdade das espécies. Neste sentido, a interação entre mioglobina e íon de $\mathrm{Zn}^{\mathrm{II}}$ é favorecida em temperaturas maiores. Em acordo com esta última observação, as curvas cinéticas em diferentes temperaturas são apresentadas na Figura 20 (nos 
estudos de dicroísmo circular) mostram que a velocidade de mudança na estrutura da mioglobina é maior quando a temperatura do sistema é elevada (293K $\rightarrow 308 \mathrm{~K})$.

Figura 22. Titulação microcalorimétrica de uma solução de metamioglobina $\left(1,16 \times 10^{-4} \mathrm{~mol} \mathrm{~L}^{-1}\right)$ com uma solução de íons de $\mathrm{Zn}^{\mathrm{II}}\left(1,74 \times 10^{-3} \mathrm{~mol} \mathrm{~L}^{-1}\right)$ em tampão acetato $\left(0,16 \mathrm{~mol} \mathrm{~L}^{-1}\right) \mathrm{pH} 5,7$.

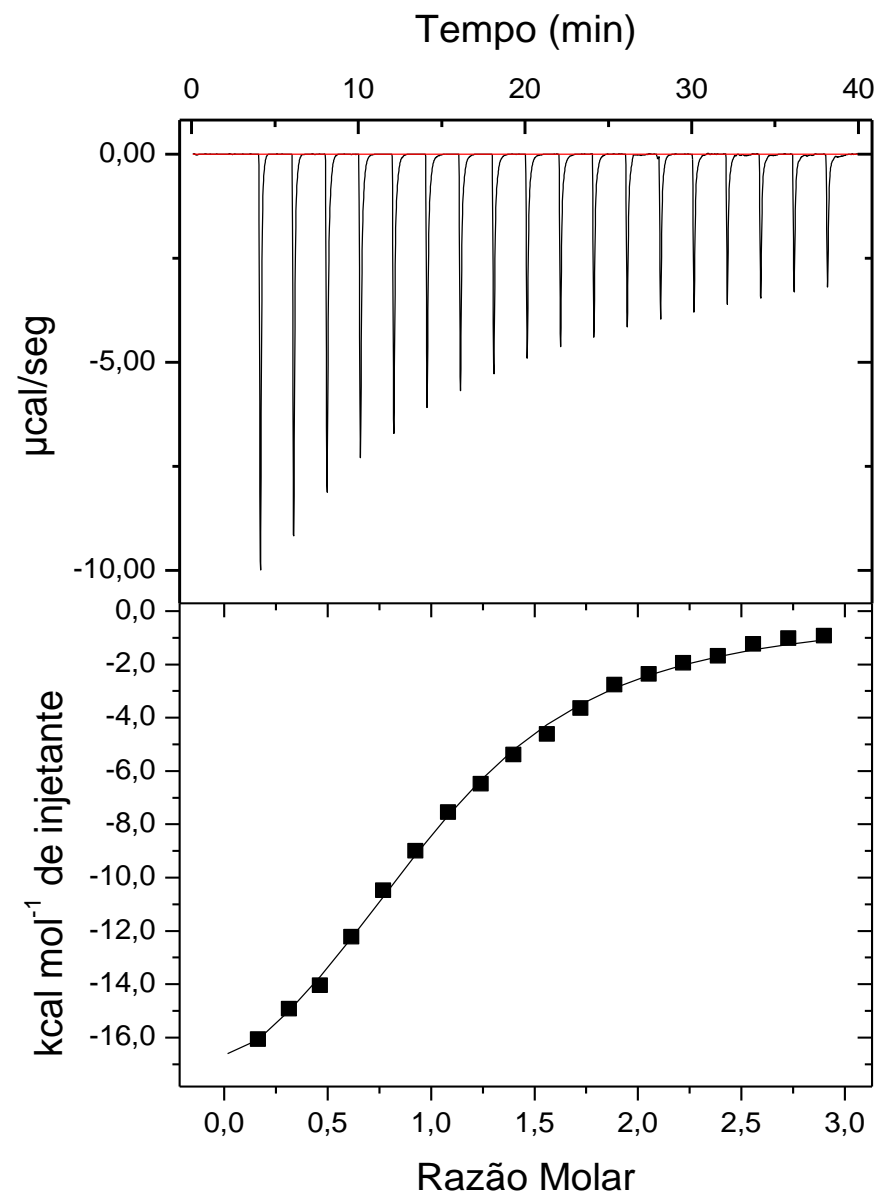

Fonte: Autoria própria

Também foi possível determinar a constante de equilíbrio em $298 \mathrm{~K}\left(\mathrm{~K}_{\mathrm{a}}=(3,22 \pm 0,21) 10^{4}\right.$ $\mathrm{L} \mathrm{mol}^{-1}$ ) e o parâmetro n (estequiometria das espécies), pela análise da curva calorimétrica (Figura 22). O número de sítios ativos indica que o processo de interação segue uma estequiometria de 1:1.

Estudos sobre interação de íons metálicos em proteínas mostram que geralmente os íons metálicos interagem em regiões de alta hidrofobicidade. Dentro dessas regiões os íons metálicos interagem com pares de elétrons (base de Lewis) de elementos como exemplo oxigênio, nitrogênio e enxofre contido no ambiente hidrofóbico (MANSON et al., 1990). 


\section{IV.5 - Espalhamento dinâmico de Luz (DLS)}

Os resultados obtidos com as amostras de $\mathrm{Zn}-\mathrm{MbFe}^{\mathrm{III}} \mathrm{H}_{2} \mathrm{O}$ em solução através de espectroscopia de espalhamento de luz dinâmico (DLS) estão sistematizados na Figura 24, na forma de raios hidrodinâmicos $(\mathrm{Rh})$ aparentes. Os raios são considerados aparentes, pois os resultados não foram extrapolados para concentração tendendo a zero (diluição infinita). Os valores de $\mathrm{Rh}$ foram calculados como a metade dos valores obtidos para o diâmetro das partículas em solução.

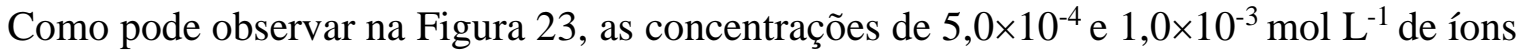
$\mathrm{Zn}^{\mathrm{II}}$ na solução de $\mathrm{Mb}$ apresentaram pequenas variações do raio hidrodinâmico, o que indica a formação da estrutura intermediária do processo de agregação conhecida como molten globule. As concentrações de $5,0 \times 10^{-3} \mathrm{~mol} \mathrm{~L}^{-1}$ e $1,0 \times 10^{-2} \mathrm{~mol} \mathrm{~L}^{-1}$ resultam na expansão do volume molecular da proteína de 2,2 $\mathrm{nm}$ a 3,8 e 4,9 $\mathrm{nm}$ respectivamente. A formação de estruturas agregadas normalmente ocorre através de um processo inicial de nucleação seguido de um processo de crescimento. Na fase de nucleação, um núcleo ordenado de agregados constituídos por unidades monoméricas é formado durante uma lag phase, depois de se atingir uma concentração crítica das espécies monoméricas. Depois da nucleação, ocorre um crescimento rápido até a formação de fibras amilóides por associação de monômeros ou oligômeros com o intermediário de nucleação amiloidogênico (ROCHET; LANSBURY JR, 2000; CHI et al., 2003; CHITI; DOBSON, 2006).

Figura 23. Valores de raio hidrodinâmico aparente de amostras de $\mathrm{Zn}^{\mathrm{II}}$ e $\mathrm{MbFe}^{\mathrm{III}} \mathrm{H}_{2} \mathrm{O}\left(5,0 \times 10^{-4}\right.$ mol L $\left.\mathrm{L}^{-1}\right)$ em função do tempo em solução tampão acetato $\left(0,16 \mathrm{~mol} \mathrm{~L}^{-1}\right)$ com pH 5,7 a $298 \mathrm{~K}$.

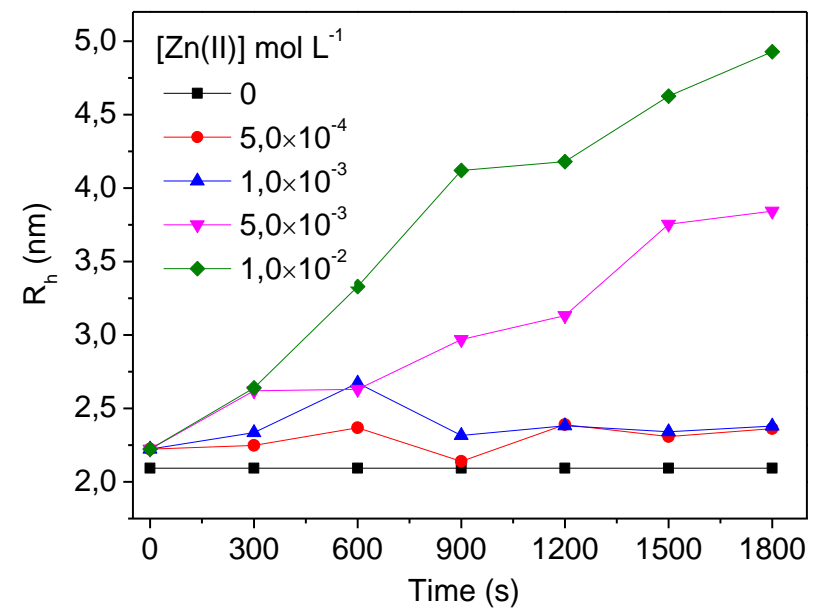

Fonte: Autoria própria 


\section{IV.6 - Microscopia eletrônica de transmissão (MET)}

Considerando os resultados obtidos através da técnica de emissão de fluorescência e de dicroismo circular, foi utilizado a microscopia eletrônica de transmissão de elétrons com o propósito de investigar os aspectos estruturais e morfológicos da proteína. As imagens em MET da metamioglobina $\left(\mathrm{MbFe}^{\mathrm{III}} \mathrm{H}_{2} \mathrm{O}\right)$ estão apresentadas na Figura 24 em diferentes escalas de resolução.

Figura 24. Imagens de MET da metamioglobina após o período de incubação de 24 horas. As escalas de aumento estão indicadas nas figuras. $\left[\mathrm{MbFe}^{\mathrm{III}} \mathrm{H}_{2} \mathrm{O}\right]=5,0 \times 10^{-4} \mathrm{~mol} \mathrm{~L}^{-1}$.
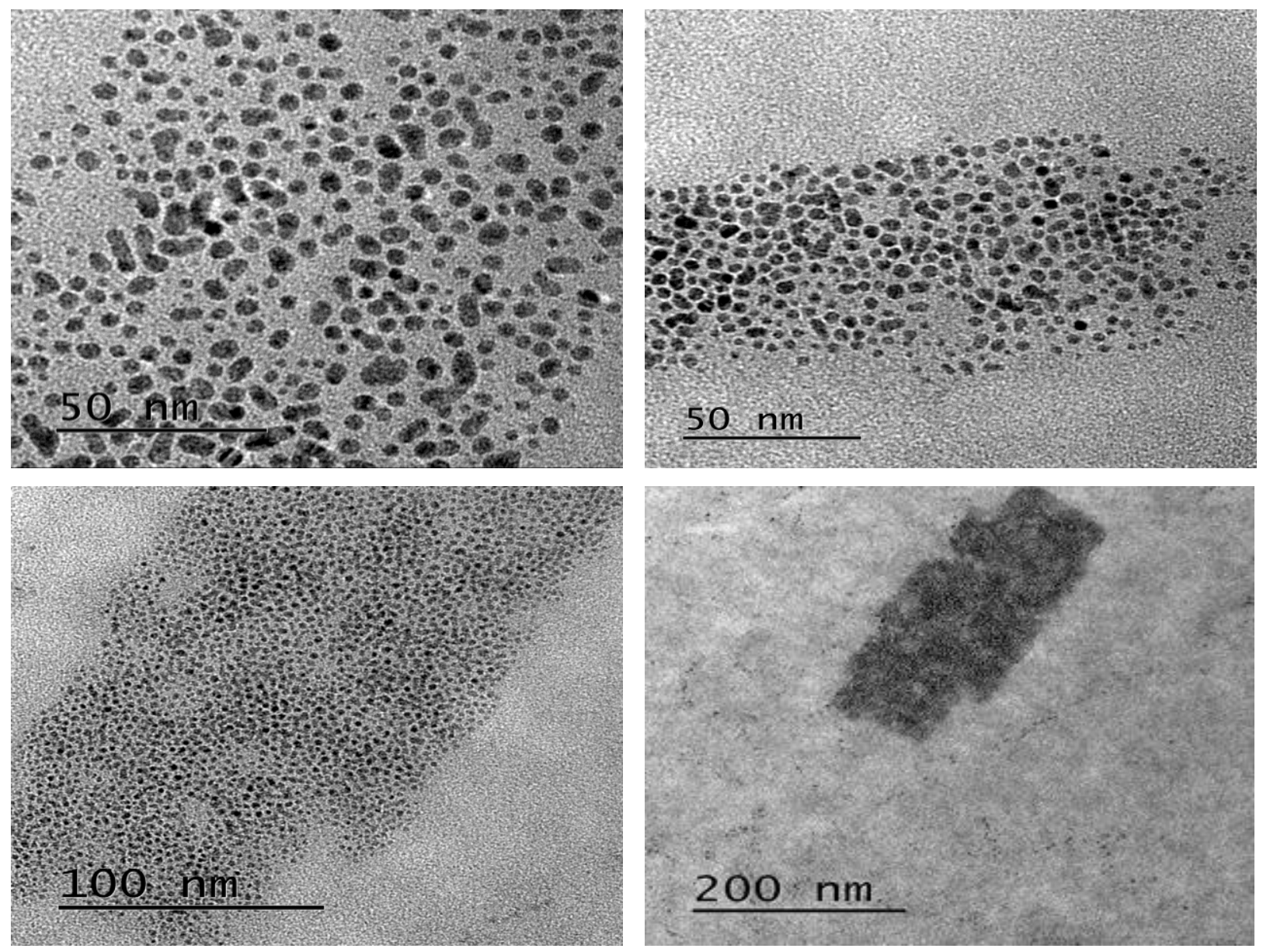

Fonte: Autoria própria

Como pode ser observado na micrografia da Figura 24, a morfologia da metamioglobina apresenta relativa uniformidade de forma e tamanho. A Figura 25 contém imagens em MET para o sistema $\mathrm{Zn}{ }^{\mathrm{II}}-\mathrm{Mb}$ em diferentes escalas de resolução. 
Figura 25. Imagens de MET para o sistema Zn-Mb após o período de incubação de 24 horas. As escalas de aumento estão indicadas nas figuras. $\left[\mathrm{MbFe}^{\mathrm{III}} \mathrm{H}_{2} \mathrm{O}\right]=5,0 \times 10^{-4} \mathrm{~mol} \mathrm{~L}^{-1} \mathrm{e}\left[\mathrm{Zn}^{\mathrm{II}}\right]=1,0 \times 10^{-}$ ${ }^{2} \mathrm{~mol} \mathrm{~L}^{-1}$.
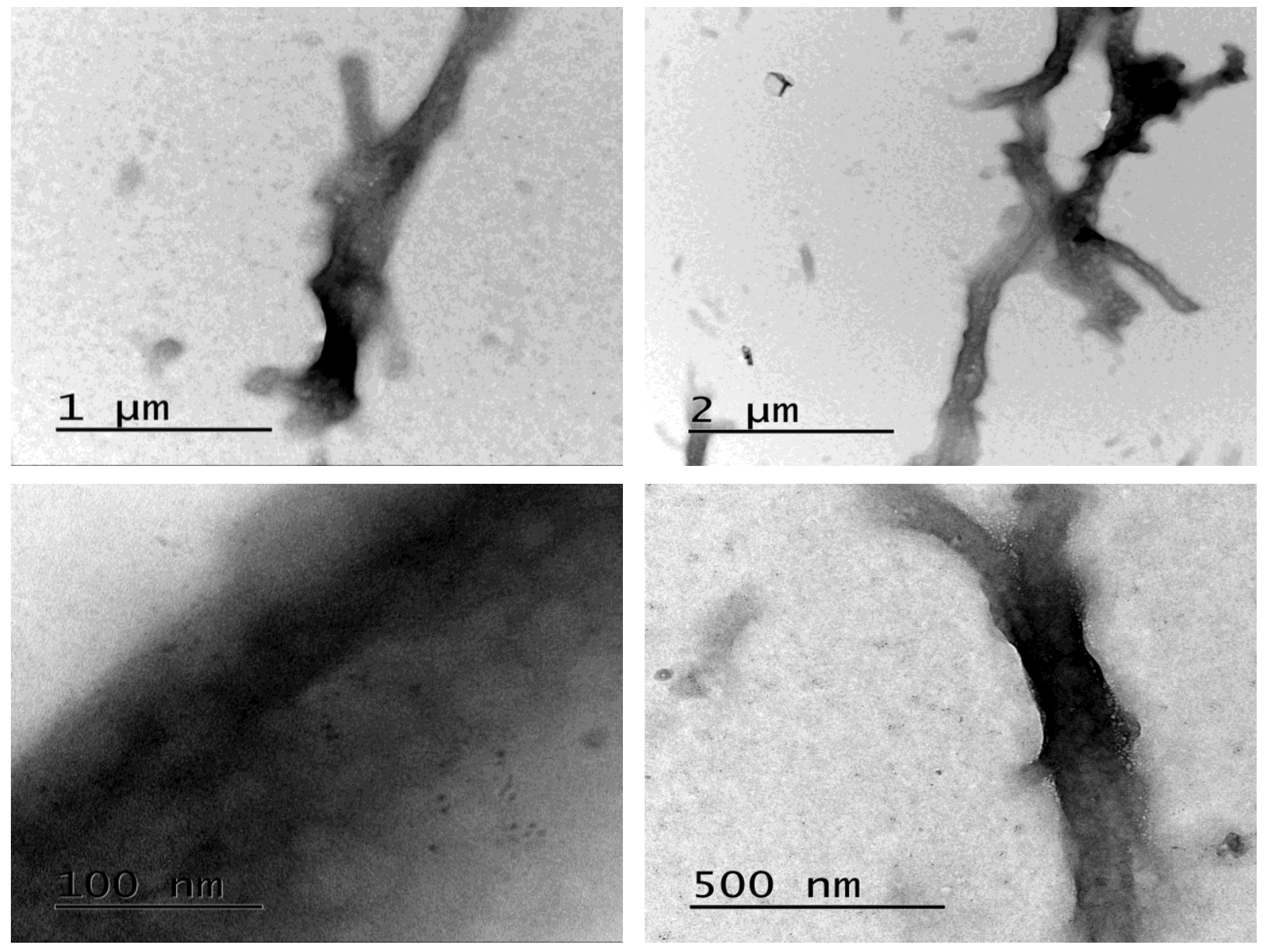

Fonte: Autoria própria

A estrutura molten globule é um dos intermediários do processo de agregação das proteínas. Estes intermediários são compactos, com elevada estrutura secundária nativa, mas com pouca ou nenhuma estrutura terciária, contendo zonas hidrofóbicas expostas (YON, 1997). Foi demonstrado que este tipo de intermediários pode potenciar a agregação proteica (UVERSKY; LI; FINK, 2001; SKORA; BECKER; ZWECKSTETTER, 2010).

As imagens apresentadas na Figura 25 indicam que os íons de $\mathrm{Zn}^{\mathrm{II}}$ induziram a formação de agregados de proteínas na forma de fibrilas, o que condiz com os dados do aumento do raio hidrodinâmico observado por DLS e do valor negativo da variação de entropia. 


\section{IV.7 - Estudo da reação de auto-oxidação da espécie Oxymioglobina ( $\left.\mathrm{MbFe}^{\mathrm{II}} \mathrm{O}_{2}\right)$}

Os estudos cinéticos envolvendo auto-oxidação de hemeproteínas têm sido considerados relevantes ferramentas para avaliar a estabilidade da ligação ferro-oxigênio. A reação de autooxidação da oxiMb foi acompanhado pela técnica de espectroscopica de absorção eletrônica (Figura 26A). Monitorando a mudança espectral em $544 \mathrm{~nm}$ em função do tempo foi possível acompanhar o decaimento de primeira ordem da oxiMb (Figura 26B).

Figura 26. (A) Evolução espectral da oximioglobina ([ $\left.\left.\mathrm{MbFe}^{\mathrm{II}} \mathrm{O}_{2}\right]=3,62 \times 10^{-5} \mathrm{~mol} \mathrm{~L}^{-1}\right)$ em intervalos de 30 minutos. (B). Gráfico da cinética de primeira ordem da auto-oxidação (absorção em $544 \mathrm{~nm})$. Solução em tampão acetato $\left(0,16 \mathrm{~mol} \mathrm{~L}^{-1}\right), \mathrm{pH}=5.8$ e T = $298 \mathrm{~K}$.
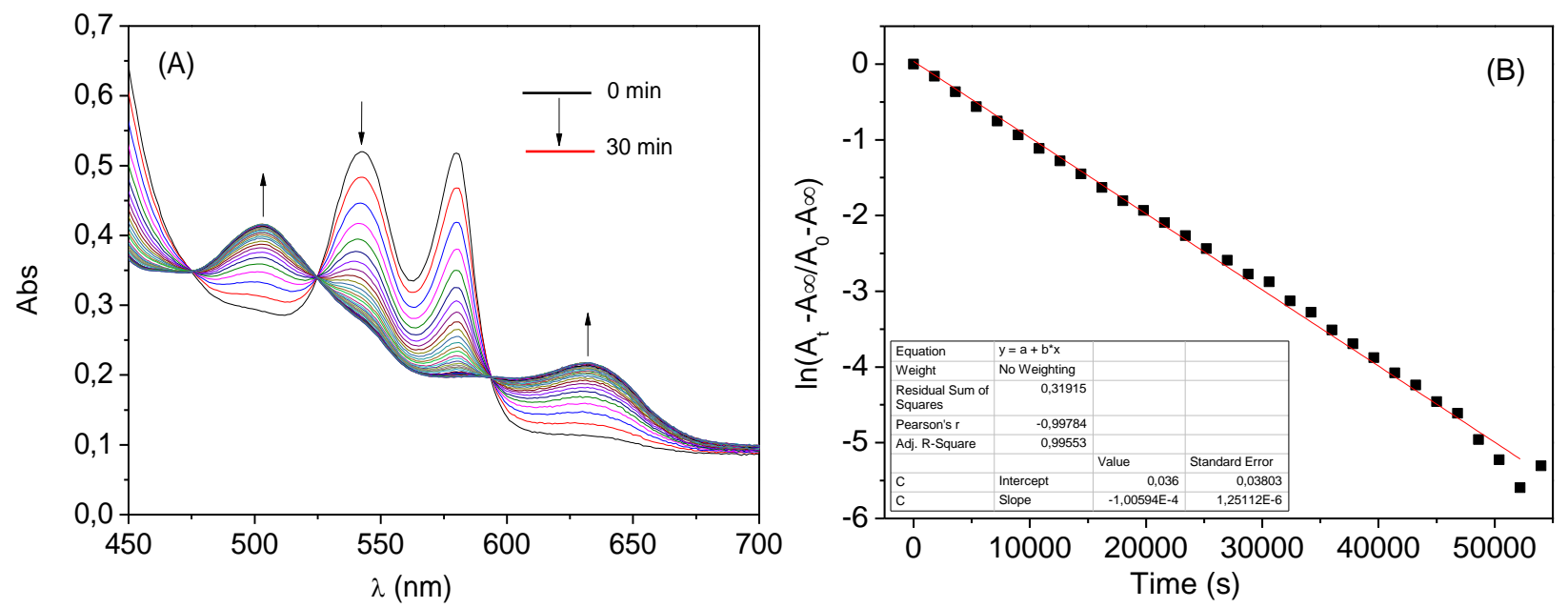

Fonte: Autoria própria

$\mathrm{O}$ comportamento cinético da auto-oxidação da Mioglobina $\left[\mathrm{MbFe}^{\mathrm{II}} \mathrm{O}_{2}\right]$ dependente da concentração da espécie $\mathrm{MbFeO}_{2}$ e da espécie $\mathrm{Zn}-\mathrm{MbFeO}_{2}$ leva a formação da espécie metamioglobina $\left(\mathrm{MbFe}^{\mathrm{III}}\right)$ através de duas vias como mostrado o Esquema 2.

Esquema 2. Esquema reacional da auto-oxidação da oxiMb na presença de íons ZnII.

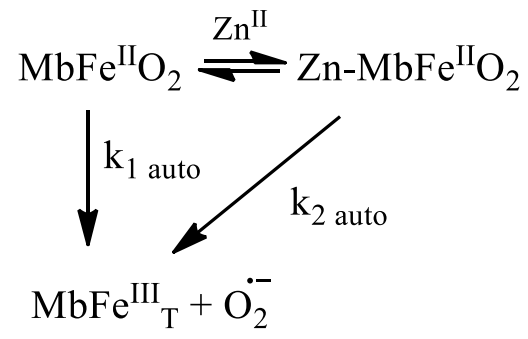


Por meio deste, a lei de velocidade é representada pela Equação 6.

$$
\frac{-\mathrm{d}\left[\mathrm{MbFe}^{\mathrm{II}} \mathrm{O}_{2}\right]_{\mathrm{T}}}{\mathrm{dt}}=\left(\frac{-\mathrm{d}\left[\mathrm{MbFe}^{\mathrm{II}} \mathrm{O}_{2}\right]}{\mathrm{dt}}\right)+\left(\frac{\mathrm{d}\left[\mathrm{Zn}-\mathrm{MbFe}^{\mathrm{II}} \mathrm{O}_{2}\right]}{\mathrm{dt}}\right)
$$

Equação 6

Onde experimentalmente foi determinada através da constante observada e a contribuição de cada espécie $(\alpha)$ - Equação 7:

$$
\frac{-\mathrm{d}\left[\mathrm{MbFe}^{\mathrm{II}} \mathrm{O}_{2}\right]}{\mathrm{dt}}=\mathrm{k}_{\mathrm{obs} 0} \alpha_{0}+\mathrm{k}_{\mathrm{obs} 1} \alpha_{1}
$$

A fração da concentração de cada espécie $(\mathrm{Mb}$ e $\mathrm{ZnMb})$ foi determinada a partir do seguinte equilíbrio:

$$
\mathrm{Mb}+\mathrm{Zn} \stackrel{\mathrm{K}}{\rightleftharpoons} \mathrm{MbZn}
$$

$[\mathrm{ZnMb}]=\mathrm{K}[\mathrm{Mb}][\mathrm{Zn}]$

$\mathrm{C}_{\mathrm{Mb}}=[\mathrm{ZnMb}]+[\mathrm{Mb}]$

$\mathrm{C}_{\mathrm{Zn}}=[\mathrm{ZnMb}]+[\mathrm{Zn}]$

$\alpha_{0}=\frac{[\mathrm{Mb}]}{\mathrm{C}_{\mathrm{Mb}}}=\frac{1}{1+\mathrm{K}[\mathrm{Zn}]}$

$\alpha_{1}=\frac{[\mathrm{MbZn}]}{\mathrm{C}_{\mathrm{Mb}}}=\frac{[\mathrm{MbZn}]}{[\mathrm{Mb}]+[\mathrm{MbZn}]} \Longrightarrow \frac{[\mathrm{MbZn}]}{[\mathrm{Mb}]+\mathrm{K}[\mathrm{Mb}][\mathrm{Zn}]}=\frac{[\mathrm{MbZn}]}{[\mathrm{Mb}](1+\mathrm{K}[\mathrm{Zn}])}$

$\alpha_{1}=\frac{1}{(1+\mathrm{K}[\mathrm{Zn}])}\left(\frac{[\mathrm{MbZn}]}{[\mathrm{Mb}]}\right) \Longrightarrow\left(\frac{1}{1+\mathrm{K}[\mathrm{Zn}]}\right)(\mathrm{K}[\mathrm{Zn}])$ 


$$
\alpha_{0}=\frac{1}{1+\mathrm{K}[\mathrm{Zn}]} \quad \alpha_{1}=\left(\frac{1}{1+\mathrm{K}[\mathrm{Zn}]}\right)(\mathrm{K}[\mathrm{Zn}])
$$

Substituindo os coeficientes $\alpha_{0}$ e $\alpha_{1}$ na Equação 7 :

$$
\frac{-\mathrm{d}[\mathrm{Mb}]}{\mathrm{dt}}=\mathrm{k}_{\mathrm{obs} 0}\left(\frac{1}{1+\mathrm{K}[\mathrm{Zn}]}\right)+\mathrm{k}_{\mathrm{obs} 1}\left[\left(\frac{1}{1+\mathrm{K}[\mathrm{Zn}]}\right)(\mathrm{K}[\mathrm{Zn}])\right]
$$

Equação 8

A Figura 27 contém as constantes de velocidade de primeira ordem em função da concentração crescente de íons de $\mathrm{Zn}^{\mathrm{II}}$ com o ajuste não linear da Equação 8. Os espectros de absorção eletrônica e os gráficos da cinética de primeira ordem da auto-oxidação da espécie Zn$\mathrm{MbFe}^{\mathrm{II}} \mathrm{O}_{2}$ em diferentes concentrações de $\mathrm{Zn}^{\mathrm{II}}$ estão contidos no Apêndice A.

Figura 27. Constantes de velocidade da reação auto-oxidação da oximioglobina em função da concentração de íons de $\mathrm{Zn}^{\mathrm{II}}$. [ $\left[\mathrm{MbFe}^{\mathrm{II}} \mathrm{O}_{2}\right]=3,62 \times 10^{-5} \mathrm{~mol} \mathrm{~L}^{-1} \mathrm{em}$ solução tampão acetato $(0,16 \mathrm{~mol}$ $\left.\mathrm{L}^{-1}\right), \mathrm{pH}=5,8$ e $\mathrm{T}=298 \mathrm{~K}$.

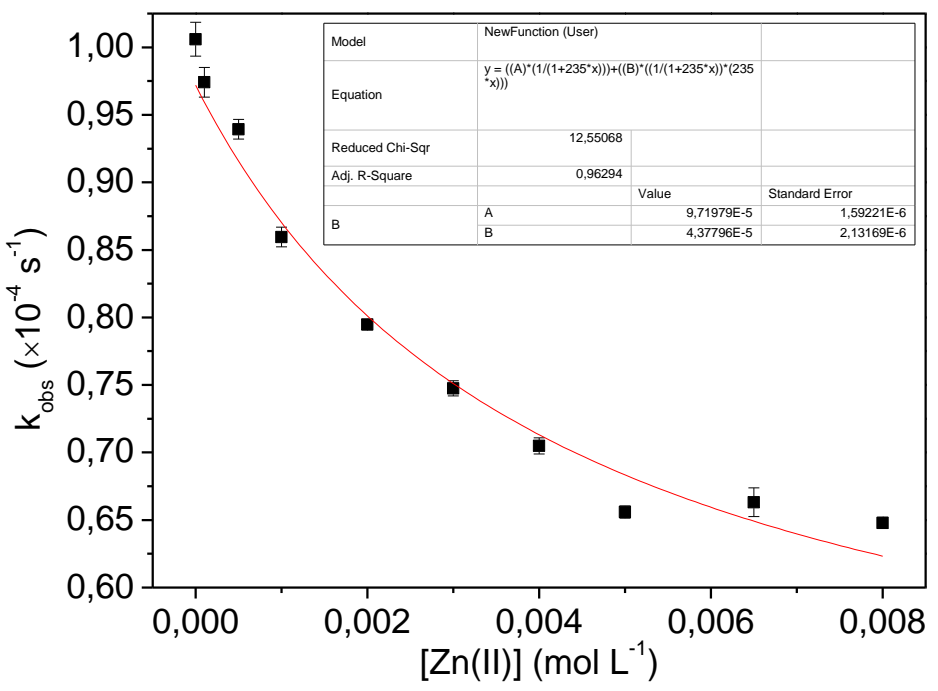

Fonte: Autoria própria.

A Figura 27 mostra que a constante de primeira ordem da auto-oxidação da oxiMb diminui concomitantemente com o aumento da concentração de íons de $\mathrm{Zn}^{\mathrm{II}}$. Através do ajuste não linear 
da equação 8 foi possível determinar as constantes $\mathrm{k}_{\mathrm{obs} 0}=(1,04 \pm 0,01) \times 10^{-4} \mathrm{~s}^{-1}$ e $\mathrm{k}_{\mathrm{obs} 1}=(4,32 \pm$ $0,02) \times 10^{-5} \mathrm{~s}^{-1}$.A constante de ligação $(\mathrm{K})$ determinada para este processo foi de $\mathrm{K}=(2,35 \pm$ $0,01) \times 10^{2}$. Este comportamento pode ser interpretado pela formação da estrutura molten globule como visto nos dados de DLS e MET e a formação do ânion superóxido pode ser estabilizado pelos íons de $\mathrm{Zn}^{\mathrm{II}}$, dificultando a saída do ânion superóxido e, consequentemente, a diminuição da velocidade de auto-oxidação.

\section{IV.8 - Estudo de transientes das espécies $\mathrm{MbFe}^{\mathrm{II}} \mathrm{L}$}

$\mathrm{O}$ estudo de transientes das espécies $\mathrm{MbFe}{ }^{\mathrm{II}} \mathrm{L}$ (onde $\mathrm{L}=\mathrm{O}_{2}$ ou $\mathrm{CO}$ ) permite avaliar a estrutura terciária do bolsão hidrofóbico da proteína através da recombinação do ligante com o ferro-heme. Utilizando-se a técnica de Fotólise de Laser Pulsado (LFP) no acompanhamento da dinâmica de absorção da deoximioglobina com os ligantes $\mathrm{O}_{2}$ e CO. As Figuras 28A e 28B mostram os espectros de transientes da oximioglobina $\left(\mathrm{MbFe}^{\mathrm{II}} \mathrm{O}_{2}\right)$ e carboximioglobina $\left(\mathrm{MbFe}{ }^{\mathrm{II}} \mathrm{CO}\right)$. As medidas foram realizadas em solução tampão acetato $(0,16 \mathrm{M}, \mathrm{pH} 5,7)$ registrado a diferentes tempos após o pulso de laser de $532 \mathrm{~nm}$ (energia de $10 \mathrm{~mJ} . \mathrm{cm}^{2}$ e duração de $8 \mathrm{~ns}$ ). Os espectros de diferença de absorção de transiente foram estudados na região da banda Soret (370-500 nm), onde as espécies oximioglobina e carboximioglobina possuem o $\lambda$ máximo de absorção dez vezes mais intenso.

Figura 28. Espectro de diferença de absorção do transiente no tempo da oximioglobina (A) e carboximioglobina (B) em solução tampão acetato pH 5,7 (Força iônica ajustada $0,16 \mathrm{~mol} \mathrm{~L}^{-1}$ ) a 298 K. O pulso de laser em $532 \mathrm{~nm}(8 \mathrm{~ns})$ e intensidade de $10 \mathrm{~mJ} . \mathrm{cm}^{2}$, solução contendo $3,1 \times 10^{-6}$ mol L ${ }^{-1}$ de $\mathrm{Mb}$.
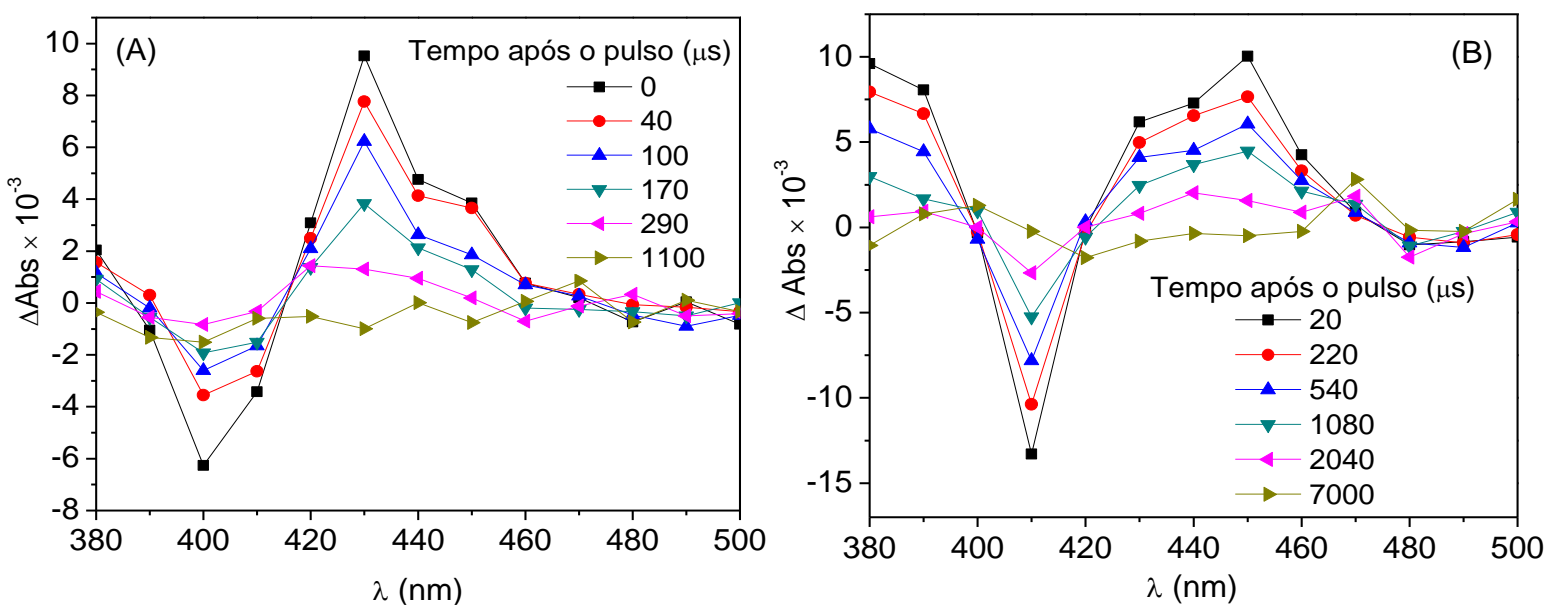
Nos espectros da Figura 28, pode-se observar duas regiões de absorção, uma negativa na região de $390 \mathrm{~nm}-410 \mathrm{~nm}$ correspondente a transição $\mathrm{S}_{0} \rightarrow \mathrm{S}_{1}$ da espécie mioglobina ligante $\left(\mathrm{MbFe}^{\mathrm{II}} \mathrm{L}\right)$, no estado fundamental e uma positiva na região de $420 \mathrm{~nm}-460 \mathrm{~nm}$ corresponde a transição $\mathrm{S}_{0} \rightarrow \mathrm{S}_{1}$ da espécie desoximioglobina $\left(\mathrm{MbFe}^{\mathrm{II}}\right)$, no estado fundamental.

Ainda na Figura 28, os espectros adquiridos em diferentes tempos após pulso de laser indicam a presença de um ponto isosbéstico, que de fato confirma uma dependência entre o consumo da espécie $M b F e^{\mathrm{II}} \mathrm{L}$ e a formação da espécie $\mathrm{MbFe}{ }^{\mathrm{II}}$. O tempo de conversão da $\mathrm{MbFe}^{\mathrm{II}} \mathrm{L}$ em espécie $\mathrm{MbFe}^{\mathrm{II}}$ não pode ser detectada na escala temporal em que foi realizada a medida de LFP. Entretanto, pode-se dizer que a conversão ocorre em tempos inferiores à 100 ns.

Após a observação da formação da deoximioglobina $\left(\mathrm{MbFe}^{\mathrm{II}}\right)$, pode-se observar que esta espécie obedece a um decaimento mono-exponencial, em que a deoximioglobina é então novamente recombinada com o ligante $\left(\mathrm{O}_{2}\right.$ e CO). De fato, a Figura 29 mostra uma identidade entre a curva de decaimento da deoximioglobina $\left(\mathrm{MbFe}^{\mathrm{II}}\right.$ ) (curva cinética em preto) e a curva cinética de fotobleaching da espécie $\mathrm{MbFe}^{\mathrm{II}} \mathrm{L}$ (curva em vermelho, onde $\mathrm{L}=\mathrm{O}_{2}(\mathrm{~A})$ e $\mathrm{CO}(\mathrm{B})$ ).

Figura 29. (A) Curva cinética de transiente da oximioglobina (curva em vermelho) e deoximioglobina (curve em preto). (B) Curva cinética de transiente da carboximioglobina (curva em vermelho) e deoximioglobina (curva em preto). Solução tampão acetato pH 5,7 (Força iônica ajustada $0,16 \mathrm{~mol} \mathrm{~L}^{-1}$ ) a $298 \mathrm{~K}$. $\left[\mathrm{MbFe}^{\mathrm{II}} \mathrm{L}\right]=3,1 \times 10^{-6} \mathrm{~mol} \mathrm{~L}^{-1}$. (pulso de laser em $532 \mathrm{~nm}$ com energia de $10 \mathrm{~mJ} \mathrm{~cm}^{-2}$ ).
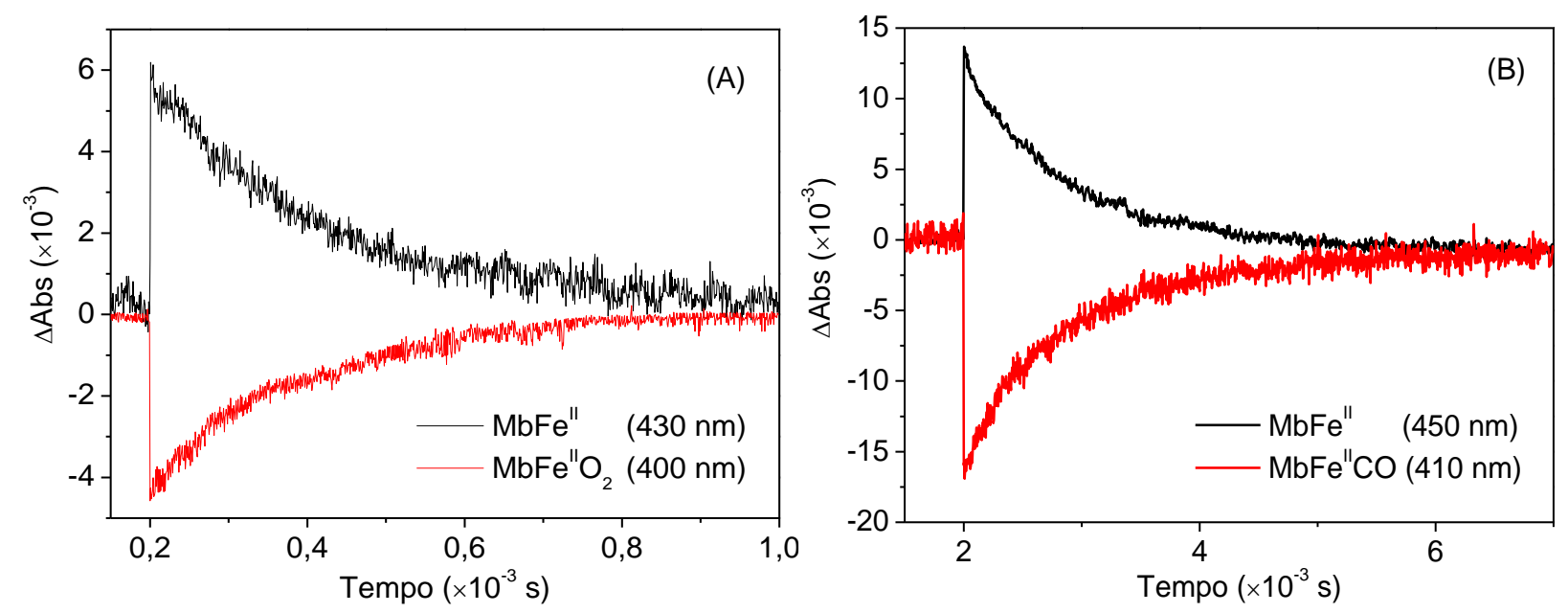

Fonte: Autoria própria 
Ainda na Figura 29A, pode-se observar que para a espécie oximioglobina $\left(\mathrm{MbFe}^{\mathrm{II}} \mathrm{O}_{2}\right)$, as duas curvas cinéticas (em $400 \mathrm{~nm}$ e $430 \mathrm{~nm}$ ) não voltam ao valor de absorção inicial ( $\Delta \mathrm{A}=$ zero). Esta diferença de absorção observada indica uma perda de amostra menor que $2 \%$. Sabendo que a espécie $\mathrm{MbFe}^{\mathrm{III}} \mathrm{H}_{2} \mathrm{O}$ também é formada no consumo reacional da oximioglobina (Esquema 1), a possibilidade de uma segunda cinética paralela de conversão da deoximioglobina em metamioglobina não será por hora descartada.

\section{IV.8.1 - Fotólise da deoximioglobina na presença de íons de $\mathrm{Zn}^{\mathrm{II}}$}

Nesta etapa da investigação, a afinidade química da deoximioglobina pelos ligantes $\mathrm{O}_{2}$ e $\mathrm{CO}$ foi investigada na presença de $\mathrm{Zn}{ }^{\mathrm{II}}$. Para a conversão química da espécie $\mathrm{MbFe}{ }^{\mathrm{II}}$ em $\mathrm{MbFe}^{\mathrm{II}} \mathrm{L}$, as constantes de velocidade foram calculadas a partir do ajuste de decaimento monoexponencial (Figura 31 A-C) utilizando-se a Equação 9.

$$
\operatorname{Abs}(\mathrm{t})=\mathrm{A}_{\mathrm{o}} \times \exp \left(-\mathrm{k}_{\mathrm{obs}} \mathrm{t}\right)+\Delta_{\infty}
$$

Para valores constantes de $\mathrm{pH}$ e temperatura foi observada uma dependência linear com a concentração total de íons de $\mathrm{Zn}^{\mathrm{II}}$ (Figura 30B-D). Na Figura 30A-C, pode-se observar que as curvas cinéticas da deoximioglobina tende a zero na presença de concentrações crescentes de íons $\mathrm{Zn}^{\mathrm{II}}$, sugerindo desta forma que a oximioglobina e a carboximioglobina é regenerada no final do processo cinético de desativação da deoximioglobina. As curvas de decaimentos apresentam uma concomitante diminuição do máximo de absorção $\Delta$ abs na presença de íons $\mathrm{Zn}$. . Isto pode ser atribuído a formação da conformação de molten globule diminuindo a formação da quantidade da espécie transiente deoximioglobina $\left(\mathrm{MbFe}^{\mathrm{II}}\right)$.

A relação entre $\mathrm{k}_{\text {obs }}$ e a concentração total de $\mathrm{Zn}{ }^{\mathrm{II}}$ permitiu a determinação da constante de velocidade de segunda ordem $\left(\mathrm{k}_{2}\right)$ que foi obtida pelo ajuste linear da equação da reta através dos pontos experimentais da Figura 30B-D, sendo $\mathrm{k}_{2}=0.138 \pm 0.017 \mathrm{~L} \mathrm{~mol}^{-1} \mathrm{~s}^{-1}$ para a espécie oximioglobina $\left(\mathrm{MbFe}^{\mathrm{II}} \mathrm{O}_{2}\right)$ e $\mathrm{k}_{2}=0.031 \pm 0.004 \mathrm{~L} \mathrm{~mol}^{-1} \mathrm{~s}^{-1}$ para a espécie carboximioglobina (MbFe $\left.{ }^{\mathrm{II}} \mathrm{CO}\right)$. 
Figura 30. Efeito da presença de concentrações crescentes de íons de $\mathrm{Zn}^{\mathrm{II}}$ na cinética de recombinação da $\mathrm{MbFe}^{\mathrm{II}}$ com os ligantes $\mathrm{O}_{2}$. (A) e com $\mathrm{CO}(\mathrm{C})$. Gráfico de $\mathrm{k}_{\text {obs }}$ vs concentração de $\mathrm{Zn}^{\mathrm{II}}$ para os ligantes $\mathrm{O}_{2}(\mathrm{~B})$ e $\mathrm{CO}(\mathrm{D})$. [MbFeIIL] $=3,1 \times 10^{-6} \mathrm{~mol} \mathrm{~L}{ }^{-1}$, Solução tampão $\mathrm{pH}=5,7$ (Força iônica $\left.0,16 \mathrm{~mol} \mathrm{~L}^{-1}\right)$ à $298 \mathrm{~K}$. Pulso de laser em $532 \mathrm{~nm}\left(10 \mathrm{~mJ} \mathrm{~cm}^{-2}\right.$ e duração de $\left.8 \mathrm{~ns}\right)$.
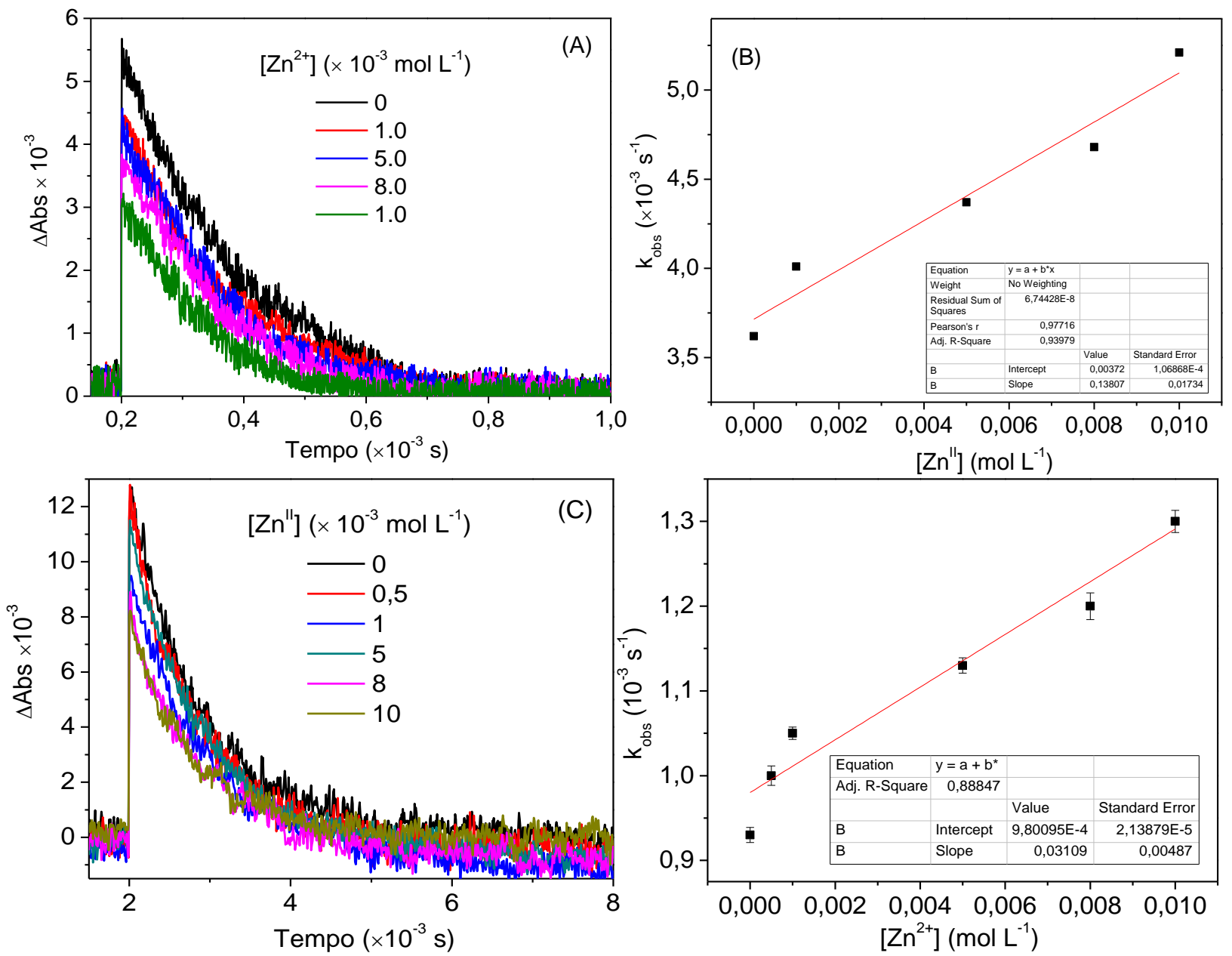

Fonte: Autoria própria

As constantes de velocidade associativas $\mathrm{k}_{\text {ass }}$, dissociativas $\mathrm{k}_{\text {diss }}$ (Equação 10) e a razão entre esses coeficientes $\mathrm{K}=\mathrm{k}_{\text {ass }} / \mathrm{k}_{\text {diss }}$ calculados para os ligantes $\mathrm{L}=\mathrm{O}_{2}$ e $\mathrm{CO}$, estão mostrados na Tabela 5.

$$
\mathrm{Zn}-\mathrm{MbFe} \mathrm{II}^{\mathrm{II}} \underset{\mathrm{k}_{\text {ass }}^{\prime}}{\stackrel{\mathrm{k}_{\text {diss }}^{\prime}}{\leftrightarrows}} \mathrm{Zn}-\mathrm{MbFe}^{\mathrm{II}}+\mathrm{L}
$$


Tabela 5. Valores das constantes de associação, dissociação e equilíbrio para a reação de recombinação da $\mathrm{Mb}$ com os ligantes $\mathrm{O}_{2}$ e CO. Solução tampão acetato, pH 5,8 a $298 \mathrm{~K}$. [MbFe ${ }^{\mathrm{II}}$ ] $=3,6 \times 10^{-6} \mathrm{~mol} \mathrm{~L}^{-1} ;\left[\mathrm{Zn}^{\mathrm{II}}\right]=0,008 \mathrm{~mol} \mathrm{~L}^{-1}$.

\begin{tabular}{cccc}
\hline Espécie & $\mathbf{k}_{\text {ass }}\left(\mathbf{L}\right.$ mol $\left.^{-\mathbf{1}} \mathbf{s}^{\mathbf{- 1}}\right)$ & $\mathbf{k}_{\text {diss }}\left(\mathbf{s}^{\mathbf{- 1}}\right)$ & $\mathbf{K}\left(\mathbf{L} \mathbf{~ m o l}^{\mathbf{- 1}}\right)$ \\
\hline $\mathrm{MbFe}^{\mathrm{II}} \mathrm{O}_{2}$ & $3629,04 \pm 17,60$ & $3210,5 \pm 38,30$ & 1,13 \\
\hline $\mathrm{MbFe}{ }^{\mathrm{II}} \mathrm{CO}$ & $756,71 \pm 8,50$ & $716,21 \pm 7,60$ & 1,05 \\
\hline $\mathrm{Zn}-\mathrm{MbFe}^{\mathrm{II}} \mathrm{O}_{2}$ & $4847,18 \pm 18,50$ & $3850,8 \pm 44,90$ & 1,26 \\
\hline $\mathrm{Zn}-\mathrm{MbFe}{ }^{\mathrm{II}} \mathrm{CO}$ & $805,4 \pm 10,20$ & $739,6 \pm 1,30$ & 1,09 \\
\hline
\end{tabular}

Fonte: Autoria própria

Ao comparar os dados da Tabela 5, de maneira geral, verifica-se que na presença de íons de $\mathrm{Zn}^{\mathrm{II}}$ obteve-se um aumento no valor das constantes de velocidade e na constante de equilíbrio para ambas as espécies de $\mathrm{Mb}$. As espécies de $\mathrm{Mb}$ com o ligante $\mathrm{O}_{2}$ é estabilizado pela histidina distal (como visto na Figura 6) por conta disso, os valores maiores das constantes das espécies com o ligante $\mathrm{CO}$.

Como já visto anteriormente, a interação de íons de $\mathrm{Zn}^{\mathrm{II}}$ causa uma mudança na estrutura conformacional da proteína. Na literatura é conhecido que a histidina distal pode atuar como um "portão" ("gate") ou uma "porta giratória" ("swinging door") (SHIKAMA, MATSUOKA, 2003). Nesta linha de investigação, a interação histidina (ferro-profirina) proporciona ao bolsão hidrofóbico contendo o grupo heme um controle seletivo em relação à entrada de ligantes na cavidade.

\section{IV.9 - Estudo da redução da espécie ferrilmioglobina $\left(\mathrm{MbFe}^{\mathrm{IV}}=\mathrm{O}\right)$}

\section{IV.9.1- Estudo da auto-redução da espécie ferrilmioglobina na presença de íons $\mathrm{Zn}^{\mathrm{II}}$}

A velocidade de auto-redução da espécie ferrilmioglobina $\left(\mathrm{MbFe}^{\mathrm{IV}}=\mathrm{O}\right)$ é um processo dependente da concentração hidrogêniônica do meio (LIBARDI et al., 2014). No entanto, para esta reação foi investigada o efeito de íons $\mathrm{Zn}^{\mathrm{II}}$ em solução tampão acetato $\mathrm{pH}=5,7$.

O comportamento da auto-redução da espécie ferrilmioglobina foi monitorado por espectroscopia de absorção eletrônica $(580 \mathrm{~nm})$ em função do tempo na ausência e na presença de 
diferentes concentrações de íons $\mathrm{Zn}^{\mathrm{II}}$ e estão contidos no Apêndice B. A Figura 31 ilustra a variação da absorção da reação de auto-redução da espécie ferrilmioglobina em função do tempo.

Figura 31. Variação de absorção do processo de auto-redução da espécie ferrilmioglobina $\left(5,0 \times 10^{-}\right.$ ${ }^{5} \mathrm{~mol} \mathrm{~L}^{-1}$ ) em função do tempo na presença de diferentes concentrações de íons $\mathrm{Zn}{ }^{\mathrm{II}}$. Tampão acetato pH 5,7 a $298 \mathrm{~K}$.

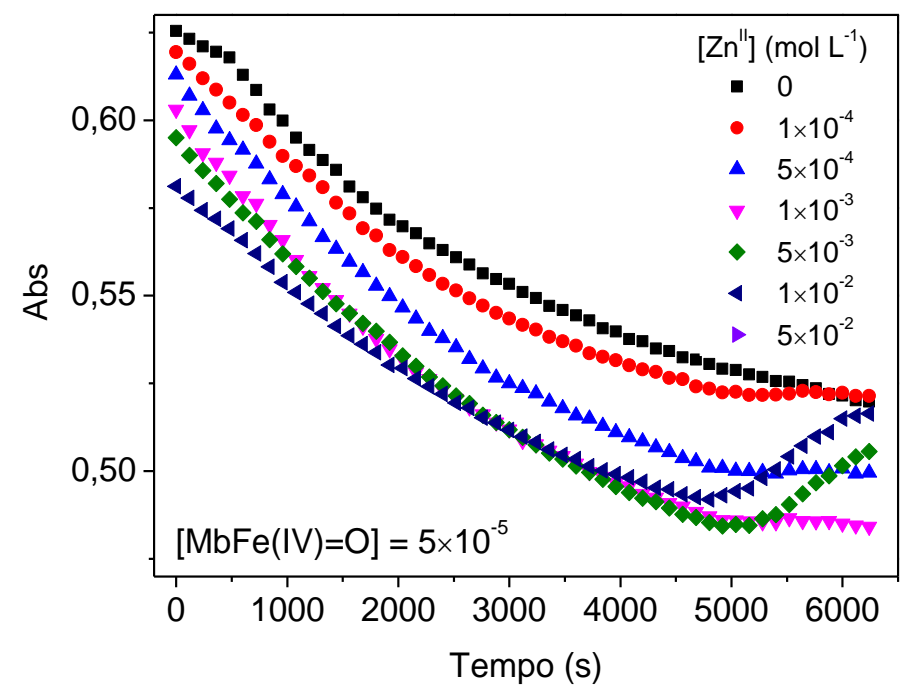

Fonte: Autoria própria

O gráfico da Figura 31 mostra o decaimento da espécie ferrilmioglobina centrada em 580 $\mathrm{nm}$ ao longo do tempo, com a adição de diferentes concentrações de íons de $\mathrm{Zn}$. Observa-se um perfil similar entre os decaimentos da espécie ferrilmioglobina indicando que não há alteração da estrutura ferro-porfirina no processo de auto-redução. Pode ser observado uma diminuição da absorção com o aumento da concentração de íons $\mathrm{Zn}^{\mathrm{II}}$ na solução devido ao processo de molten globule da proteína, como já observado.

\section{IV.9.2 - Análise da estrutura secundária da ferrilmioglobina por Dicroísmo Circular UV-vis}

A técnica de dicroísmo circular na região do UV-vis foi utilizada neste estudo com a intenção de avaliar as mudanças na estrutura da proteína, neste caso, da espécie ferrilmioglobina. Os espectros obtidos estão ilustrados na Figura $32 \mathrm{em}$ diferentes temperaturas e a predição da estrutura secundária foi realizada a partir do programa CDNN Deconvolution. Os valores percentuais determinados para cada estrutura secundária são relatados na Tabela 6 . 
Figura 32. Espectros de $\mathrm{CD}$ da ferrilmioglobina $\left(1,2 \times 10^{-5} \mathrm{~mol} \mathrm{~L}^{-1}\right)$ na presença de íons $\mathrm{Zn}^{\mathrm{II}}$, em tampão acetato $\left(1,0 \times 10^{-2} \mathrm{~mol} \mathrm{~L}^{-1}\right), \mathrm{pH} 5,8$ e força iônica de $0,16 \mathrm{~mol} \mathrm{~L}^{-1}$ ajustado com $\mathrm{NaCl}$. A cubeta utilizada possui um percurso óptico de $0,1 \mathrm{~mm}$. Para cada espectro, foram acumulados 8 varrimentos a $298 \mathrm{~K}$.

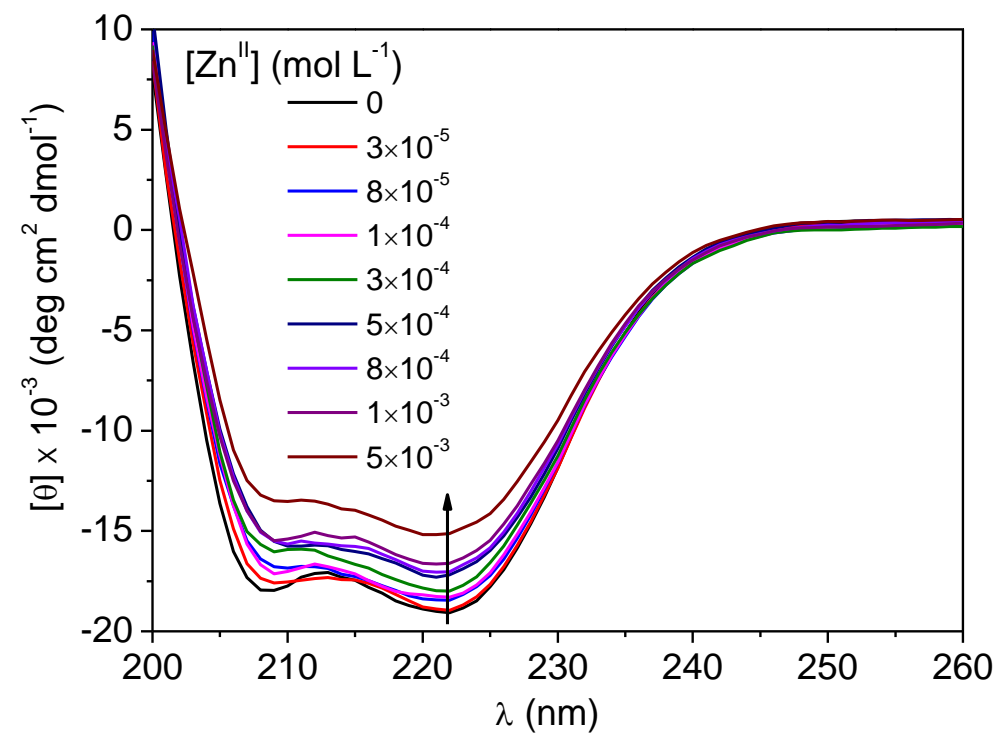

Fonte: Autoria própria.

Tabela 6. Propriedades estruturais e espectroscópicas da ferrilmioglobina $\left(1.2 \times 10^{-5} \mathrm{~mol} \mathrm{~L}^{-1}\right) \mathrm{em}$ diferentes concentrações de íons $\mathrm{Zn}^{\mathrm{II}}$ a $298 \mathrm{~K}$.

\begin{tabular}{|c|c|c|c|c|c|c|c|c|c|}
\hline$\left[\mathrm{Zn}^{\mathrm{II}}\right]\left(\mathrm{mol} \mathrm{L}^{-1}\right)$ & $\mathbf{0}$ & $3 \times 10^{-5}$ & $8 \times 10^{-5}$ & $1 \times 10^{-4}$ & $3 \times 10^{-4}$ & $5 \times 10^{-4}$ & $8 \times 10^{-4}$ & $1 \times 10^{-3}$ & $5 \times 10^{-3}$ \\
\hline hélice- $\alpha(\%)$ & 60,1 & 59,2 & 57,9 & 57,8 & 55,5 & 53,8 & 52,8 & 51,6 & 46,7 \\
\hline Antiparalela (\%) & 3,6 & 3,7 & 3,8 & 3,8 & 4,1 & 4,3 & 4,5 & 4,7 & 5,4 \\
\hline Paralela (\%) & 4,0 & 4,2 & 4,4 & 4,4 & 4,7 & 5,0 & 5,1 & 5,2 & 6,1 \\
\hline Folha- $\beta(\%)$ & 12,8 & 12,90 & 13,0 & 13,0 & 13,3 & 13,5 & 13,7 & 13,9 & 14,5 \\
\hline Randômica (\%) & 17,8 & 18,50 & 19,4 & 19,5 & 20,6 & 21,6 & 22,0 & 22,4 & 25,3 \\
\hline Total (\%) & 98,4 & 98,40 & 98,6 & 98,5 & 98,2 & 98,3 & 98,1 & 97,8 & 98,1 \\
\hline
\end{tabular}

Fonte: Autoria própria.

De acordo com os dados obtidos da Figura 32 e reportados na Tabela 6, observa-se o aumento do valor absoluto do sinal de elipticidade molar (Figura 27) indicando mudanças conformacionais significativas com o aumento da concentração de íons $\mathrm{Zn}^{\mathrm{II}}$. A deconvolução dos espectros contidos na Figura 33 indica um decréscimo de estrutura secundária tipo hélice- $\alpha$ logo após a adição de íons $\mathrm{Zn}^{\mathrm{II}}$ com um ganho de estrutura secundária em folha- $\beta$ e um acréscimo de 
estrutura randômica. Comportamento semelhante foi observado com os dados de CD da espécie metamioglobina $\left(\mathrm{MbFe}^{\mathrm{III}} \mathrm{H}_{2} \mathrm{O}\right)$.

\section{IV.9.3 - Estudo da reatividade da ferrilmioglobina pela cisteína na presença de íons $\mathrm{Zn}^{\mathrm{II}}$}

A redução da espécie ferrilmioglobina $\left(\mathrm{MbFe}^{\mathrm{IV}}=\mathrm{O}\right)$ pela cisteína produzindo a metamioglobina $\left(\mathrm{MbFe}^{\mathrm{III}}\right)$ e sulfomioglobina $\left(\mathrm{SulfMbFe}^{\mathrm{II}}\right)$ pode ser investigada utilizando-se da espectroscopia UV-Vis para monitorar em tempo real os precursores e produtos de reação (ROMERO et al., 1992). A formação da espécie sulfomioglobina foi observada para a reação conduzida em meio ácido a neutro, enquanto que para a reação em condições alcalinas, observa-se a formação majoritária da espécie oximioglobina (LIBARDI et al., 2014; CALSEN; SKOVGAARD; SKIBSTED, 2003). A Figura 33 contém a evolução espectral da reação de redução da ferrilmioglobina pela cisteína em meio ácido ( $\mathrm{pH}$ 5,7), monitorado pela técnica espectroscópica de absorção eletrônica.

Figura 33. Espectros de absorção eletrônica coletados a cada $5 \mathrm{~s}$ da reação entre a espécie $\mathrm{MbFe}^{\mathrm{IV}}=\mathrm{O}\left(5 \times 10^{-5} \mathrm{~mol} \mathrm{~L}^{-1}\right)$ e a cisteína $\left(2,5 \times 10^{-3} \mathrm{~mol} \mathrm{~L}^{-1}\right)$. Tampão acetato $0,16 \mathrm{~mol} \mathrm{~L}^{-1}(\mathrm{pH} 5,7)$ a $298 \mathrm{~K}$.

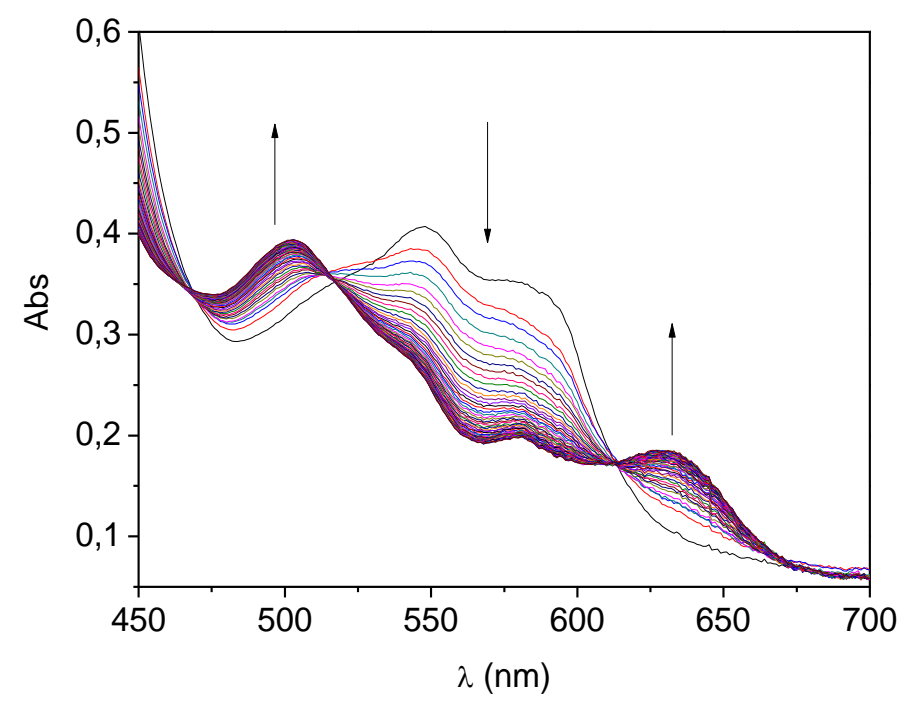

Fonte: Autoria própria

A formação da espécie sulfomioglobina foi monitorada em $625 \mathrm{~nm}$ e o decaimento da espécie ferrilmioglobina em $580 \mathrm{~nm}$ em condições de pseudo-primeira ordem com crescentes concentrações de cisteína. As constantes em condições de pseudo-primeira ordem foram 
determinadas através do ajuste não linear (Figura 34) utilizando-se a Equação 10. A constante de velocidade de segunda ordem $\mathrm{k}_{2}\left(\mathrm{~L} \mathrm{~mol}^{-1} \mathrm{~s}^{-1}\right.$ equação 11$)$, foi obtida através do coeficiente angular da reta obtida pelo ajuste linear da equação da reta ao gráfico de $\mathrm{k}_{1}$ ' versus concentração de cisteína (Figura 34).

$$
\begin{gathered}
\mathrm{A}_{(\mathrm{t})}=\mathrm{A}_{0}+\left(\text { Plato }-\mathrm{A}_{0}\right)\left(1-\mathrm{e}^{(-\mathrm{kt})}\right) \\
\mathrm{k}_{\mathrm{obs}}=\mathrm{k}_{\text {autoredução }}+\mathrm{k}_{1}[\text { cisteína }]
\end{gathered}
$$

Equação 10

Equação 11

Figura 34. Dependência linear da constante de velocidade com a concentração de cisteína em condições de pseudo-primeira ordem em solução tampão acetato ( $\mathrm{pH} 5,7)$ e força iônica de 0,16 mol L ${ }^{-1}$ a $298 \mathrm{~K}\left(\left[\mathrm{MbFe}^{\mathrm{IV}}=\mathrm{O}\right]=5 \times 10^{-5} \mathrm{~mol} \mathrm{~L}^{-1}\right)$. Em $625 \mathrm{~nm}$ referente a espécie SulfMbFe ${ }^{\mathrm{II}}(\mathrm{A}) \mathrm{e}$ em $580 \mathrm{~nm}$ referente a espécie $\mathrm{MbFe}^{\mathrm{IV}}=\mathrm{O}(\mathrm{B})$. A direita, correlação linear entre kobs e concentração de total de cisteína a fim de se obter as constantes de segunda ordem através do coeficiente angular do ajuste linear da reta.
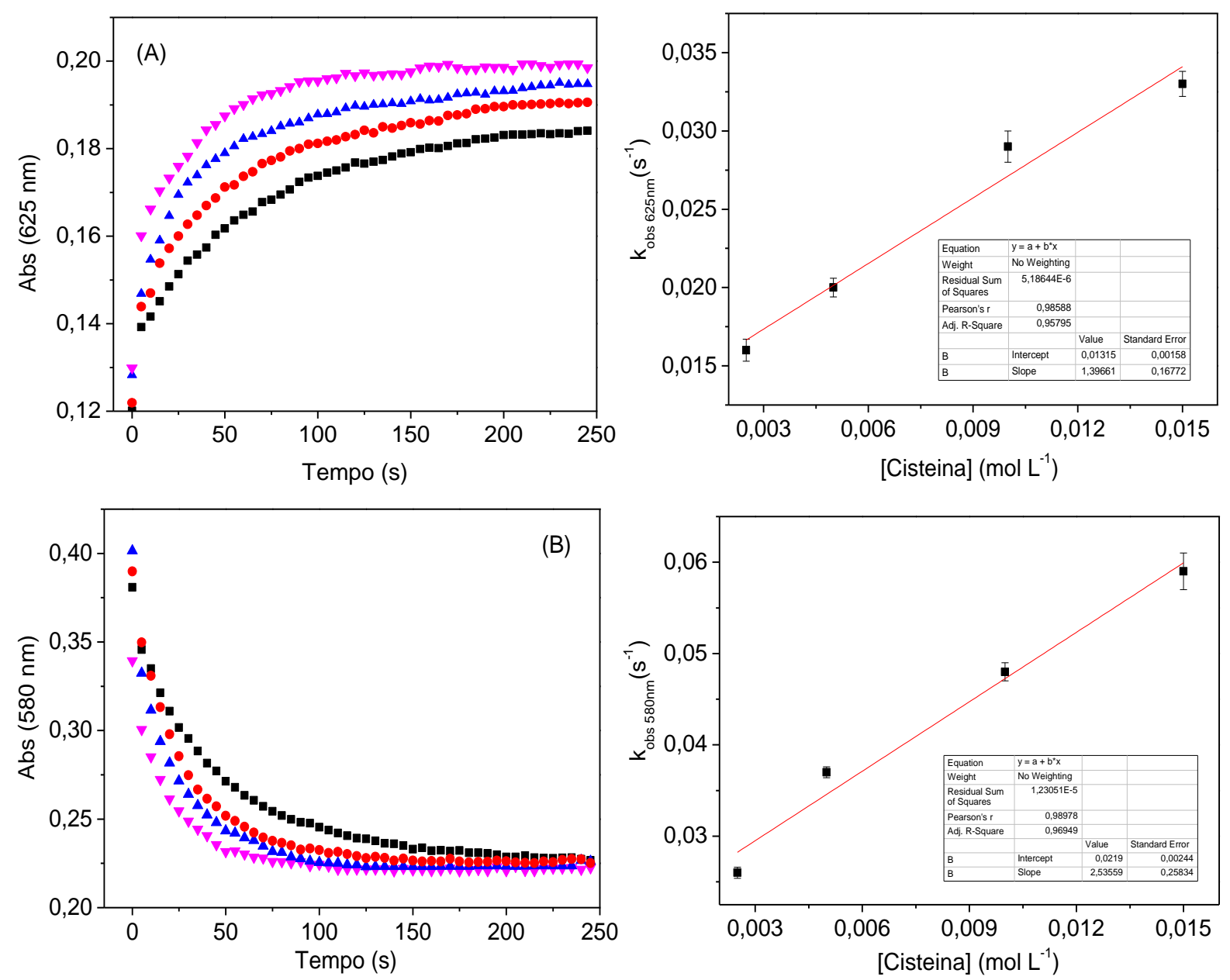

Fonte: Autoria própria. 
A constante de velocidade observada de pseudo-primeira ordem corresponde à $\mathrm{k}_{\mathrm{obs}}$ na Equação 11 e na Figura 34A-B apresenta dependência linear com o aumento da concentração em excesso do redutor cisteína. O intercepto no eixo-y obtido pela regressão linear dos dados contidos na Figura 35, corrobora com os valores de constante de velocidade de autoredução da espécie ferrilmioglobina, $\mathrm{k}_{\text {auto }}=0,013 \pm 0,001 \mathrm{~s}^{-1}$ para a formação da $\operatorname{SulfMbFe}^{\mathrm{II}}(625 \mathrm{~nm})$ e $\mathrm{k}_{\text {auto }}=$ $0,021 \pm 0,002 \mathrm{~s}^{-1}$ para o decaimento da $\mathrm{MbFe}^{\mathrm{IV}}=\mathrm{O}(580 \mathrm{~nm})$ em condições de $\mathrm{pH} 5,7 \mathrm{e}$ a temperatura de $298 \mathrm{~K}$.

A constante de velocidade de segunda ordem para a formação da espécie SulfMbFe ${ }^{\mathrm{II}}$ $(625 \mathrm{~nm})$ e o decaimento da espécie $\mathrm{MbFe}^{\mathrm{IV}}=\mathrm{O}(580 \mathrm{~nm})$ foi acompanhada em diferentes concentrações de íons $\mathrm{Zn}^{\mathrm{II}}$ estão contidos no Apêndice C. A Figura 35 ilustra as constantes de segunda ordem da reação de redução da espécie ferrilmioglobina em função da concetração de íons $\mathrm{Zn}{ }^{\mathrm{II}}$.

Figura 35. Constante de segunda ordem $(\mathrm{k} 2)$ do processo de redução da espécie ferrilmioglobina pela cisteína em função da concentração de íons $\mathrm{Zn}^{\mathrm{II}}\left(\left[\mathrm{MbFe}^{\mathrm{IV}}=\mathrm{O}\right]=5 \times 10^{-5} \mathrm{~mol} \mathrm{~L}^{-1}\right)$. Em $580 \mathrm{~nm}$ referente a espécie $\mathrm{MbFe}^{\mathrm{IV}}=\mathrm{O}(\mathrm{A})$ e em $625 \mathrm{~nm}$ referente a espécie $\operatorname{SulfMbFe}^{\mathrm{II}}(\mathrm{B})$. Tampão acetato à temperatura de $298 \mathrm{~K}$.
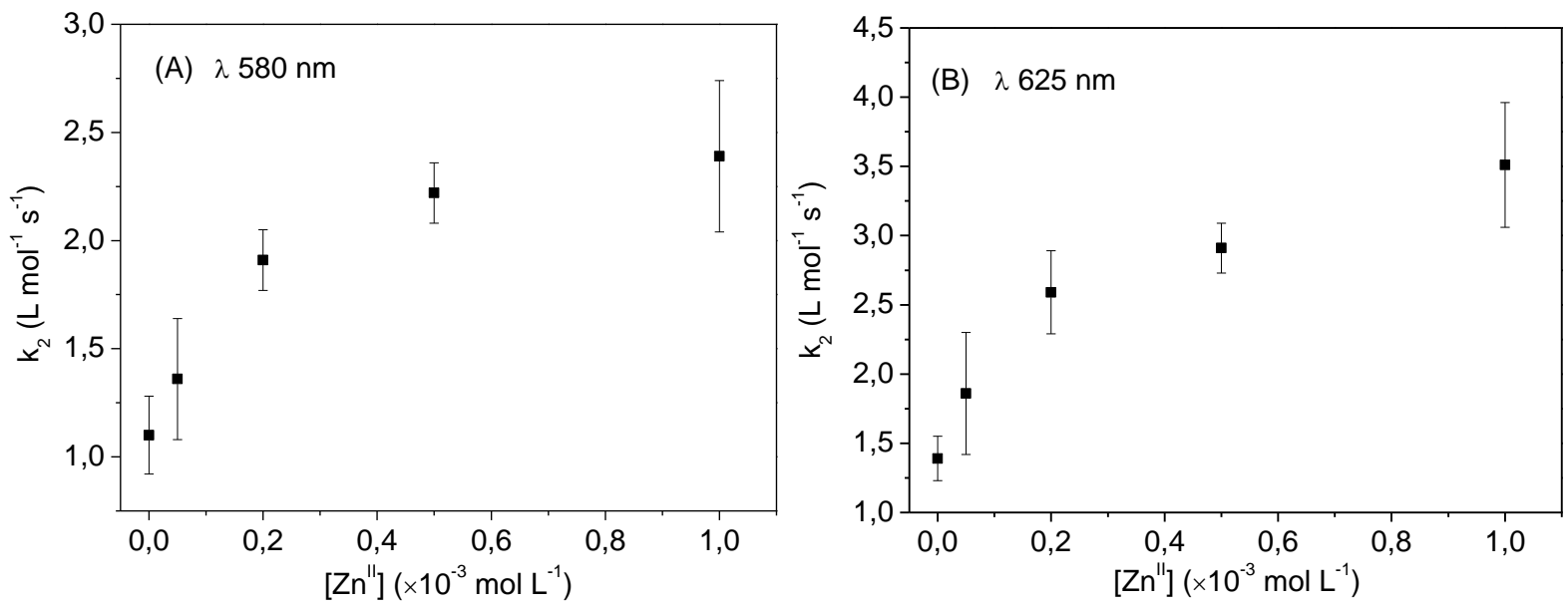

Fonte: Autoria própria.

A espécie SulfMbFe ${ }^{\mathrm{II}}$ é o principal produto para a reação de redução da espécie $\mathrm{MbFe}^{\mathrm{IV}}=\mathrm{O}$ pela cisteína nessas condições e o processo de redução na ausência e presença de íons $\mathrm{Zn}^{\text {II }}$ pode ser representado pela reação 12 . 


$$
\begin{gathered}
\mathrm{MbFe}^{\mathrm{IV}}=\mathrm{O}+\text { cys } \underset{\text { via } 1}{\stackrel{\mathrm{k}_{2}}{\longrightarrow}} \text { SulfMbFe }^{\mathrm{II}}+\mathrm{RCHO} \\
\mathrm{Zn}-\mathrm{MbFe}^{\mathrm{II}}=\mathrm{O}+\text { cys } \underset{\text { via } 2}{\stackrel{\mathrm{k}_{2}^{\prime}}{\longrightarrow}} \mathrm{Zn}-\mathrm{SulfMbFe}^{\mathrm{II}}+\mathrm{RCHO}
\end{gathered}
$$

onde $\mathrm{RCHO}=$ derivado oxidado da cisteína.

$\mathrm{O}$ valor de $\mathrm{k}_{2}=1,39 \pm 0,16 \mathrm{~L} \mathrm{~mol}^{-1} \mathrm{~s}^{-1}$ obtido quando $\left[\mathrm{Zn}^{\mathrm{II}}\right]=0$ (via 1 ), é concordante do valor conhecido na literatura (LIBARDI et al., 2014). Sendo a interação dos íons de $\mathrm{Zn}$ II na Mb um processo espontâneo (visto os dados de ITC), pode-se considerar que praticamente a reação se passa majoritariamente pela via 2 , sendo $\mathrm{k}_{2} \approx 3,25 \pm 0,18 \mathrm{~L} \mathrm{~mol}^{-1} \mathrm{~s}^{-1}$ a $298 \mathrm{~K}$.

\section{9.4 - Estudo da influência de íons $\mathrm{Zn}$ II na oxidação do monóxido de carbono mediada pela espécie Perferrilmioglobina $\left(\mathrm{MbFe}^{\mathrm{IV}}=\mathrm{O}^{\circ+}\right)$}

Tendo em vista a mobilidade do $\mathrm{CO}$ em proteínas heme hipervalentes, bem como a desativação de radicais hidroperóxidos, o presente estudo procurou determinar parâmetros cinéticos para o melhor entendimento da reatividade da espécie $\mathrm{Zn}-\mathrm{MbFe}^{\mathrm{IV}}=\mathrm{O}^{\bullet+}$ com o $\mathrm{CO}$, a fim de elucidar reações que ocorrem em produtos cárneos e sistemas biológicos. $\mathrm{O}$ cátion radical perferrilmioglobina $\left(\mathrm{MbFe}^{\mathrm{IV}}=\mathrm{O}^{\bullet+}\right)$ apresenta um tempo de vida muito curto $(260 \mu \mathrm{s})$ (ZHANG et al., 2005) e pode ser formado através da técnica FLP (equação 13), o qual sofre processo de autoredução ou então pode ser reduzido por uma molécula de proteína ou lipídeo formando a espécie ferrilmioglobina $\left(\mathrm{MbFe}^{\mathrm{IV}}=\mathrm{O}\right)$ já conhecida por não apresentar reatividade com o monóxido de carbono (LIBARDI; SKIBSTED; CARDOSO, 2014).

$$
\mathrm{MbFe}^{\mathrm{IV}}=\mathrm{O} \underset{\mathrm{k}_{\text {auto }}}{\stackrel{\mathrm{h} v-\mathrm{e}^{-}}{\rightleftharpoons}} \mathrm{MbFe}^{\mathrm{IV}}=\mathrm{O}^{++}
$$

Equação 13

Os espectros de transientes da reação de redução da perferrilmioglobina pelo monóxido de carbono na ausência e na presença de íons de $\mathrm{Zn}^{\mathrm{II}}$ estão elucidadas na Figura 36A e 36B respectivamente. 
Utilizando os dados espectroscópicos da Figura 36 foi possível acompanhar a reação de formação $(430 \mathrm{~nm})$ e decaimento $(410 \mathrm{~nm})$ da espécie perferrilmioglobina no estado excitado em alguns intervalos de tempo. O espectro da espécie Zn-PerferrilMb (Figura 36B) apresenta uma pequena supressão de transiente quando comparado com o espectro da espécie PerferilMb (Figura 36A).

Figura 36. Espectro de diferença de absorção do transiente no tempo da reação de redução da perferrilmioglobina pelo $\mathrm{CO}$ (A) e na presença de $1 \times 10^{-3} \mathrm{~mol} \mathrm{~L}^{-1}$ de $\mathrm{Zn}^{\mathrm{II}}$ (B) em solução tampão acetato pH 5,7 (Força iônica ajustada $0,16 \mathrm{~mol} \mathrm{~L}^{-1}$ ) a $298 \mathrm{~K}$. O pulso de laser em $355 \mathrm{~nm}(8 \mathrm{~ns}$ ) e intensidade de $10 \mathrm{~mJ} . \mathrm{cm}^{2}$, solução contendo $3,1 \times 10^{-6} \mathrm{~mol} \mathrm{~L}^{-1}$ de $\mathrm{Mb}$ e $0,7 \times 10^{-3} \mathrm{~mol} \mathrm{~L}^{-1}$ de CO.
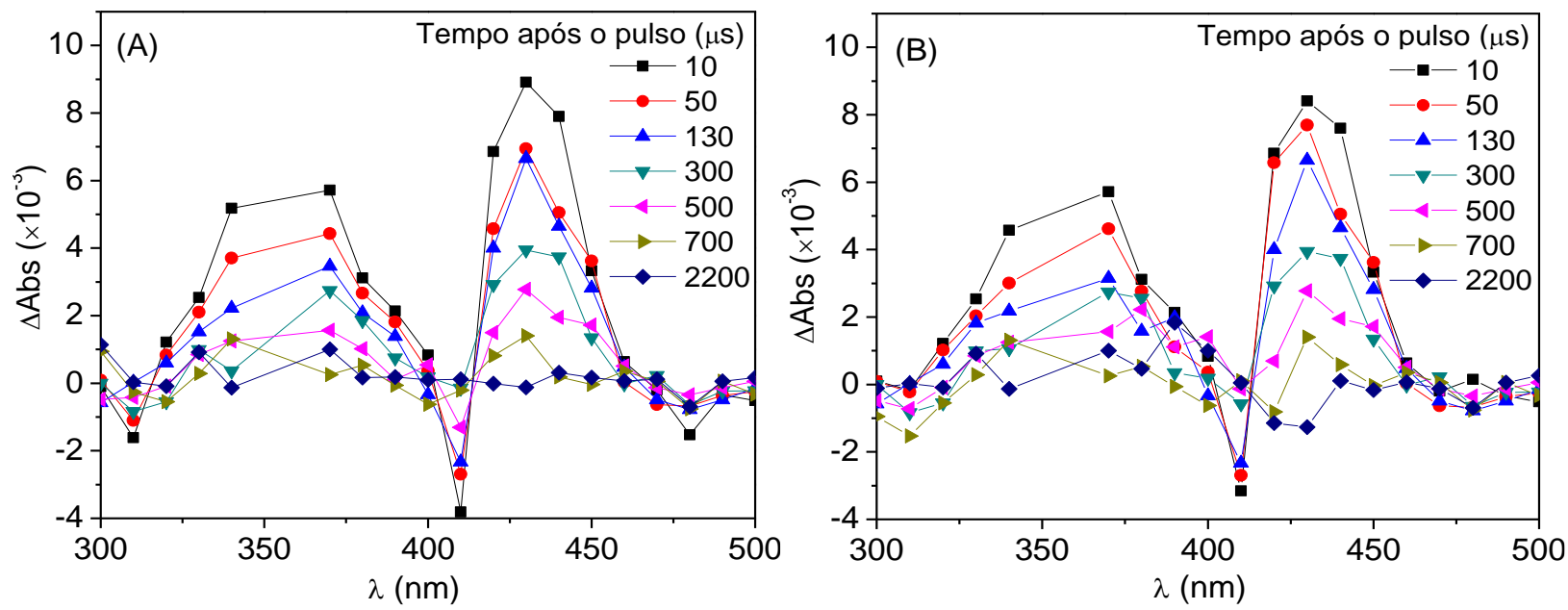

Fonte: Autoria própria.

Monitorando-se o decaimento do transiente centrado em $430 \mathrm{~nm}$ da espécie perferrilmioglobina na ausência e presença de diferentes concentrações de íons de $\mathrm{Zn}{ }^{\mathrm{II}}$ observa-se que o decaimento da espécie perferril ocorre exponencialmente e é acelerado pela presença de íons de $\mathrm{Zn}^{\mathrm{II}}$ (Figura 37A). A Figura 37B refere-se aos valores de decaimento monoexonencial da espécie perferril em diferentes concentrações de íons de $\mathrm{Zn}$ II. 
Figura 377. (A) Curva de decaimento da espécie perferrilmioglobina $\left(3 \times 10^{-5} \mathrm{~mol} \mathrm{~L}^{-1}\right)$ em diferentes concentrações de $\mathrm{Zn}^{\mathrm{II}}$ utilizando $\mathrm{CO}$ como redutor. em solução tampão acetato pH 5,7 (Força iônica ajustada $0,16 \mathrm{~mol} \mathrm{~L}^{-1}$ ) a $298 \mathrm{~K}$. O pulso de laser em $355 \mathrm{~nm}$ (8 ns) e intensidade de $10 \mathrm{~mJ} . \mathrm{cm}^{2}$. (B) Gráfico de kobs versus concentração de acetato de zinco. A partir do ajuste não linear do gráfico (equação 18) calculou-se os valores e k2 e K Kigação.
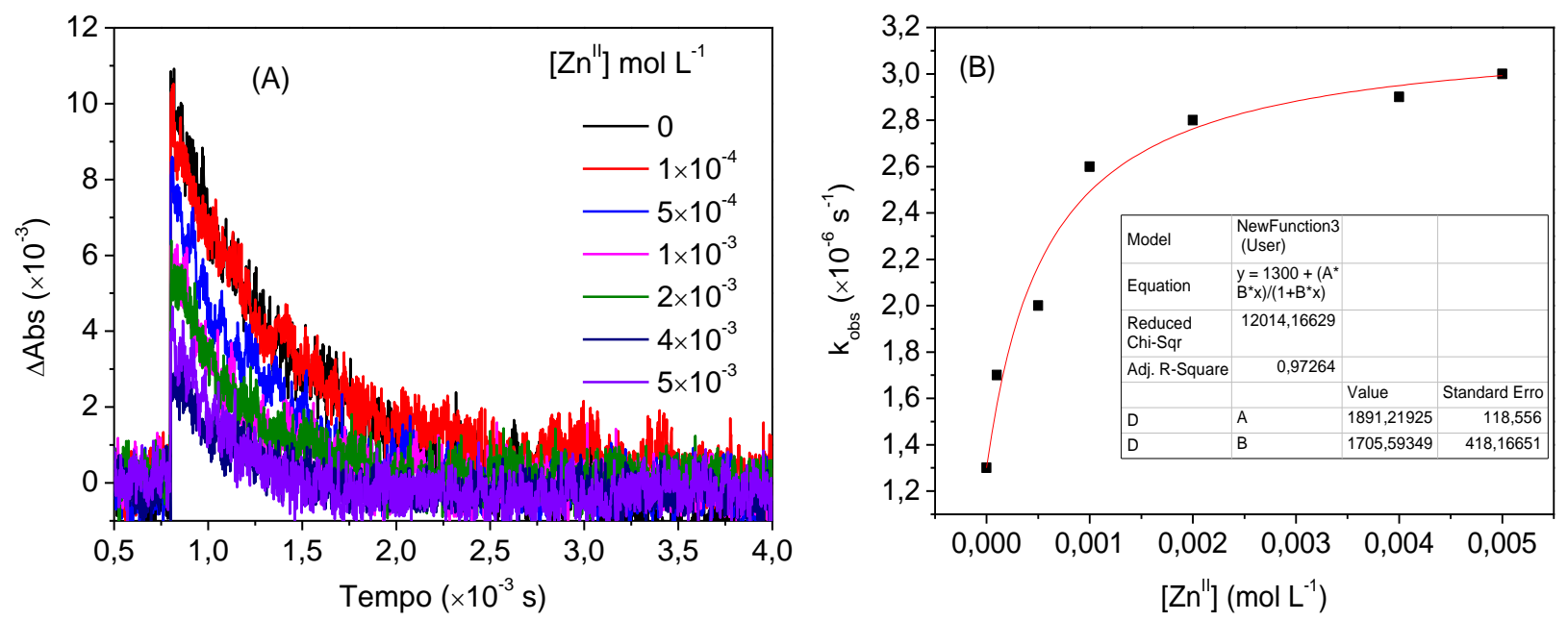

Fonte: Autoria própria

A partir da interação de íons de $\mathrm{Zn}^{\mathrm{II}}$ ( $\mathrm{K}_{\text {lig }}$ ), seguido da reação de redução da perferrilMb $\left(\mathrm{k}_{2}\right)$ pode ser representado por:

$$
\mathrm{Zn}{ }^{\mathrm{II}}+\mathrm{MbFe}^{\mathrm{IV}}=\mathrm{O} \stackrel{\mathrm{K}_{\text {lig }}}{\rightleftharpoons} \mathrm{Zn}^{\mathrm{II}}-\mathrm{MbFe}^{\mathrm{IV}}=\mathrm{O} \stackrel{\mathrm{k}_{2}}{\longrightarrow} \mathrm{Zn}^{\mathrm{II}}-\mathrm{MbFe}^{\mathrm{III}} \mathrm{H}_{2} \mathrm{O}
$$

Equação 14

Em que a interação reversível de Zn com a Mb pode ser expresso pela Equação 15:

$$
\frac{\left[\mathrm{Zn}^{\mathrm{II}}-\mathrm{MbFe}^{\mathrm{IV}}=\mathrm{O}\right]}{\left[\mathrm{Zn}^{\mathrm{II}}\right]\left[\mathrm{MbFe}^{\mathrm{IV}}=\mathrm{O}\right]}=\mathrm{K}_{\mathrm{lig}}
$$

Equação 15

Assim, monitorando a formação da espécie $\mathrm{Zn}$-metamioglobina $\left(\mathrm{Zn}^{\mathrm{II}}-\mathrm{MbFe}^{\mathrm{III}} \mathrm{H}_{2} \mathrm{O}\right)$ :

$$
\begin{gathered}
\mathrm{d}\left[\mathrm{Zn}^{\mathrm{II}}-\mathrm{MbFe}^{\mathrm{III}} \mathrm{H}_{2} \mathrm{O}\right] / \mathrm{dt}-\mathrm{k}\left(\left[\mathrm{Zn}^{\mathrm{II}}\right]+\left[\mathrm{Zn}^{\mathrm{II}}-\mathrm{MbFe}^{\mathrm{IV}}=\mathrm{O}\right]\right)= \\
=\mathrm{k}_{2}\left[\mathrm{Zn}^{\mathrm{II}}-\mathrm{MbFe}^{\mathrm{IV}}=\mathrm{O}\right]=\mathrm{k}_{2} \mathrm{~K}_{\text {lig }}\left[\mathrm{Zn}^{\mathrm{II}}\right]\left[\mathrm{MbFe}^{\mathrm{IV}}=\mathrm{O}\right]
\end{gathered}
$$

Da Equação 15 e 16: 


$$
\mathrm{k}_{\mathrm{obs}}=\mathrm{k}_{1}+\left(\frac{\mathrm{k}_{2} \mathrm{~K}_{\mathrm{lig}}\left[\mathrm{Zn}^{\mathrm{II}}\right]}{1+\mathrm{K}_{\mathrm{lig}}\left[\mathrm{Zn}^{\mathrm{II}}\right]}\right)
$$

O ajuste não linear do gráfico da Figura 37 permitiu o cálculo dos valores de $\mathrm{k}_{2}$ e $\mathrm{K}_{\text {Ligação, }}$, a partir da Equação 17. O valor de $\mathrm{k}_{\text {obs }}$ aumenta com o aumento da concentração de íons $\mathrm{Zn}^{\mathrm{II}}$, no entanto, aproxima-se de um valor limite e $\mathrm{k}_{1}$ refere-se a constante de velocidade na ausência de íons de $\mathrm{Zn}$ "II conforme mostrado na Figura 37. Para as condições atuais, os valores calculados foram $\mathrm{k}_{2}=1,9 \times 10^{3} \mathrm{~s}^{-1}$ e $\mathrm{K}_{\text {Ligação }}=1,7 \times 10^{3} \mathrm{~mol} \mathrm{~L}^{-1}$ para a espécie Zn-ferrilmioglobina.

A reação entre $\mathrm{CO}$ e a perferrilmioglobina resulta em uma oxidação do $\mathrm{CO}$ sendo liberado $\mathrm{CO}_{2}$ em quantidades muito pequenas. Assim, para medir o $\mathrm{CO}_{2}$ liberado pela reação foi necessária a utilização de uma medida direta com a técnica de FT-IR da fase gasosa em equilíbrio com a fase líquida da solução perferrilmioglobina e CO após o tempo de irradiação (Figura 38).

A detecção de $\mathrm{CO}_{2}$ foi possível devido ao aparecimento das bandas em 2335 e $2361 \mathrm{~cm}^{-1}$ como mostra a Figura 38. A identificação da espécie ferro-heme formado a partir da irradiação do sistema perferrilmioglobina e monóxido de carbono, foi realizada análise através da solução irradiada por espectroscopia de absorção eletrônica.

Figura 38. Espectro de FTIR da fase gasosa em tampão acetato pH 5,7 e 298 K. Solução ferrilmioglobina e $\mathrm{CO}$ (curva em preto). Após 2 minutos de irradiação $(355 \mathrm{~nm}$ ), reação e equilíbrio da fase gasosa e líquida (curva em vermelho). $\left[\mathrm{MbFe}^{\mathrm{IV}}=\mathrm{O}\right]=1 \times 10^{-4} \mathrm{~mol} \mathrm{~L}^{-1} ;[\mathrm{CO}]=7 \times 10^{-4} \mathrm{~mol}$ $\mathrm{L}^{-1}$.

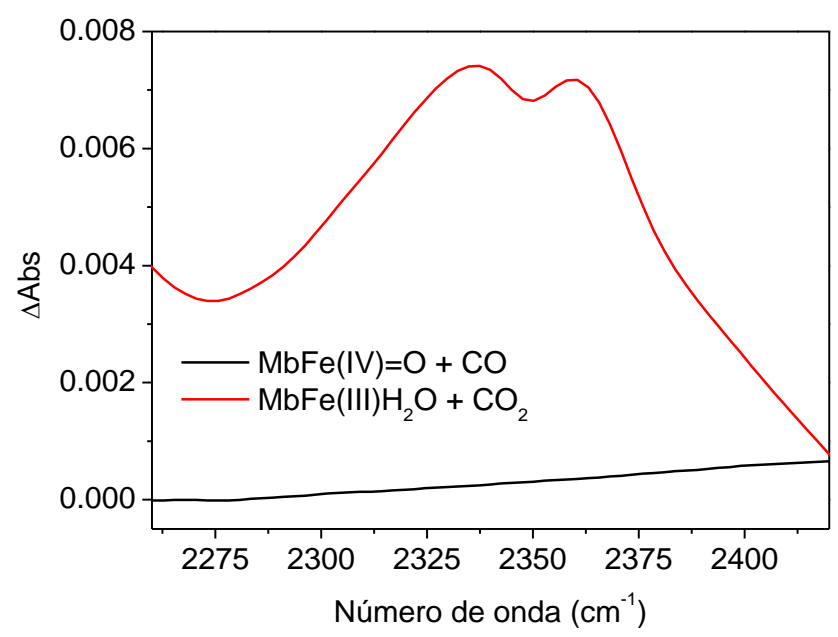

Fonte: Autoria própria. 
A Figura 39 ilustra o espectro de absorção eletrônica do sistema perferril e monóxido de carbono antes e após o tempo de dois minutos de irradiação.

Figura 39. Espectros de absorção eletrônica da mistura ferrilmioglobina e CO (curva em preto) e após 2 minutos de irradiação (curva em vermelho). Solução tampão acetato pH 5,8 a $298 \mathrm{~K}$. $\lambda_{\mathrm{ex}}$ $=355 \mathrm{~nm} .\left[\mathrm{MbFe}^{\mathrm{IV}}=\mathrm{O}\right]=4,15 \times 10^{-5} \mathrm{~mol} \mathrm{~L}^{-1} ;[\mathrm{CO}]=7,0 \times 10^{-4} \mathrm{~mol} \mathrm{~L}^{-1}$.

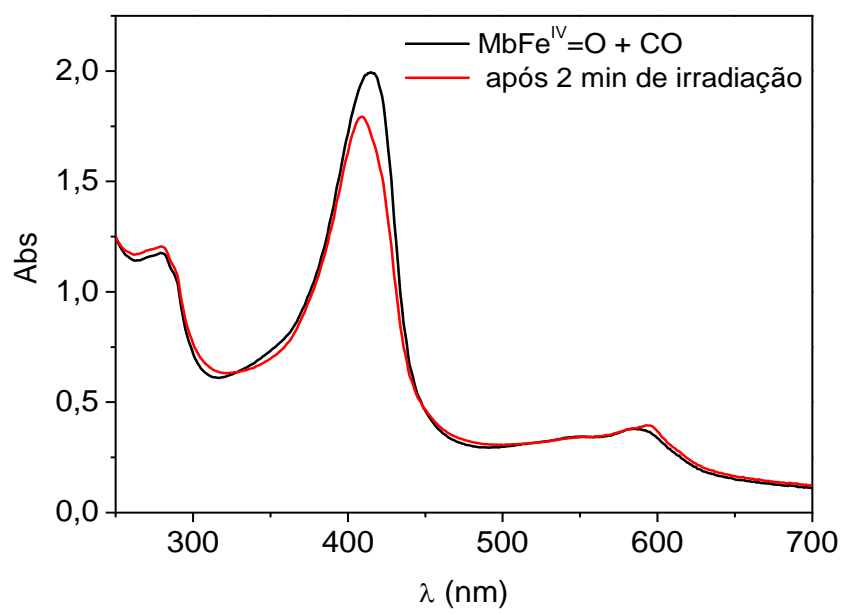

Fonte: Autoria própria.

Com a leitura dos espectros da Figura 39 é possível observar o perfil espectral característico da espécie ferrilmioglobina $\left(\mathrm{FeMb}^{\mathrm{IV}}=\mathrm{O}\right.$, curva em preto) e da espécie metamioglobina (FeMb ${ }^{\mathrm{III}} \mathrm{H}_{2} \mathrm{O}$, curva em vermelho). Após o tempo de irradiação, a espécie ferrilmioglobina $\left(\mathrm{FeMb}^{\mathrm{IV}}=\mathrm{O}\right)$ gera a espécie perferrilmioglobina $\left(\mathrm{FeMb}^{\mathrm{IV}}=\mathrm{O}^{\bullet+}\right)$ levando a oxidação do $\mathrm{CO}$ a $\mathrm{CO}_{2}$ com comcomitante redução via 2 elétrons da perferrilmioglobina levando a formação da espécie metamioglobina (Equação 18).

$$
\mathrm{MbFe}^{\mathrm{IV}}=\mathrm{O}^{+}+\mathrm{CO} \stackrel{\mathrm{k}_{\mathrm{red}}}{\longrightarrow} \mathrm{MbFe}{ }^{\mathrm{III}} \mathrm{H}_{2} \mathrm{O}+\mathrm{CO}_{2}
$$

Equação 18

\section{9.5 - Cinética de oxidação monóxido de carbono mediada pela Perferrilmioglobina $\left(\mathrm{MbFe}^{\mathrm{IV}}=\mathrm{O}^{\cdot+}\right)$}

A constante de velocidade da reação de redução da espécie perferrilmioglobina pelo monóxido de carbono foi determinada através do decaimento da espécie perferrilmioglobina em diferentes concentrações de monóxido de carbono (Equação 19). 
A constante de velocidade de decaimento da espécie perferrilmioglobina seguiu uma cinética de pseudo-primeira ordem e a constante de velocidade observada foi encontrada como dependente da concentração de monóxido de carbono (solução saturada de $\mathrm{CO}=7,0 \times 10^{-4} \mathrm{~mol} \mathrm{\textrm {L } ^ { - }}$ ${ }^{1}$ ) e a partir da regressão linear da equação 19 plotado na Figura 41B.

$$
\mathrm{k}_{\mathrm{obs}}=\mathrm{k}_{0}-\mathrm{k}_{\mathrm{red}}[\mathrm{CO}]
$$

Equação 19

onde $\mathrm{k}_{0}$ é a constante de velocidade de primeira ordem para a reação de auto-redução.

A partir da regressão linear da Figura 40B e de acordo com a equação 23, as constantes de velocidade de segunda ordem $\left(\mathrm{k}_{\mathrm{red}}\right)$ de reação de auto-redução $\left(\mathrm{k}_{0}\right)$ e redução da espécie perferrilmioglobina foram de $\mathrm{k}_{\mathrm{red}}=(3,73 \pm 0,13) \times 10^{6} \mathrm{~mol} \cdot \mathrm{L}^{-1} \cdot \mathrm{s}^{-1} \mathrm{e} \mathrm{k}_{0}=(883,32 \pm 57,78) \mathrm{s}^{-1}$ respectivamente. Ainda nas curvas de decaimento da Figura 40 observa-se uma diminuição no máximo de absorção indicando uma diminuição de formação de transientes $\left(\mathrm{MbFeIV}^{\bullet+}\right)$ com o aumento da concentração de CO. Como mostrado na Equação 19, a redução da espécie MbFe ${ }^{\mathrm{IV}}$ leva a formação da espécie MbFe ${ }^{\mathrm{III}}$.

Figura 40. (A) Curvas de decaimento em $440 \mathrm{~nm}$ da perferrilmioglobina $\left(\left[\mathrm{MbFe}^{\mathrm{IV}}=\mathrm{O} \bullet+\right]=3,1 \times 10^{-}\right.$ ${ }^{5}$ mol L ${ }^{-1}$ ) em diferentes concentrações de $\mathrm{CO}$ a $298 \mathrm{~K}$. Solução tampão acetato força iônica ajustada 0,16 mol L $^{-1}$ (pulso de laser em $355 \mathrm{~nm}$ com energia de $30 \mathrm{~mJ} . \mathrm{cm}^{2}$ ). (B) Constantes de primeira ordem em $\mathrm{s}^{-1}$ para a reação da perferrilmioglobina em função da concentração de monóxido de carbono.
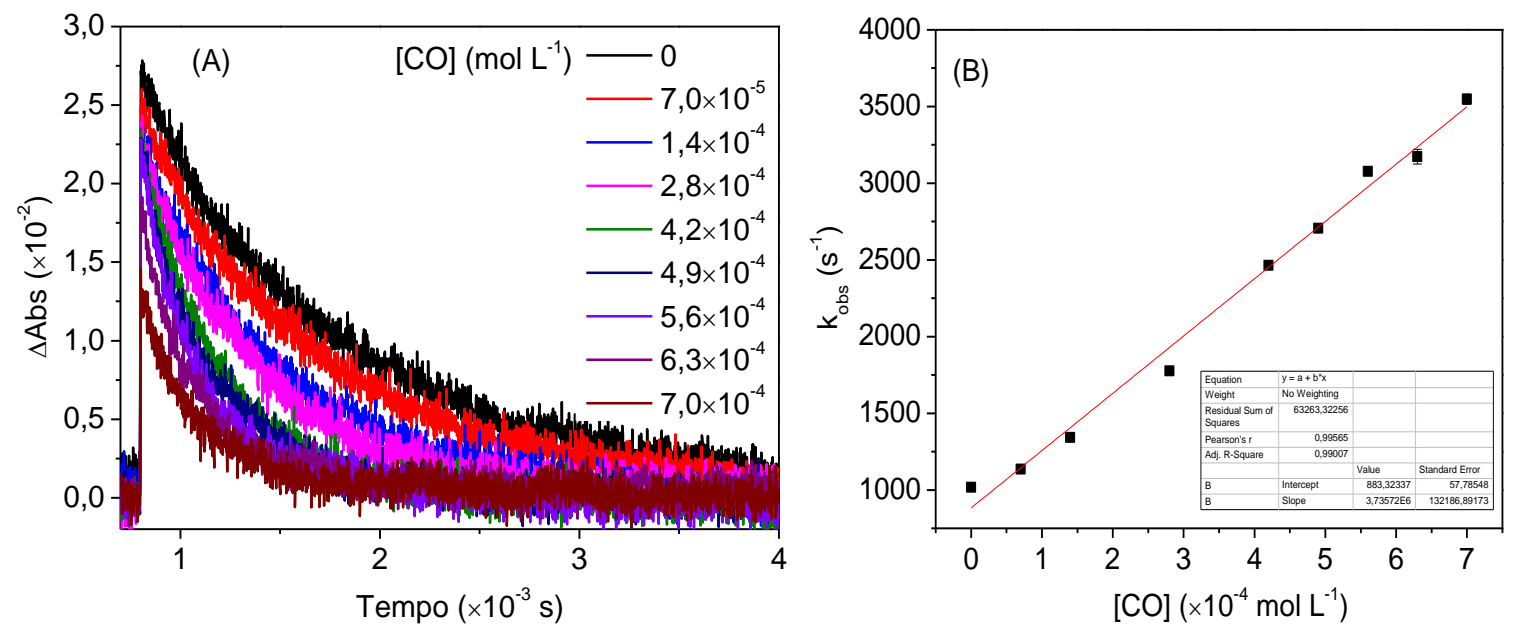

Fonte: Autoria própria. 
Os resultados foram obtidos na ordem de microsegundos, por isso, a oxidação do CO para $\mathrm{CO}_{2}$ via FLP ocorre provavelmente na espécie perferilmioglobina com cátion radical porfirina que tem um tempo de vida de $\tau \sim 10^{-6} \mathrm{~s}$ em $\mathrm{pH}$ neutro a $298 \mathrm{~K}$. 


\section{CONCLUSÃO}

A partir da interação química entre mioglobina e íons zinco $\left(\mathrm{Zn}^{\mathrm{II}}\right)$, estudos espectroscópicos foram realizados com o objetivo de caracterizar e acompanhar os processos envolvidos nesta interação. Os resultados indicaram que a presença de íons zinco induz mudanças significativas nas propriedades fotofísicas (exemplo: absorção UV-vis, emissão de fluorescência, absorção de luz polarizada e tempos de vida de transientes) da mioglobina.

Os resultados de absorção eletrônica no UV-Vis mostraram que a presença de íons $\mathrm{Zn}{ }^{\mathrm{II}}$ não desloca as bandas Soret $\left(0,0\right.$ e 1,0) da $\mathrm{MbFe}^{\mathrm{III}} \mathrm{H}_{2} \mathrm{O}$, indicando a ausência de oxidação e/ou redução do centro metálico. Entretanto, uma mudança estrutural da proteína confere uma distorção no anel profirínico, aumentando a absortividade molar da banda Soret $(1,0)$ e diminuindo a absortividade molar da banda Soret $(0,0)$.

$\mathrm{O}$ aumento da intensidade de fluorescência na presença de íons $\mathrm{Zn}^{\mathrm{II}}$ foi atribuída a uma alteração na estrutura conformacional que tende a distanciar o resíduo triptofano externo do supressor "água”, alocando o triptofano em um sítio mais hidrofóbico, uma vez que o triptofano possui baixo rendimento quântico de emissão de fluorescência em ambientes polares.

$\mathrm{O}$ estudo de dicroísmo circular confirma que a presença de íons $\mathrm{Zn}^{\mathrm{II}}$ induz mudanças significativas na estrutura helicoidal da proteína. Após a adição de íons zinco, observou-se o aumento do índice percentual de $\alpha$-hélice com a dimimuição concomitante de folhas- $\beta$ e estrutura randômica.

Os resultados de espalhamaneto de luz dinâmica (DLS) mostraram que a concentração de íons $\mathrm{Zn}{ }^{\mathrm{II}}$ no meio de proteína induz a formação de agregados e o tamnho das mesmas. A análise das imagens de transmissão indica que os agregados formados tendem a crescer de forma ordenada, formando estruturas de fibrilas.

A partir dos resultados de fluorescência, DLS e dicroísmo circular, sugere-se que a formação de fibrilas se dá pelo estrelaçamento das cadeias de proteínas, que então escondem o resíduo externo de triptofano em um ambiente mais hidrofóbico. Assim, a emissão de fluorescência do sistema químico é aumentada pelo ambiente mais apolar em que o triptofano está contido.

A partir das medidas de titulação isotérmica, a constante de equilíbrio da interação química entre mioglobinaferrica e íon zinco foi determinada, apresentando o valor de $K_{a}=(3,22 \pm 0,21) \times 10^{4}$ 
$\mathrm{L} \mathrm{mol}^{-1}$ ). O número de sítios ativos $\mathrm{n}$ foi determinado, indicando que o processo de interação segue uma estequiometria de 1:1.

Com base nos resultados de fotólise por pulso de laser, a detecção de absorção de transientes da deoximioglobina mostrou que a presença de íons de $\mathrm{Zn}^{\mathrm{II}}$ aumenta significativamente a constante de velocidade de recombinação bimolecular entre a deoximioglobina e o oxigênio molecular triplete na ordem de 1,33 vezes para a oximioglobina e de 1,20 vezes para a carboximioglobina. A mudança na estrutura conformacional da proteína induzida pelos íons de $\mathrm{Zn}^{\mathrm{II}}$ ocasiona no deslocamento da histidina (His64) distal para fora do bolsão hidrofóbico da proteína. Com a abertura da His64, a possibilidade do oxigênio molecular (apolar) entrar no sítio hidrofóbico se torna plausível.

Os estudos da auto-redução da espécie ferrilmioglobina mostrou que não há alteração da estrutura ferro-porfirina na presença de íons de $\mathrm{Zn}^{\mathrm{II}}$. Entretanto, os estudos de DLS observou-se aumento do valor absoluto do sinal de elipticidade molar indicando mudanças conformacionais significativas com o aumento da concentração de íons $\mathrm{Zn}^{\mathrm{II}}$. Já na presença de íons $\mathrm{Zn}{ }^{\mathrm{II}}$, a constante de segunda ordem de formação da espécie sulfumioglobina SulfMb é aumentada na ordem de 2,3 vezes.

A espécie perferrilMb gerada através da irradiação $(355 \mathrm{~nm})$ da espécie ferrilMb foi investigada na presença de moléculas de $\mathrm{CO}$ resultando na oxidação do $\mathrm{CO}$ para $\mathrm{CO}_{2}$ com a comcomitante redução via 2 elétrons da perferrilmioglobina levando a formação da espécie metamioglobina. $\mathrm{O}$ valor de $\mathrm{k}_{\mathrm{obs}}$ aumenta com o aumento da concentração de íons $\mathrm{Zn}^{\mathrm{II}}$ até aproximar-se de um valor limite de saturação. 


\section{REFERÊNCIA BIBLIOGRÁFICA}

AJLOO, D.; MOOSAVI-MOVAHEDI, A. A.; HAKIMELAHI, G. H.; SABOURY, A. A.; GHARIBI, H. The effect of dodecyl trimethylammonium bromide on the formation of methemoglobins and hemichrome, Colloids Surfaces B: Biointerfaces. v. 26, p. 185-196, 2002.

ANTONINI, E.; ROSSI-BERNARD, L.; CHIANCONE, E. Methods in enzimology. Academic Press, 1981.

BARENDS, T. R. M.; FOUCAR, L.; ARDEVOL, A.; NASS, K.; AQUILA, A.; BOTHA, S.; DOAK, R. B.; FALAHATI, K.; HARTMANN, E.; HILPERT, M.; HEINZ, M.; HOFFMANN, M. C.; KÖFINGER, J.; KOGLIN, J. E.; KOVACSOVA, G.; LIANG, M.; MILATHIANAKI, D.; LEMKE, H. T.; REINSTEIN, J.; ROOME, C. M.; SHOEMAN, R. L.; WILLIAMS, G. J.; BURGHARDT, I.; HUMMER, G.; BOUTET, S.; SCHLICHTING, I. Direct observation of ultrafast collective motions in CO myoglobin upon ligand dissociation. Science. v. 350, i 6259, p. 445-449, 2015

BECKER, E. M.; WESTERMANN, S.; HANSSON, M.; SKIBSTED, L. H. Parallel enzymatic and non-enzymatic formation of zinc protoporphyrin IX in pork. Food Chemistry, v.130, p. 832-840, 2012.

BERNE, J.; LAUZIER, B.; ROCHETTE L.; VERGELY, C. Carbon monoxide protects against ischemia-reperfusion injury in vitro via antioxidant properties. Celular Physiology and Biochemistry, v. 29, p. 475-484, 2012.

BOWEN, W. J. The Absorption Spectra an Extinction Coeficients of Myoglobin. Journal Biological Chemistry, v. 179, p. 6696-6701, 1969.

BRASIL. Ministério da Agricultura. Secretaria Nacional de Defesa Agropecuária. Laboratório Nacional de Referência Animal (LANARA). Portaria nº 01, de 07 de outubro de 1981. Métodos Analíticos Oficiais para Controle de Produtos de Origem Animal e seus Ingredientes: métodos físicos e químicos. Diário Oficial da União, Brasília - DF, 13 de outubro de 1981.

BRYANT C. M.; MCCLEMENTS D. J. Molecular basis of protein functionality with special consideration of cold-set gels derived from heat-denatured whey. Trends in Food Science and Technology. v. 9, p. 143-151, 1998.

BULHELLER, B. M., RODGER, A., HIRST, J. D., 2007. Circular and linear dichroism of proteins. Physical Chemistry Chemical Physics. v. 9, p. 2020-2035, 2007.

CALSEN, C.U.; SKOVGAARD, I. M.; SKIBSTED, L.H. Pseudoperoxidase Activity of Myoglobin: Kinetics and Mechanism of the Peroxidase Cycle of Myoglobin with $\mathrm{H} 2 \mathrm{O} 2$ and 2,2Azino-bis(3-ethylbenzthiazoline-6-sulfonate) as Substrates Heme-iron in lipid oxidation. Journal of Agricultural and Food Chemistry, v. 51, p. 5815-5823, 2003.

CARLSEN, C. U.; MØLLER, J. K. S.; SKIBSTED L. H. Heme-iron in lipid oxidation. Coordination Chemistry Reviews. v. 249, i. 3-4, p. 485-498, 2005.

CHATFIELD, M. J., LAMAR, N. G.; KAUTEN, R. J. Proton NMR characterization of isomeric sulfmyoglobins: preparation, interconversion, reactivity patterns, and structural features.

Biochemistry, v. 26, n. 22, p. 6939-6950, 1987. 
CHI, E. Y; KRISHNAN, S.; RANDOLPH, T. W.; CARPENTER, J. F. Physical stability of proteins in aqueous solution: mechanism and driving forces in nonnative protein aggregation. Pharmacological Research. v. 20, p. 1325-1336, 2003.

CHITI, F.; DOBSON, C. M. Protein misfolding, functional amyloid, and human disease. Annual Review of Biochemistry. v. 75, p. 333-366, 2006.

CHUNG, C. S.; STOOKEY, J. D.; DARE, D. Current dietary zinc intake has a grater effect on fractional zinc absorption than does longer term zinc consumption in health adult men. The American Journal Clinical Nutrition. v. 87, p. 1224-1229, 2008.

DAUTREVAUX, M.; BOULANGER, Y.; HAN, K.; BISERTE, G. Structure covalente de la myoglobine de cheval. European Journal Biochemistry. v. 11, p. 267-277, 1969.

DEGRAY, J. A.; GUNTHER, M. R.; TSCHIRRET-GUTH R, MONTELLANO P.R.O; MANSON, R.P. Peroxidation of a specific tryptophan of metmyoglobin by hydrogen peroxide. The Journal of Biological Chemistry, v. 272, n. 4, p. 2359-2362, 1997.

DOLPHIN, D. The Porphyrins. Academic Press, New York, v. 1, 1978. 588 p.

DUNFORD, H. B. Heme peroxidases. New York: John Wiley, 1999. 507 p.

FUKUTO, J. M.; CARRINGTON, S. J.; TANTILLO, D. J.; HARRISON, J. G.; IGNARRO LJ, FREEMAN B.; CHEN, A.; WINK, D.A. Small molecule signaling agents: the integrated chemistry and biochemistry of nitrogen oxides, oxides of carbon, dioxygen, hydrogen sulfide, and their derived species. Chemical Research in Toxicology, v. 25, n. 4, p. 769-793, 2012.

FUKUZUMI, S. Progress in Inorganic Chemistry, v. 56, p. 49-154, 2009.

FUKUZUMI, S.; OHKUBOA, K.; MORIMOTO, Y. Mechanisms of metal ion-coupled electron transfer. Physical. Chemistry Chemistry Physical, v. 14, p. 8472-8484, 2012.

GIBBONS, S. J.; FARRUGIA, G. The role of carbon monoxide in the gastrointestinal tract. The Journal of Physiology, v. 556, p. 325-336, 2004.

GIBBONS, S. J.; VERHULST P.J.; BHARUCHA A.; FARRUGIA G. Review article: carbon monoxide in gastrointestinal physiology and its potential in therapeutics. Alimentary

Pharmacology \& Therapeutics, v. 38, n. 7, p. 689-702, 2013.

GONZALEZ, G.; GILLES-GONZALES, M.A.; RYBAK-AKIMOVA, E. V.; BUCHALOVA, M.;BUSCH, D. H. Mechanisms of autoxidation of the oxygen sensor FISL and Aplysia Myoglobin: Implications for oxygen-binding heme proteins. Biochemistry, v. 37, p. 1018810194, 1998.

GOUTERMAN, M. Optical Spectra and Electronic Structure of Porphyrins and Related Rings. In David Dolphim (Ed.). The Porphyrins, Physical Chemistry, Part 1. New York: Academic Press, 1978. v. 3, p. 1-156

HONGSPRABHAS P.; BARBUT S. Structure-forming Processes in $\mathrm{Ca}^{2+}$-Induced Whey Protein Isolate Cold Gelation. International Dairy Journal. v. 7, p. 827-834, 1998.

HUHEEY, J. E.; KEITER, E. A.; KEITER, R. L. Inorganic chemistry: principles of structure and reactivity. 4. ed. New York. Harper \& Row, 1993. 964 p.

IYER H.V.; PRZYBYCIEN T.M. A Model for Metal Affinity Protein Precipitation. Journal Colloid Interface Science. v. 177, p. 391-400, 1996. 
JAMES, S. J.; JAMES, B. Meat Refrigeration. $1^{\text {a }}$ Ed. Cambridge UK, 2002, 360 p

JØRGENSEN, L. V.; ANDERSEN, H. J.; SKIBSTED, L. H. Kinetics of reduction of hypervalent iron in myoglobin by crocin in aqueous solution. Free Radical Research, v. 27, n. 1, p. $73-87$, 1997.

KARLIN, D. K. Redox control of oxoiron (IV). Nature Chemistry, v. 2, pp. 711-712, 2010.

KELLY, S. M., PRICE, N. C. The Use of Circular Dichroism in the Investigation of Protein Structure and Function. Current Protein and Peptide Science. v. 1, p. 349-384, 2000.

KELMAN, D.; DEGRAY, J. A.; MASON, R. P.; HILL, C.; CAROLINA, N. Reaction of myoglobin with hydrogen peroxide forms a peroxyl radical wich oxidizes substrates. The Journal of Biological Chemistry, v. 269, n. 10, p. 7458-7463, 1994.

KINTON, R.; CESERANI, V.; FOSKETT,D. Enciclopédia de Serviços de Alimentação. São Paulo: Varela, 1999. p. 58-67.

LEE, S.; PHILIPS, A. L.; LIEBLER, D. C.; FAUSTMAN, C. Porcine oxymyoglobin and lipid oxidation in vitro. Meat Science, v. 63, p. 241-247, 2003.

LEPESHKEVICH, S. V.; DZHAGAROV, B. M. Effect of zinc and cadmium ions on structure and function of myoglobin. Biochimica et Biophysica. v. 1794, p. 103-109, 2009.

LIBARDI, S.H.; KRISTENSEN, H. P.; JOSE MANUEL, A. R.; CARDOSO, D.R.; SKIBSTED, L. H. Reduction of ferrylmyoglobin by cysteine as affected by $\mathrm{pH}$. Royal Society Chemistry Advances. v. 4, n. 105, p. 60953-60958, 2014.

LIBARDI, S.H.; SKIBSTED, L. H.; CARDOSO, D.R.; Oxidation of Carbon Monoxide by Perferrylmyoglobin. Journal of Agricultural and Food Chemistry. v. 62, p. 1950-1955, 2014.

LIPPARD, S. J.; BERG, J. M. Principles os bioinorganic chemistry. University Science Books, Mill Valley, p. 21-45, 1994.

LUND, M. N.; LUXFORD, C.; SKIBSTED, L. H.; DAVIES, M. J. Oxidation of myosin by haem proteins generates myosin radicals and protein cross-links. Biochemical Journal, v. 410, p. 565574, 2008.

MAHLEY, R. W.; HUANG, Y. Apolipoprotein (apo) E4 and Alzheimer's disease: unique conformational and biophysical properties of apoE4 can modulate neuropathology. Acta Neurologica Scandinavica Supplementum. v. 185, p. 8-14, 2006.

MAINES, M. D. The heme oxygenase system: a regulator of second messenger gases. Annual Review of Pharmacology and Toxicology, v. 37, p. 517-554, 1997.

MASON M. YAMASHITA, M. M.; WESSON, L.; EISENMAN, G.; EISENBERG, D. Where metal ions bind in proteins. Proceedings of the National Academy of Sciences. v. 87, p. 5648-5652, 1990.

MØLLER, J. K. S. Myoglobins and nitric oxide. 2002. 105 f. Tese (Pós-Doutorado)Departament of Dairy and Food Science - Section for Food Chemistry - The Royal Veterinary and Agricultulral University, Dinamarca, 2002. 
MONDAL, S.; RAPOSO, M. L.; PRIETO, G.; GHOSH, S. Interaction of Myoglobin with Cationic and Nonionic Surfactant in Phosphate Buffer Media. Journal of Chemical \& Engineering Data, v. 61, p. 1221-1228, 2016.

MOREIRA, L. M.; RIBELATTO, J. C.; IMASATO, H. Conformações distorcida e planar do anel porfirínico em complexos e hemoptroteínas: propriedades físico-químicas e implicações espectroscópicas. Química Nova, v. 27, n. 6, p. 958-963, 2004.

MOTTRAM, D. S. Flavour formation in meat and meat products: a review. Food Chemistry. v. 62, i. 4, p. 415-424, 1998.

NAKANISHI, K., BEROVA, N., WOOD, R. W. Circular Dichroism. Principles and Applications, VCH: New York, 1994.

OHGUSHI, M.; WADA, A. "Molten-globule state": a compact form of globular proteins with mobile side-chains. FEBS Letters. v. 164(1), p. 21-24, 1983.

OLSON, J. S.; MATHEWS, A. J.; ROHLFS, R. J.; SPRINGER, B. A.; EGEBERG, K. D.; SLIGAR, S. G.; TAME, J.; RENAUD, J. P.; NAGAI, K. The role of the distal histidine in myoglobin and haemoglobin. Nature, v. 336, p. 265-266, 1988.

PECORA, R. Dynamic light scattering measurement of nanometer particles in liquids. Journal of Nanoparticle Research, v. 2, n. 2, p. 123-131, 2000.

PEGG, R. B.; SHAHIDI, F. Unraveling the chemical identy of meat pigments. Critical Reviews in Food Science and Nutrition, v. 37, n. 6, p. 567-589, 1997.

POTTER, W. T.; TUCKER, M. P.; HOUTCHENS, R. A.; CAUGHEY, W. S. Oxygen Infrared Spectra of Oxyhemoglobins and Oxymyoglobins. Evidence of Two Major Liganded $\mathrm{O}_{2}$ Structures. Biochemistry, v. 26, p. 4699-4707, 1987.

PTITSYN, O. How molten is the molten globule? Nature Structural \& Molecular Biology, v. 3(6), p. 488-490, 1996.

RAO, S. I.; WILKS, A.; HAMBERG, M.; MONTELLANO, P. R. O. The lipoxygenase activity of myoglobin. The Journal of Biological Chemistry, v. 12, n. 10, p. 7210-7216, 1994.

REIMER, L., KOHL, H. Transmission electron microscopy: physics of image formation. 5 ed. Springer Series in Optical Sciences, 2008. 590 p.

REMONDETTO G. E.; SUBIRADE M. Molecular mechanisms of $\mathrm{Fe}^{2+}$-induced betaLactoglobulin cold gelation, Biopolymers. v. 69, p. 461-469, 2003.

RENERRE, M.; ANTON, M.; GATELLIER, PH. Autooxidation of Purified Myoglobin from two bovine muscles. Meat Science. v. 32, p. 331-342, 1991.

ROCHET, J.C.; LANSBURY, J. P. T. Amyloid fibrillogenesis: Themes and variations. Current Opinion in Structural Biology. v. 10, p. 60-68, 2000.

ROMERO, F. J.; ORDONEZ, I.; ARDUINI, A.; CADENAS E. The reactivity of thiols and disulfides with different redox states of myoglobin. Journal of Biological Chemistry, v. 267, n. 3, p. 1680-1688, 1992.

RONCONE, R.; MONZANI, E.; NICOLIS, S.; CASELLA, L. Engineering and prosthetic-group modification of myoglobin: peroxidase activity, chemical stability and unfolding properties. European Journal Inorganic Chemistry. p. 2203-2213, 2004. 
RUGGERI, F. S.; HABCHIB, J.; CERRETAC, A.; DIETLER, G. AFM-Based Single Molecule Techniques: Unraveling the Amyloid Pathogenic Species. Current Pharmaceutical Design. v. 22, p. 3950-3970, 2016.

SANNA, M. T.; MANCONI, B.; CASTAGNOLA, M.; GIARDINA, B.; MASIA, D.; MESSANA, I.; OLIANAS, A.; PATAMIA, M.; PETRUZZELLI, R.; PELLEGRINI, M. Functional and structural characterization of the myoglobin from the polychaete Ophelia bicornis. Biochemical Journal. v. 389, p. 497-505, 2005.

SCHMID, F. X. Optical spectroscopy to characterize protein conformation and conformational changes. Protein Structure. A Practical Approach. v. 174, n. 11, p. 261-297, 1997.

SHIKAMA, K. The Molecular Mechanism of Autoxidation for Myoglobin and Hemoglobin: A Venerable Puzzle. Chemical Reviews. v.98, p.1357-1373, 1998.

SHIKAMA, K.; MATSUOKA, A. Human haemoglobin A new paradigm for oxygen binding involving two types of $\alpha \beta$ contacts. European Journal Biochemistry, v. 270, p. 4041-4051, 2003.

SHRIVER, D. F.; ATKINS, P. W. Inorganic Chemistry. 5 a ed. Oxford UK IE. 2009.

SKORA, L., S. B.; ZWECKSTETTER, M. Molten globule precursor states are conformationally correlated to amyloid fibrils of human beta-2-microglobulin. Journal American Chemistry Society. v. 132(27): p. 9223-5, 2010.

STADTMAN, E. R., Olivier, C. N. Metal-catalyzed oxidation of proteins. Physiological consequences. Journal Biological Chemistry, v. 266, n. 4, p. 2005-2013, 1991.

SUMAN, S. O.; JOSEPH, P. Myoglobin chemistry and meat color. Annual Review of Food Science and Technology, v. 4, p. 79-99, 2013.

TAKAGI, T.; NAITO, Y.; TSUBOI, H.; ISOZAKI, Y.; KATADA, K.; SUZUKI, T.; et al. Increased intestinal luminal carbon monoxide gas in patients with ulcerative colitis. Alimentary Pharmacology \& Therapeutics Symposium Series, v. 2, n.1, p. 233-238, 2006.

TEICHMANN, I. Tecnologia Culinária.Caxias do Sul: Educs, 2000. p. 176-188.

TOFANI, L.; FEIS, A.; SNOKE, R. E.; BERTI, D.; BAGLIONI, P.; SMULEVICH, G. Spectroscopic and interfacial properties of myoglobin/ surfactant complexes. Biophysical Journal. v. 87, p. 1186-1195, 2004.

UNIVERSITY OF LEEDS. Faculty of Biological Sciences. Disponível em: < http://www.fbs.leeds.ac.uk/facilities/cd/>. Acesso em Jan. 2018.

UVERSKY, V.N.; LI, J.; FINK, A.L. Evidence for a partially folded intermediate in alphasynuclein fibril formation. Journal Biological Chemistry. v. 276(14), p. 10737-44, 2001.

VALLEE, B. L.; FALCHUK, K. H. The biochemical basis of zinc physiology. Physiological Review. N, 73, p. 79-118, 1993.

WETLAUFER, D. B. Ultraviolet spectra Of Proteins and Amino Acids. Advances in Protein Chemistry. v. 17, p. 303-390, 1963.

WHITTEN, D. G.; LOPP, I. G.; WILDES, P. D. Journal American Chemistry Society. v. 90, p. 7196, 1968. 
YANG, J. C.; SMALL, M. W.; GRIESHABER, R. V.; RALPH G. NUZZO, R. G. Recent developments and applications of electron microscopy to heterogeneous catalysis. Chemical Society Reviews. v. 41, p. 8179-8194, 2012.

YON, J.M. Protein folding: concepts and perspectives. Cellular and Molecular Life Sciences,. v. 53(7): p. 557-67, 1997.

ZHANG, L.; LEVY, A.; RIFKIND, J. M. Autoxidation of hemoglobin enhaceded by dissociation into dimers. Journal Biological Chemistry. v. 266, p. 24698-24701, 1991.

ZHANG, R.; CHANDRASENA, R. E. P.; ARTINEZ, E.; HORNER, J. H.; NEWCOMB, M. Formation of Compound I by Photo-Oxidation of Compound II. Organic Letters. v. 7, n. 6, p. 1193-1195, 2005. 


\section{APÊNDICE A}

Figura 1A. Espectros de absorção eletrônica referente a auto-oxidação da oximioglobina (3,62 $\times$ $10^{-5} \mathrm{~mol} \mathrm{~L}^{-1}$ ) adquiridos em diferentes tempos após a adição do íon $\mathrm{Zn}^{\mathrm{II}}$. Espectros de absorção $(544 \mathrm{~nm})$ em função do tempo. Tampão acetato $0,16 \mathrm{~mol} \mathrm{~L}^{-1} \mathrm{pH}=5,8(\mathrm{~T}=298 \mathrm{~K})$.
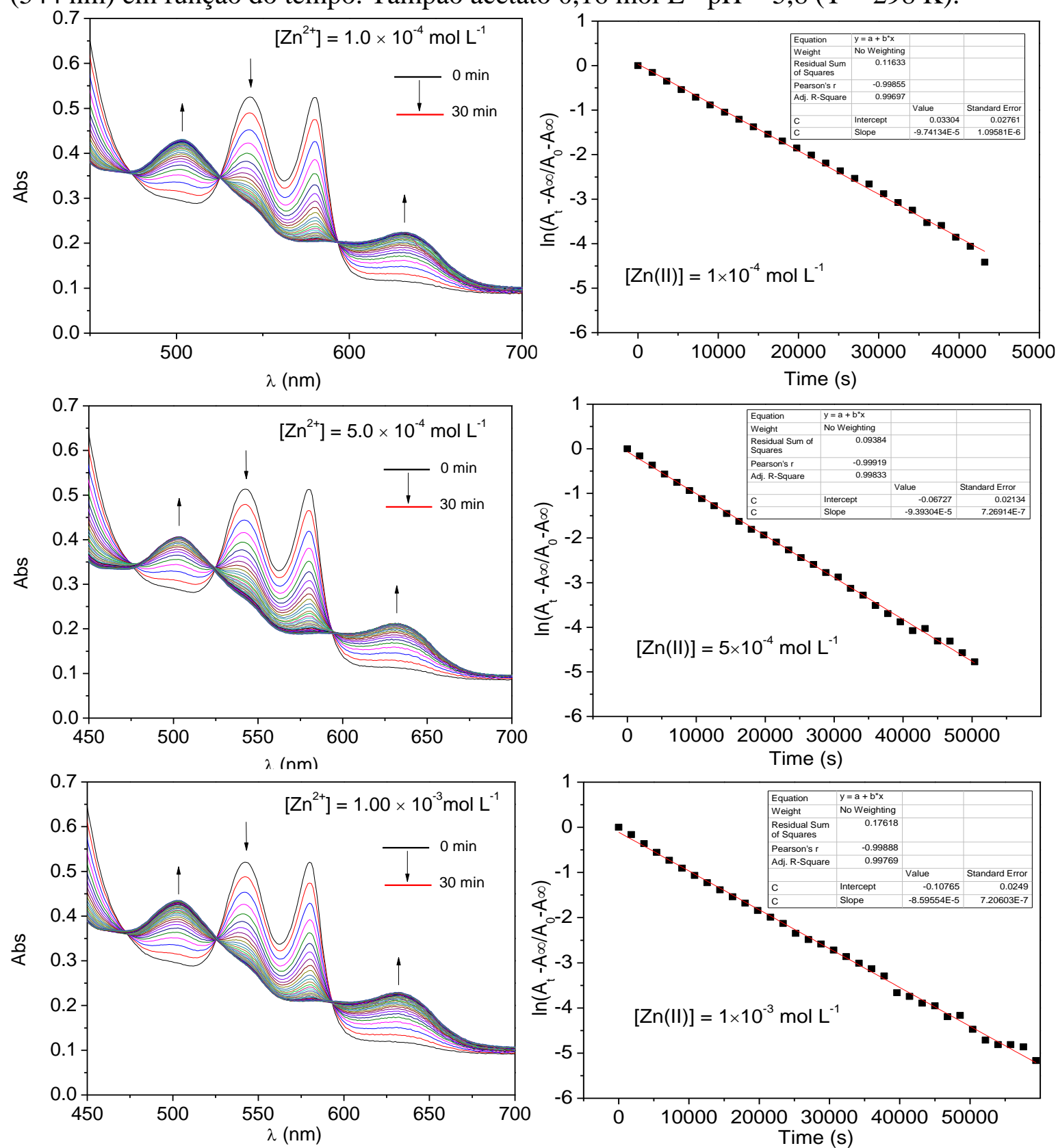

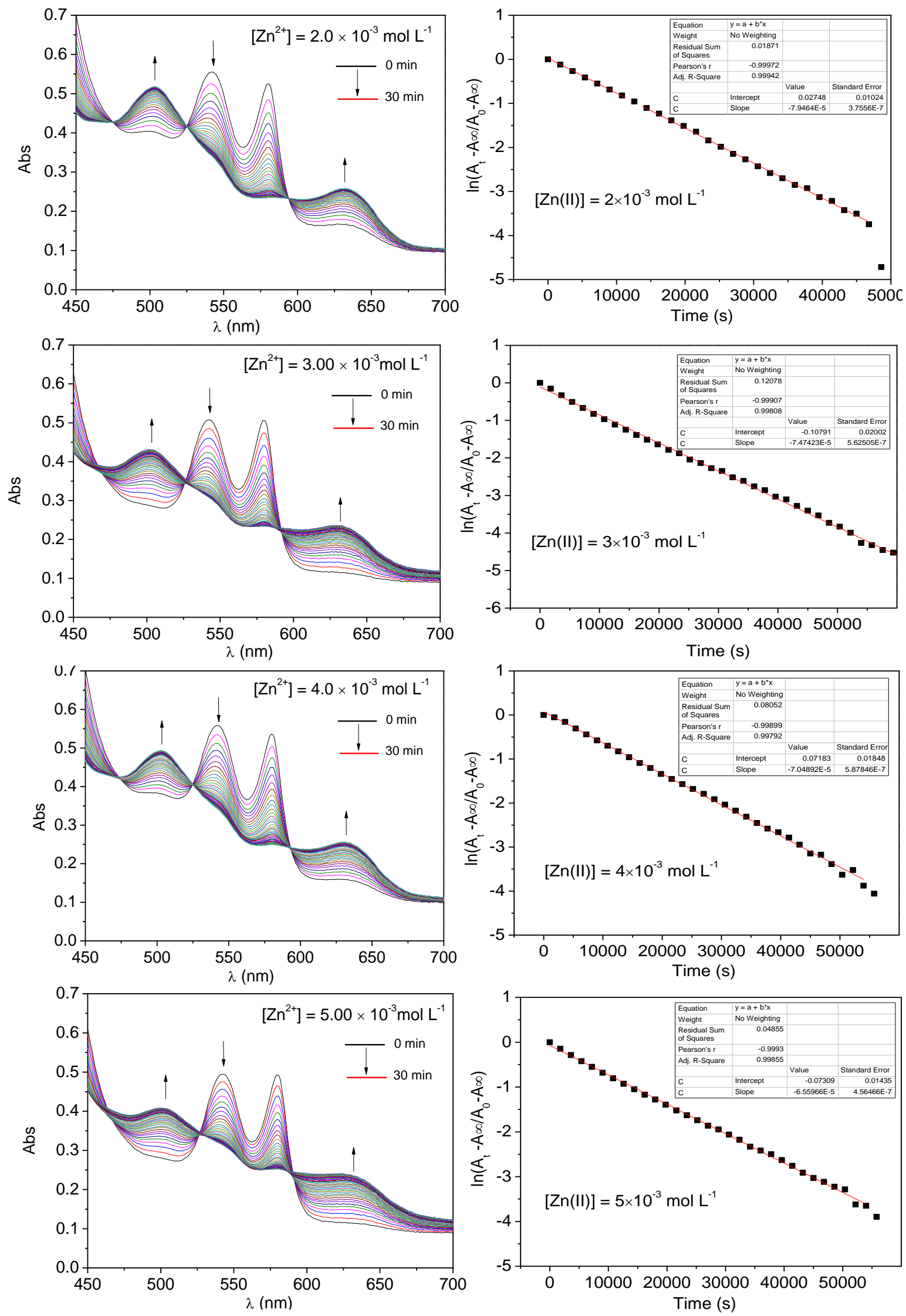

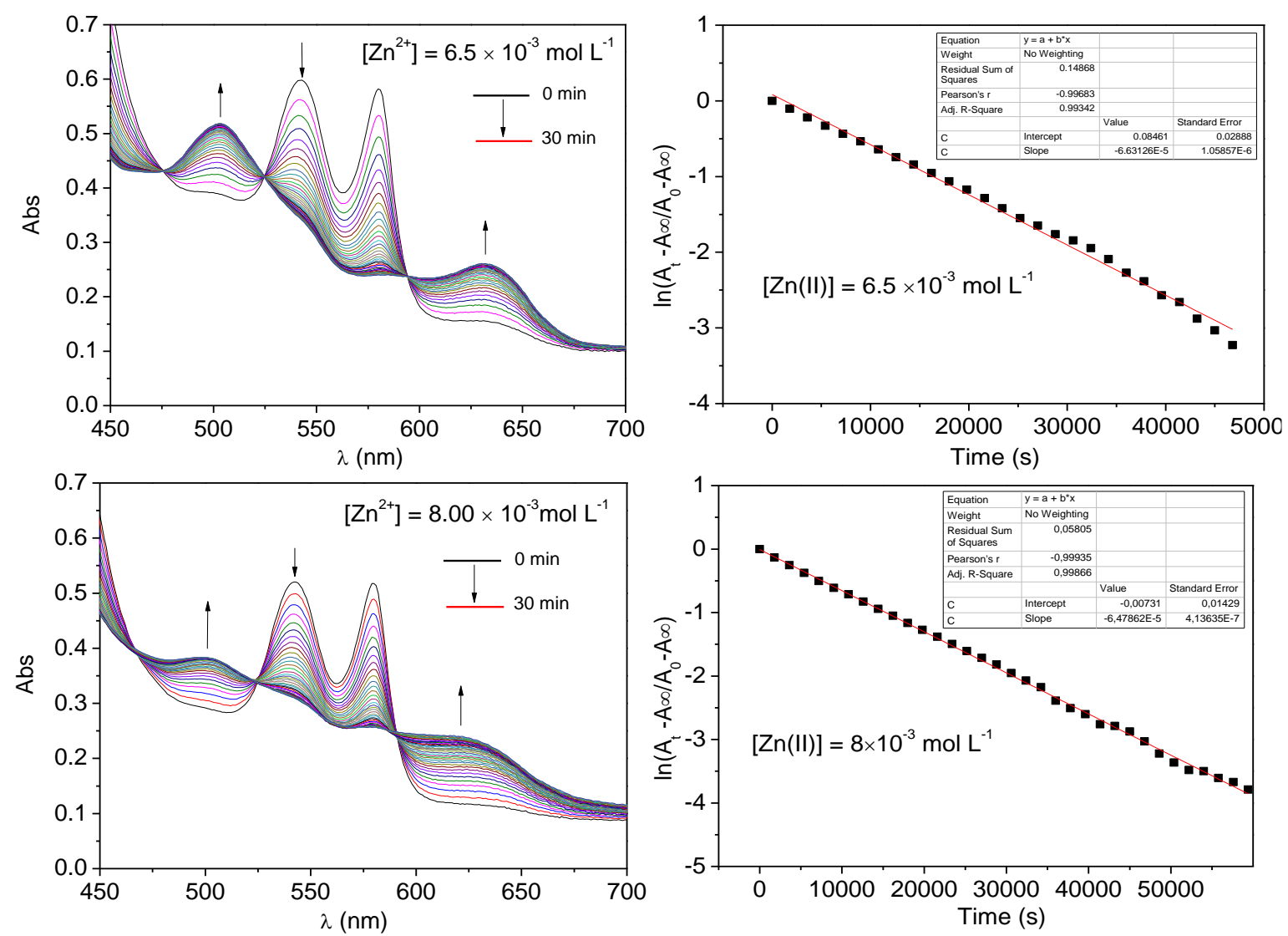


\section{APÊNDICE B}

Figura 1B. espectro de absorção eletrônica referente ao processo de auto-redução da ferrilmioglobina na presença de diferentes concentrações de $\mathrm{Zn}^{\mathrm{II}}$.
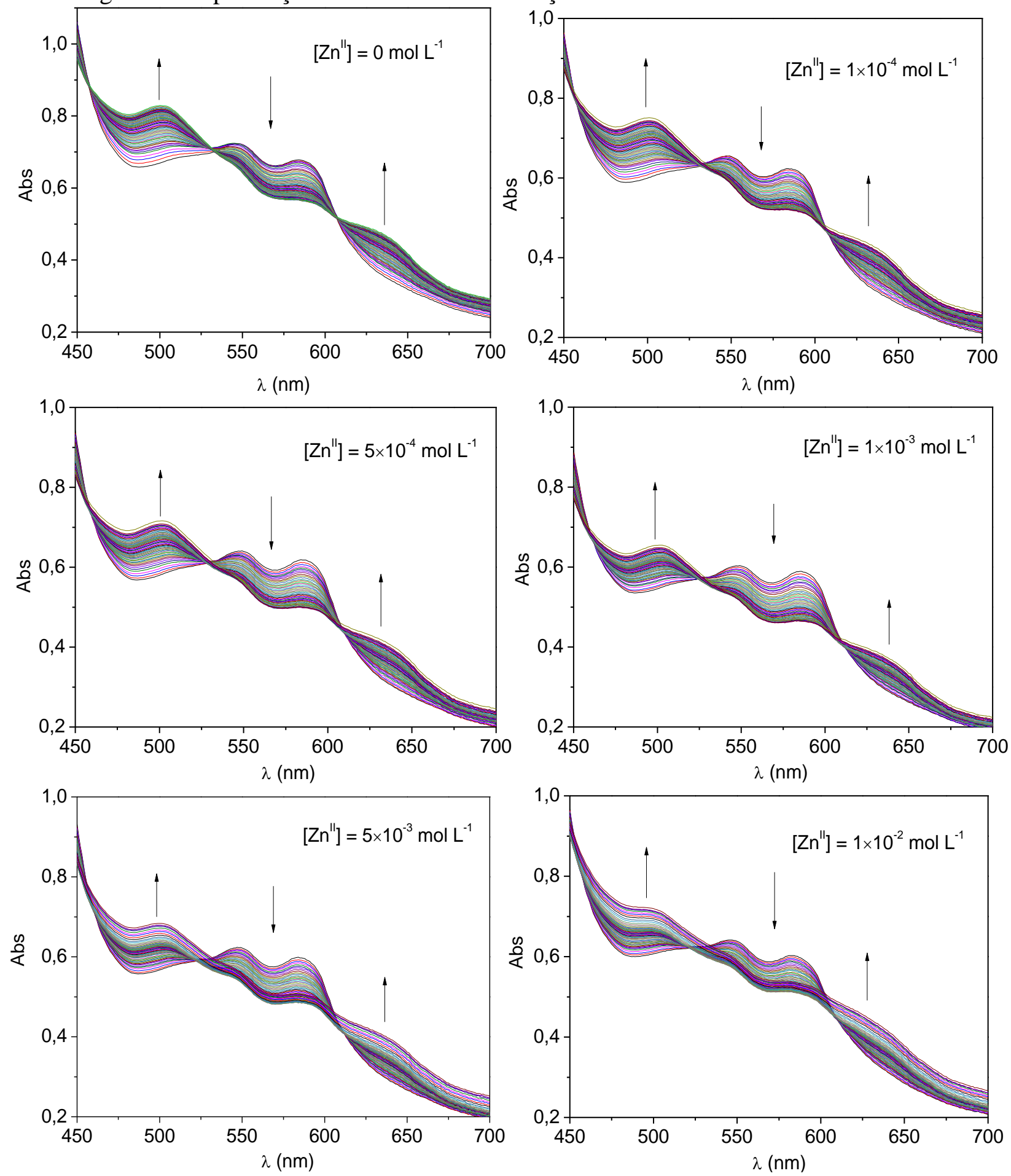


\section{APÊNDICE C}

Figura 1C. Espectro de absorção eletrônica referente a redução da ferrilmioglobina $\left(\left[\mathrm{MbFe}^{\mathrm{IV}}=\mathrm{O}\right]\right.$ $=5 \times 10^{-5} \mathrm{~mol} \mathrm{~L}^{-1}$ ) pela cisteína. (B) Absorção eletrônica em $580 \mathrm{~nm}$ e $625 \mathrm{~nm}$ em função do tempo, correspondente a espécie $\mathrm{MbFe}^{\mathrm{IV}}=\mathrm{O}$ e a espécie SulfMbFe ${ }^{\mathrm{II}}$ respectivamente. Solução tampão acetato à temperatura de $298 \mathrm{~K}$.

I. $\left[\mathrm{Zn}^{\mathrm{II}}\right]=0 \mathrm{~mol} \mathrm{~L}^{-1}$
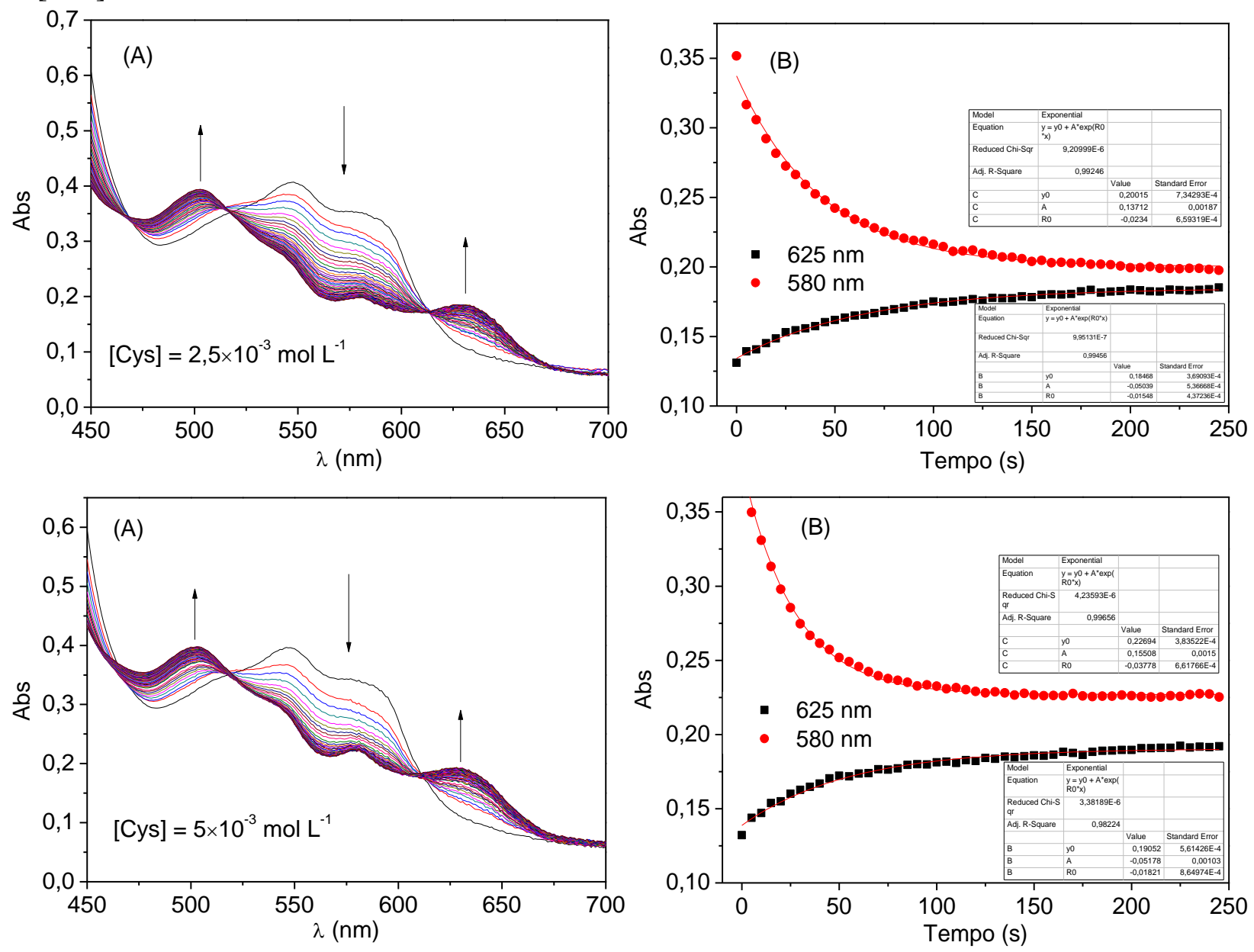

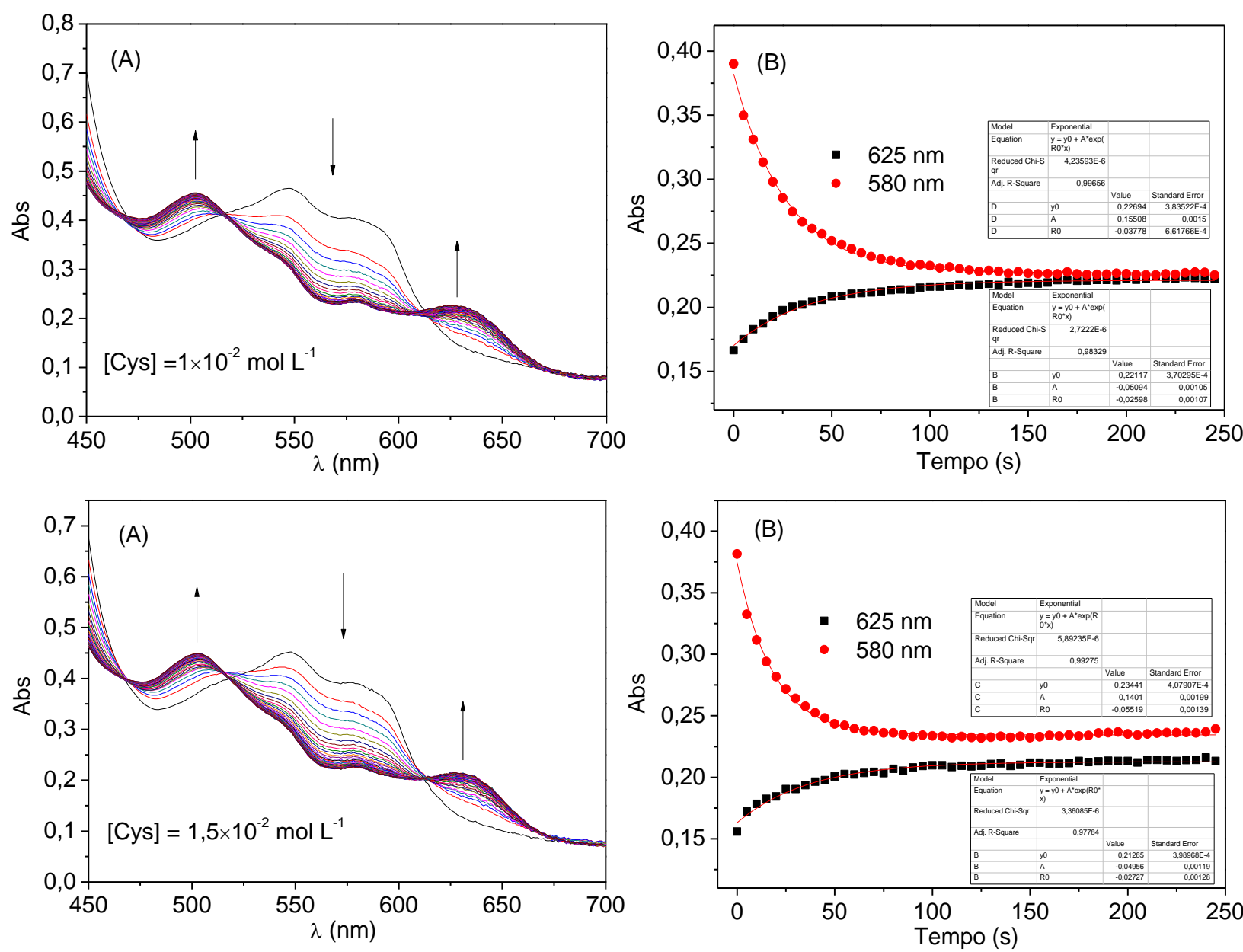

Constantes de segunda ordem $\left(\mathrm{k}_{2}\right)$ em $580 \mathrm{~nm}$ e $625 \mathrm{~nm}$ do processo de redução da espécie ferrilmioglobina em função da concentração de cisteína.
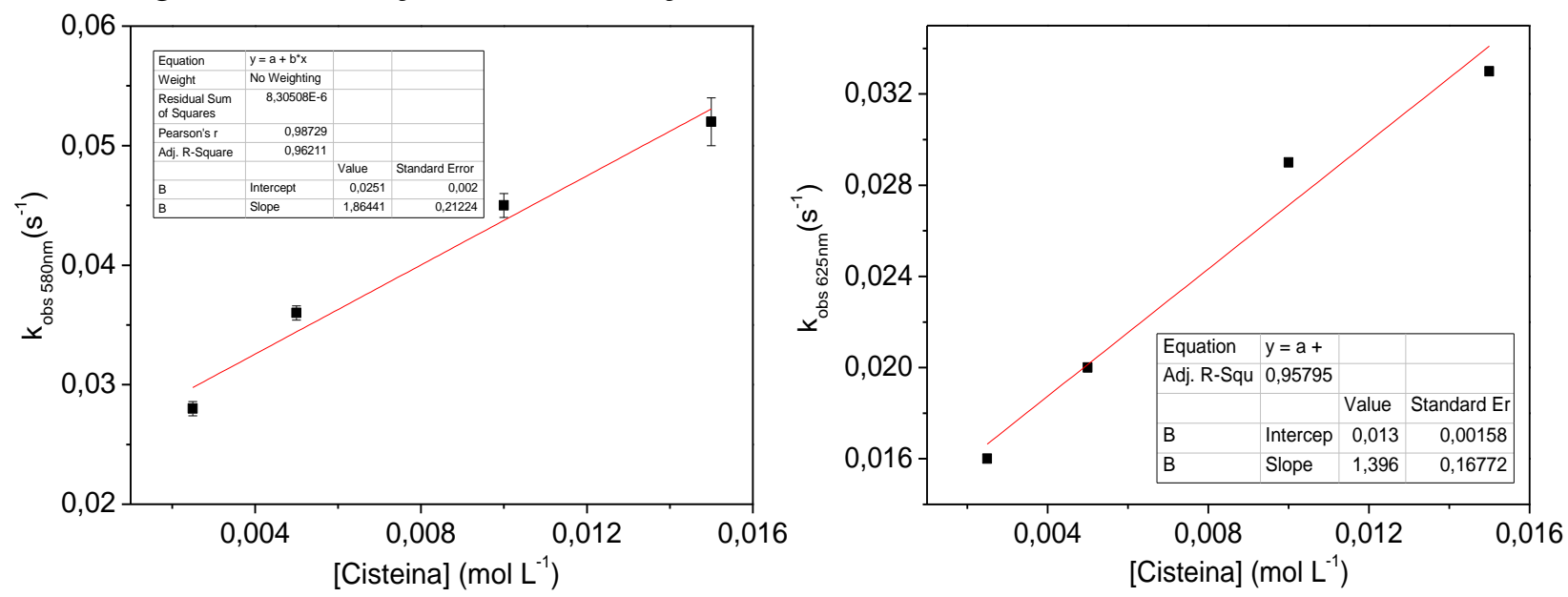
II. $\left[\mathrm{Zn}^{\mathrm{II}}\right]=5 \times 10^{-5} \mathrm{~mol} \mathrm{~L}^{-1}$
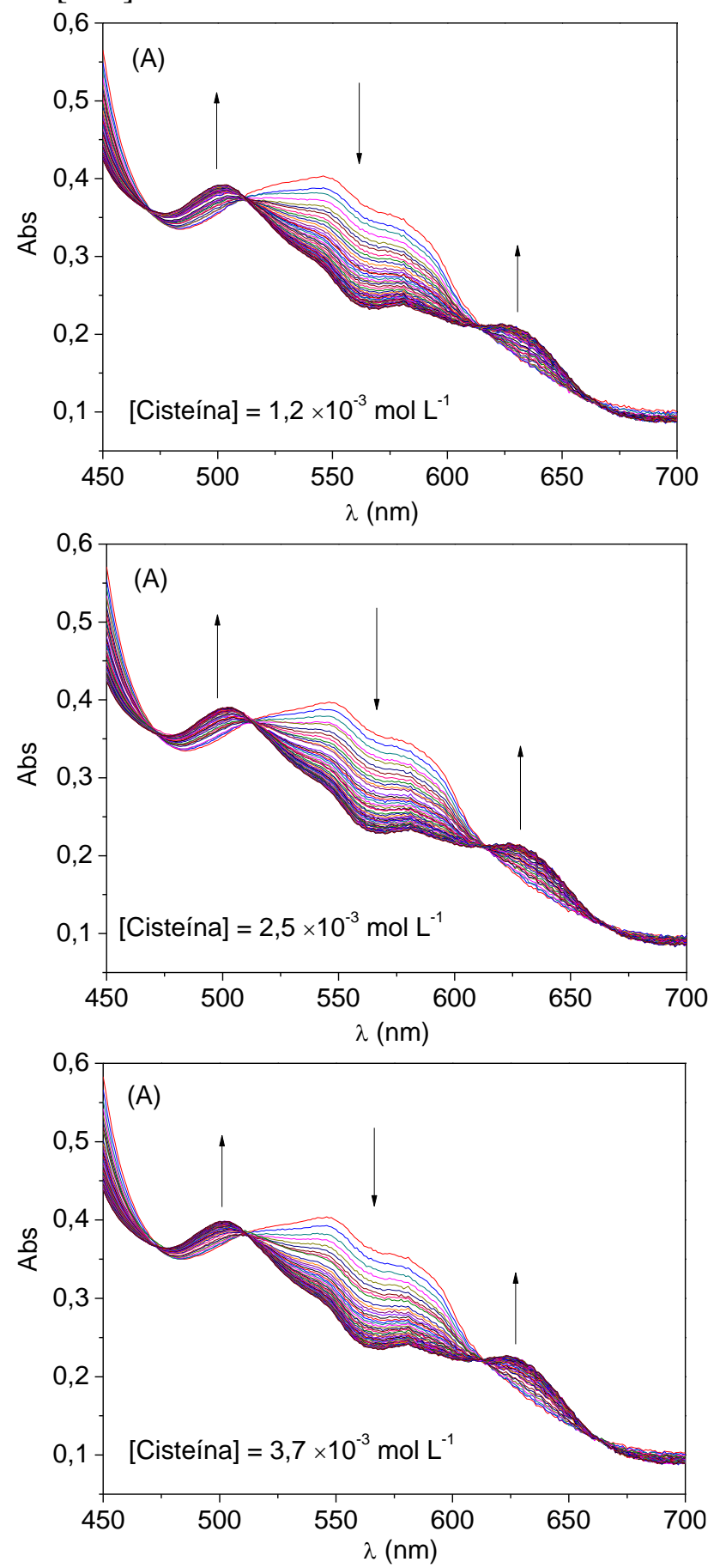
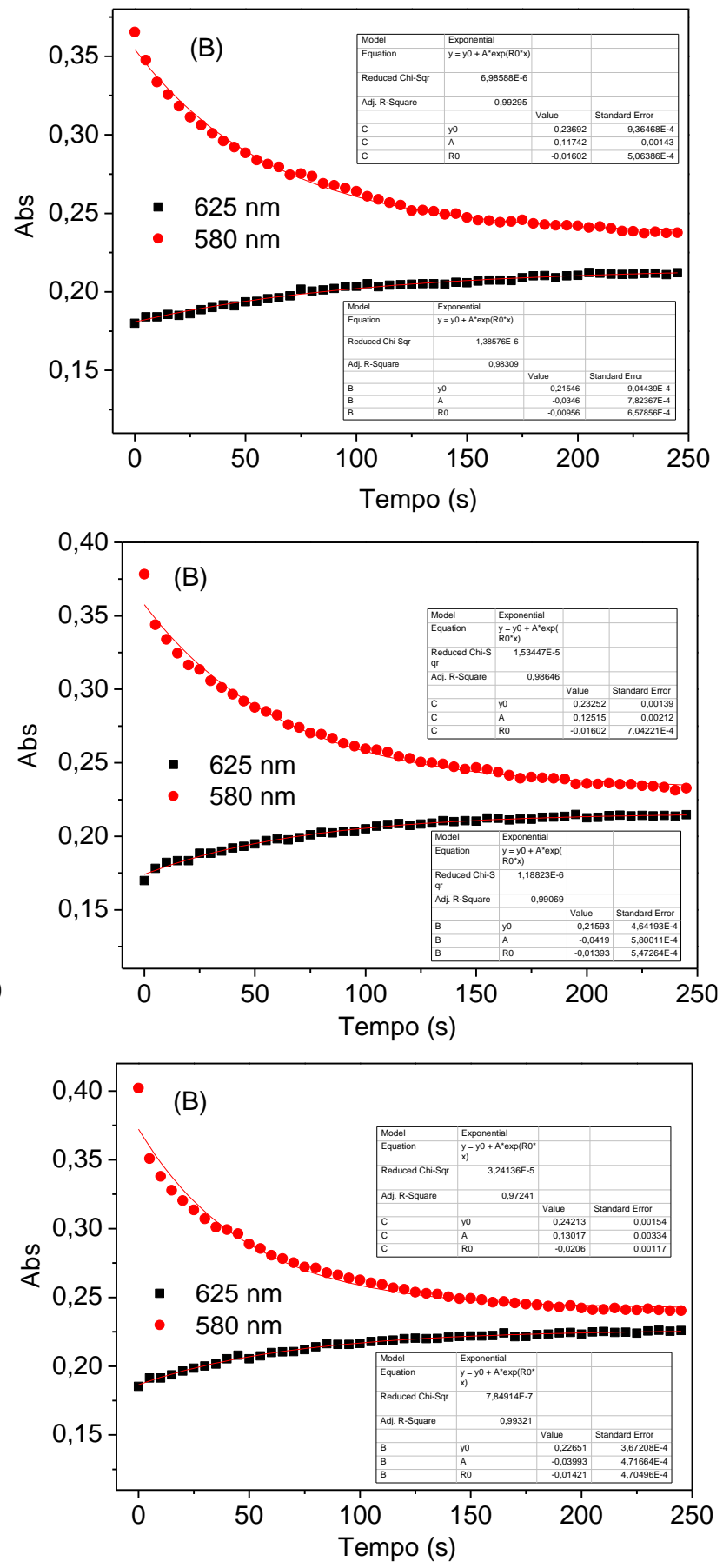

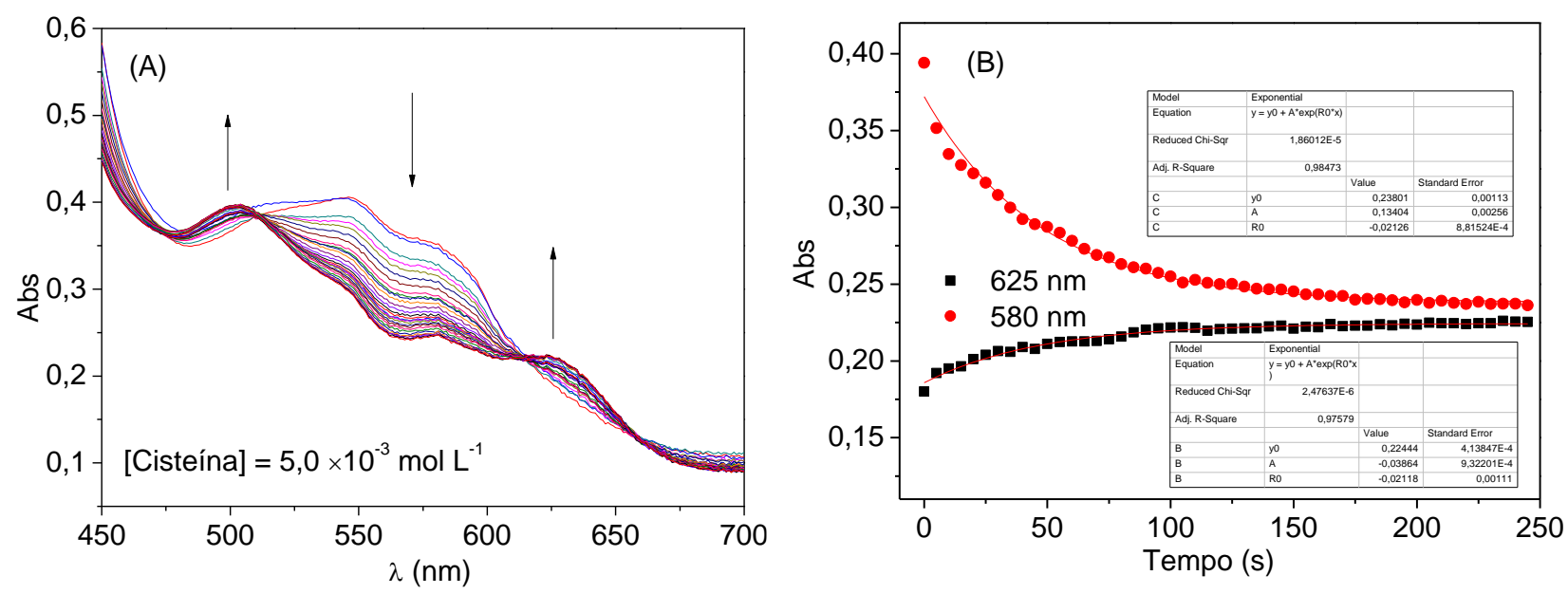

Constantes de segunda ordem $\left(\mathrm{k}_{2}\right)$ em $580 \mathrm{~nm}$ e $625 \mathrm{~nm}$ do processo de redução da espécie ferrilmioglobina em função da concentração de cisteína, para $\left[\mathrm{Zn}^{\mathrm{II}}\right]=5 \times 10^{-5} \mathrm{~mol} \mathrm{~L}^{-1}$
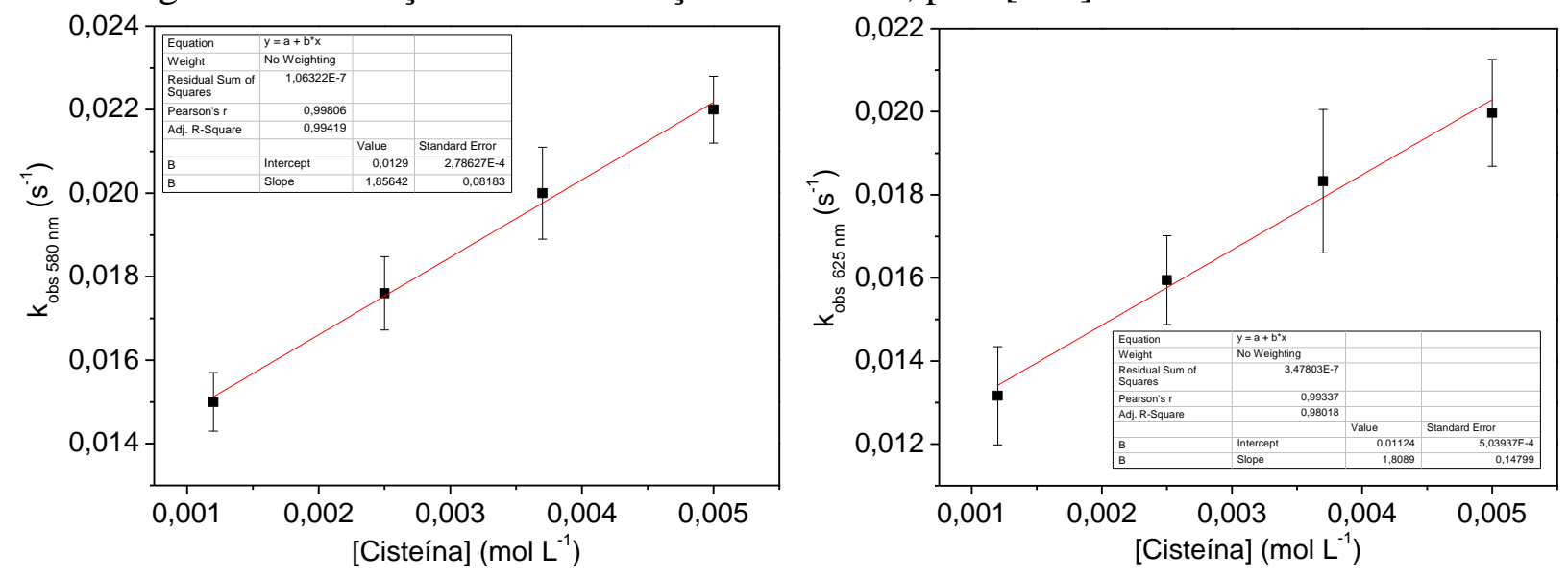

III. $\left[\mathrm{Zn}^{\mathrm{II}}\right]=2 \times 10^{-4} \mathrm{~mol} \mathrm{~L}^{-1}$
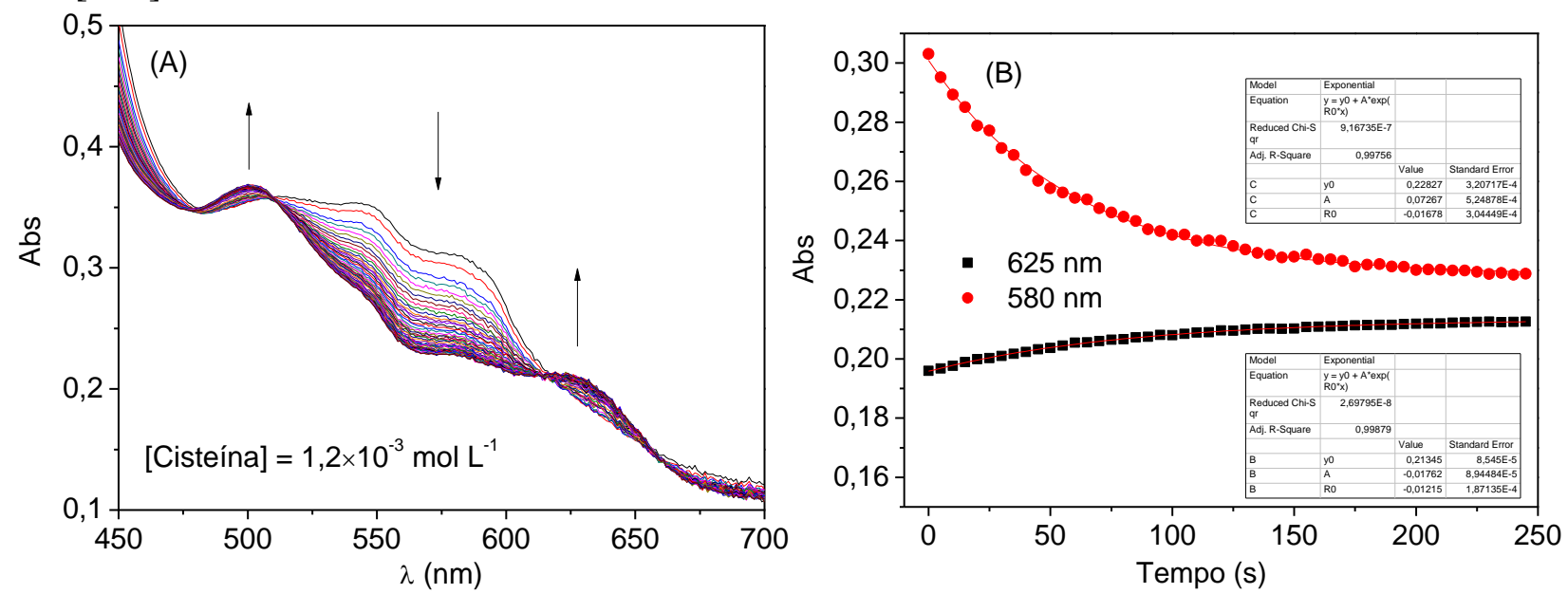

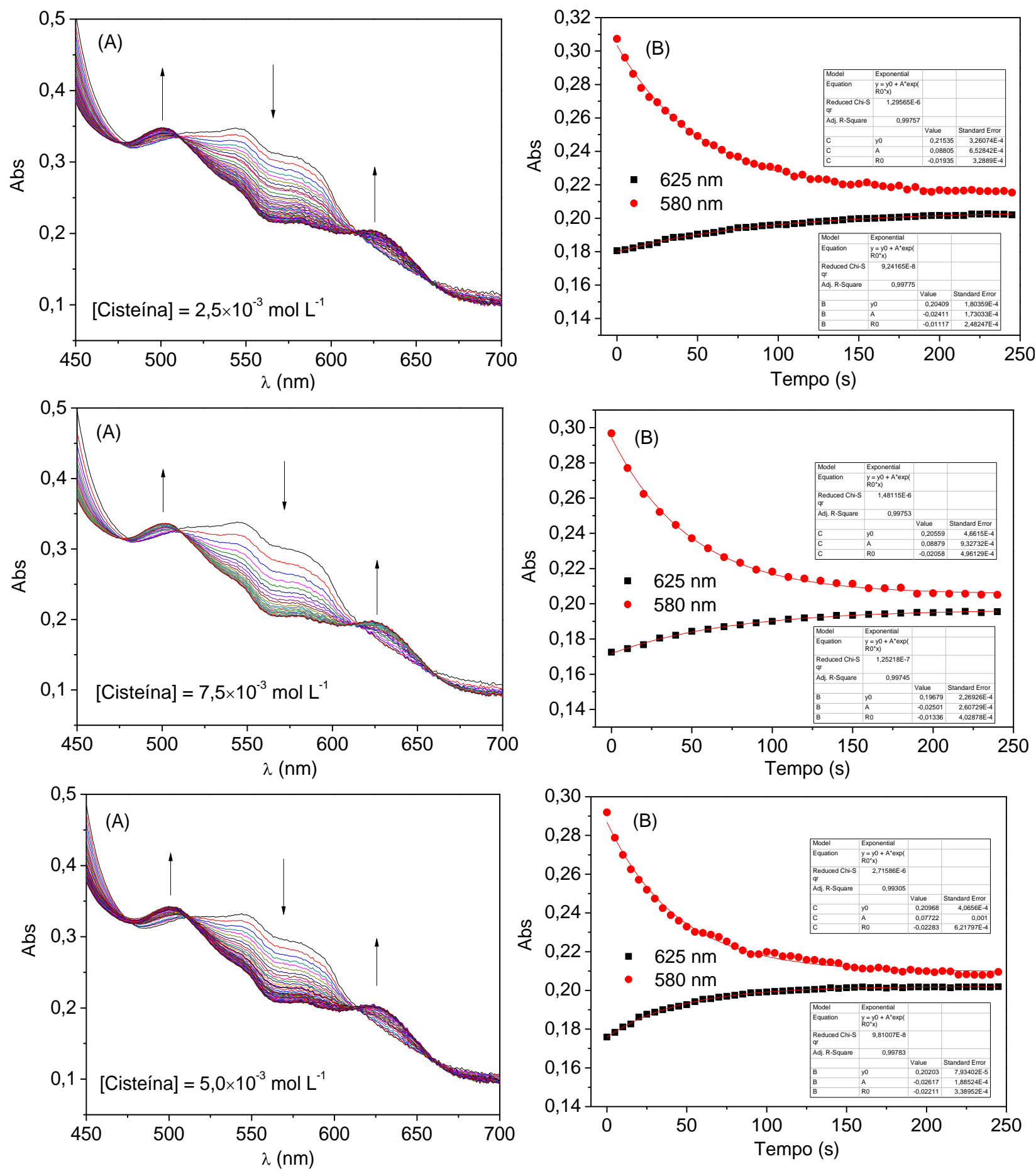
Constantes de segunda ordem $\left(\mathrm{k}_{2}\right)$ em $580 \mathrm{~nm}$ e $625 \mathrm{~nm}$ do processo de redução da espécie ferrilmioglobina em função da concentração de cisteína, para $\left[\mathrm{Zn}^{\mathrm{II}}\right]=2 \times 10^{-4} \mathrm{~mol} \mathrm{~L}^{-1}$.
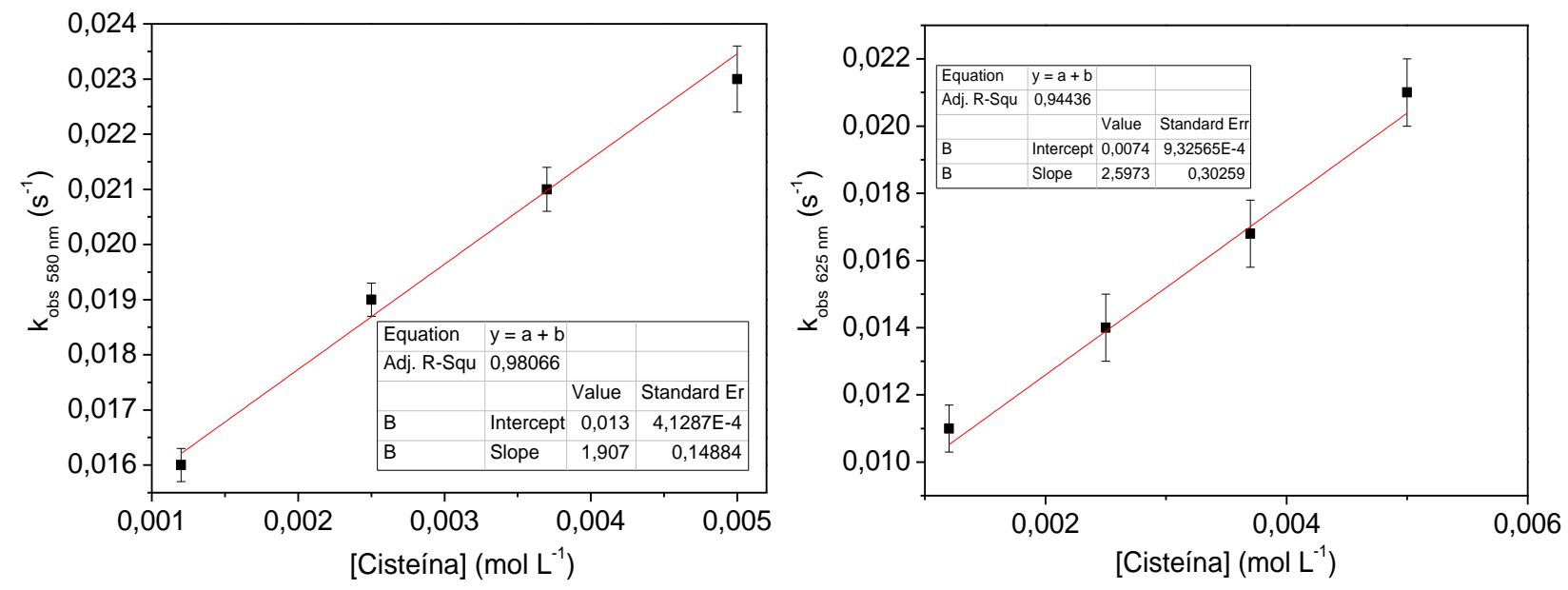

$I V .\left[\mathrm{Zn}^{\mathrm{II}}\right]=5 \times 10^{-4} \mathrm{~mol} \mathrm{~L}^{-1}$
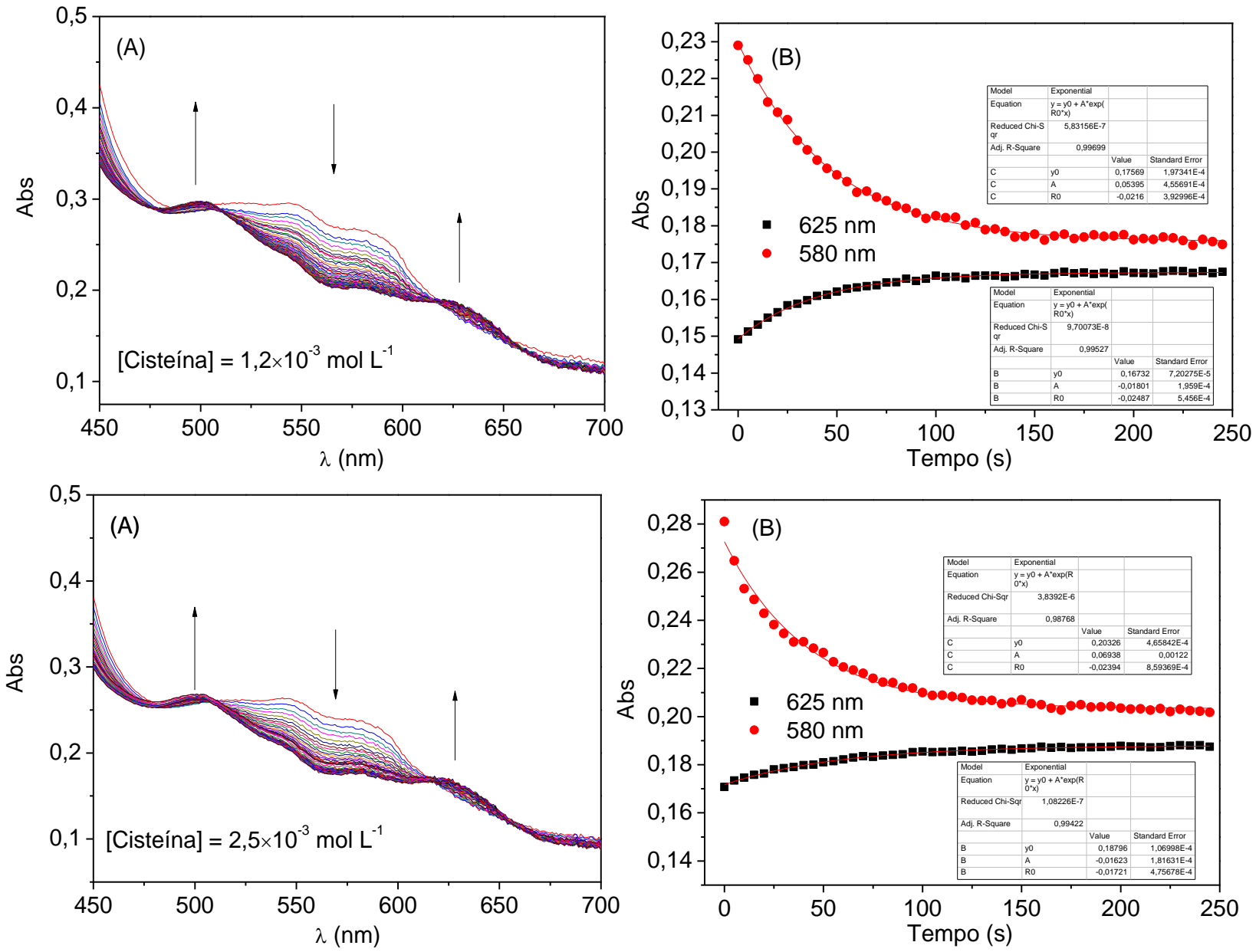

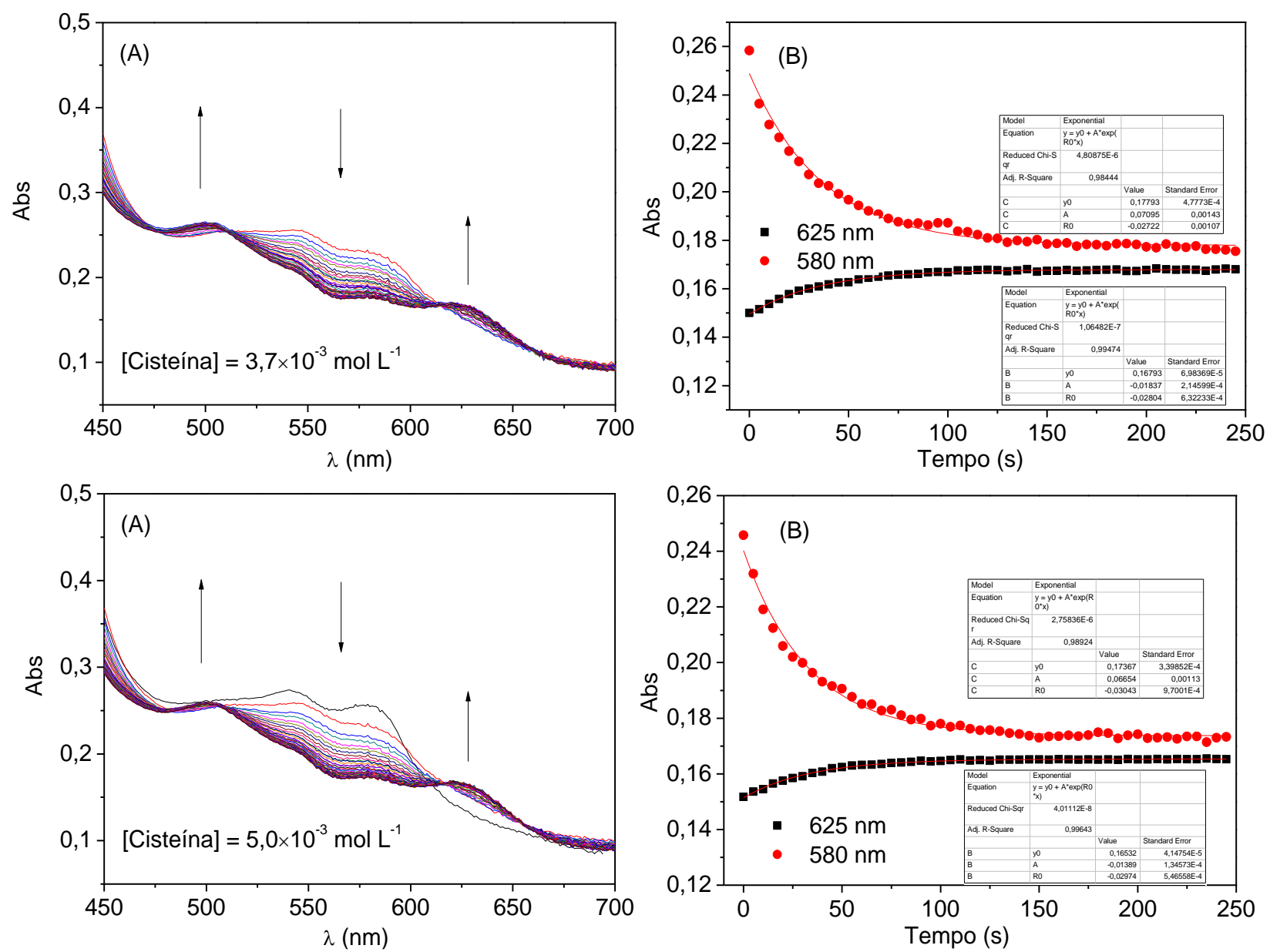

Constantes de segunda ordem $\left(\mathrm{k}_{2}\right)$ em $580 \mathrm{~nm}$ e $625 \mathrm{~nm}$ do processo de redução da espécie ferrilmioglobina em função da concentração de cisteína, para $\left[\mathrm{Zn}^{\mathrm{II}}\right]=5 \times 10^{-4} \mathrm{~mol} \mathrm{~L}^{-1}$
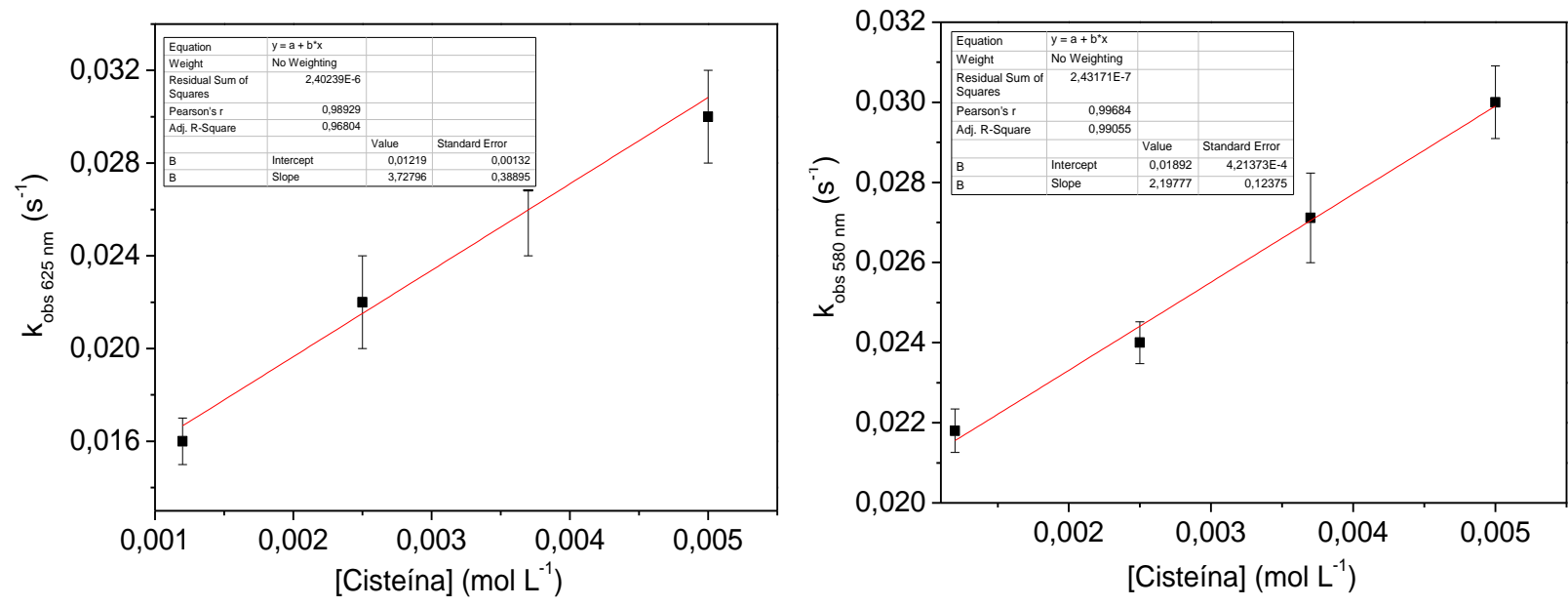
V. $\left[\mathrm{Zn}^{\mathrm{II}}\right]=8 \times 10^{-4} \mathrm{~mol} \mathrm{~L}^{-1}$
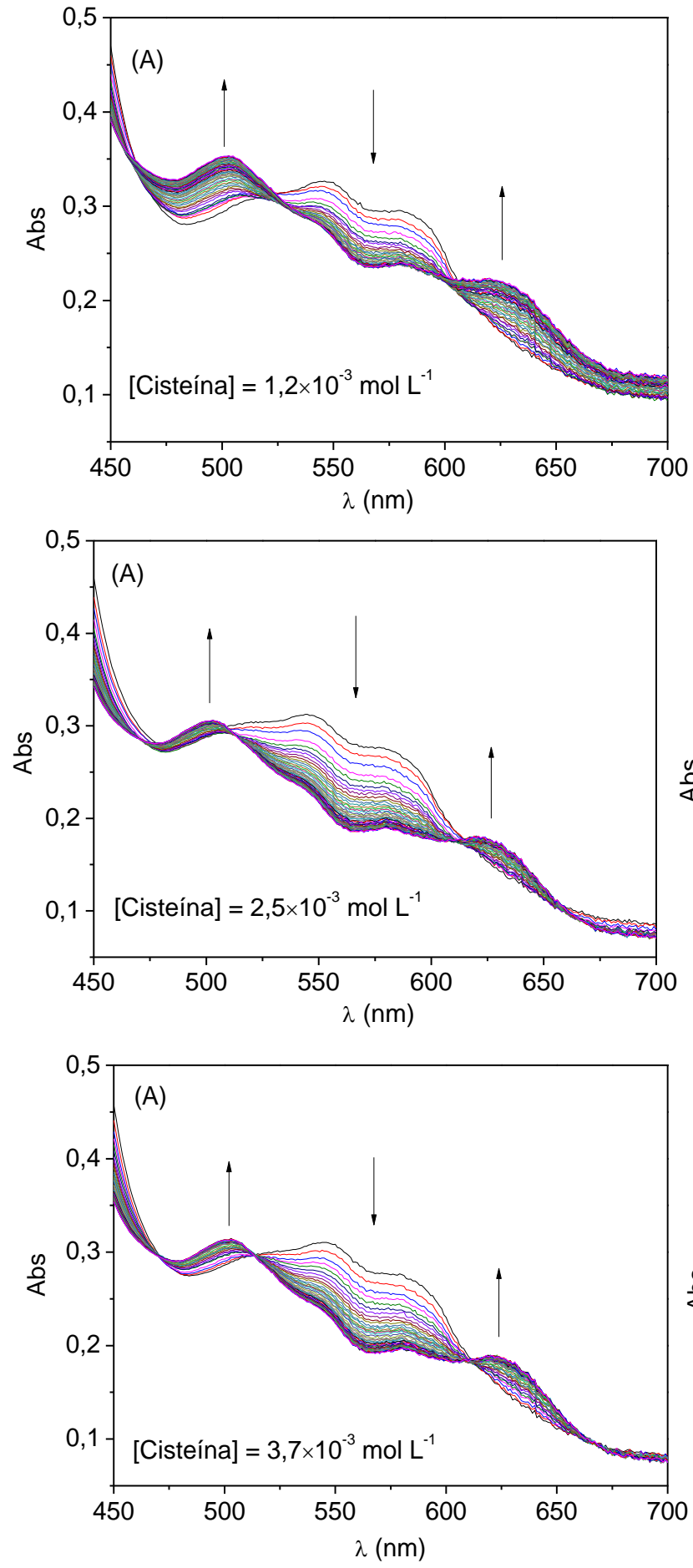
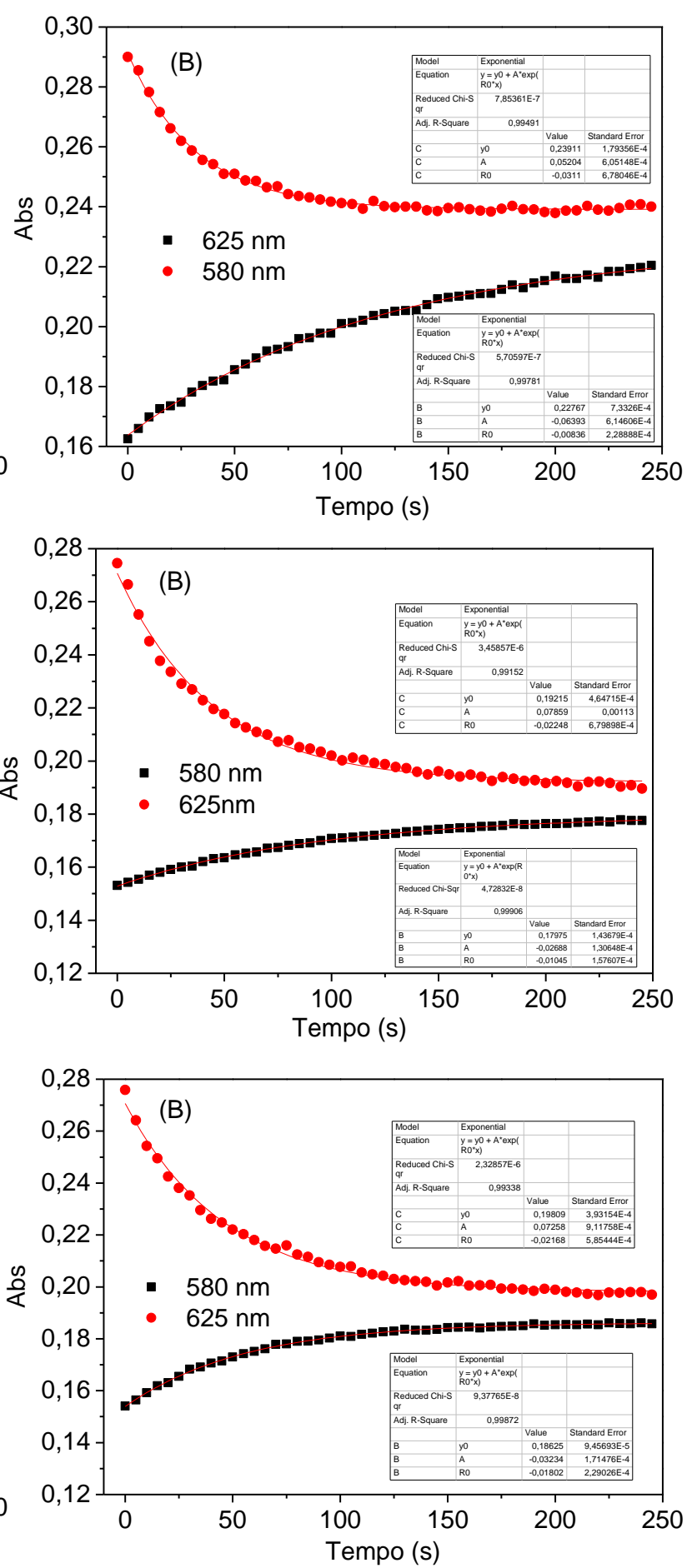

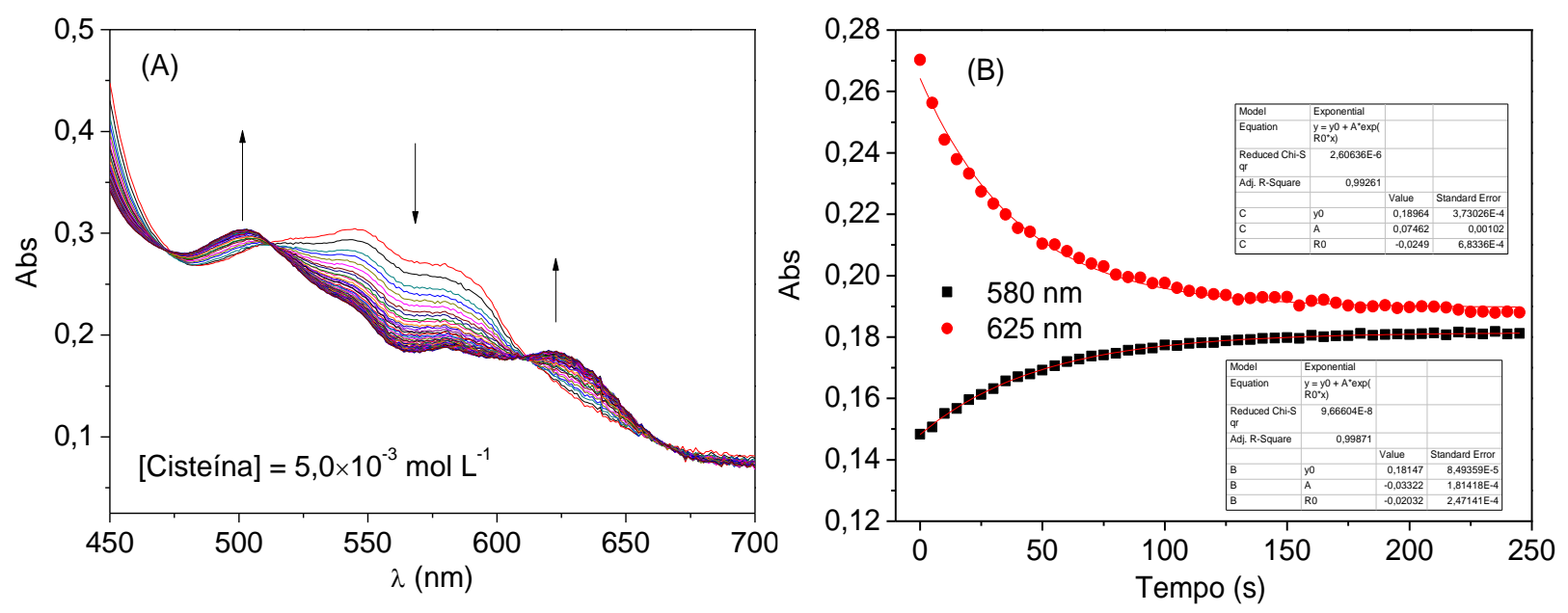

Constantes de segunda ordem $\left(\mathrm{k}_{2}\right)$ em $580 \mathrm{~nm}$ e $625 \mathrm{~nm}$ do processo de redução da espécie ferrilmioglobina em função da concentração de cisteína, para $\left[\mathrm{Zn}^{\mathrm{II}}\right]=8 \times 10^{-4} \mathrm{~mol} \mathrm{~L}^{-1}$.
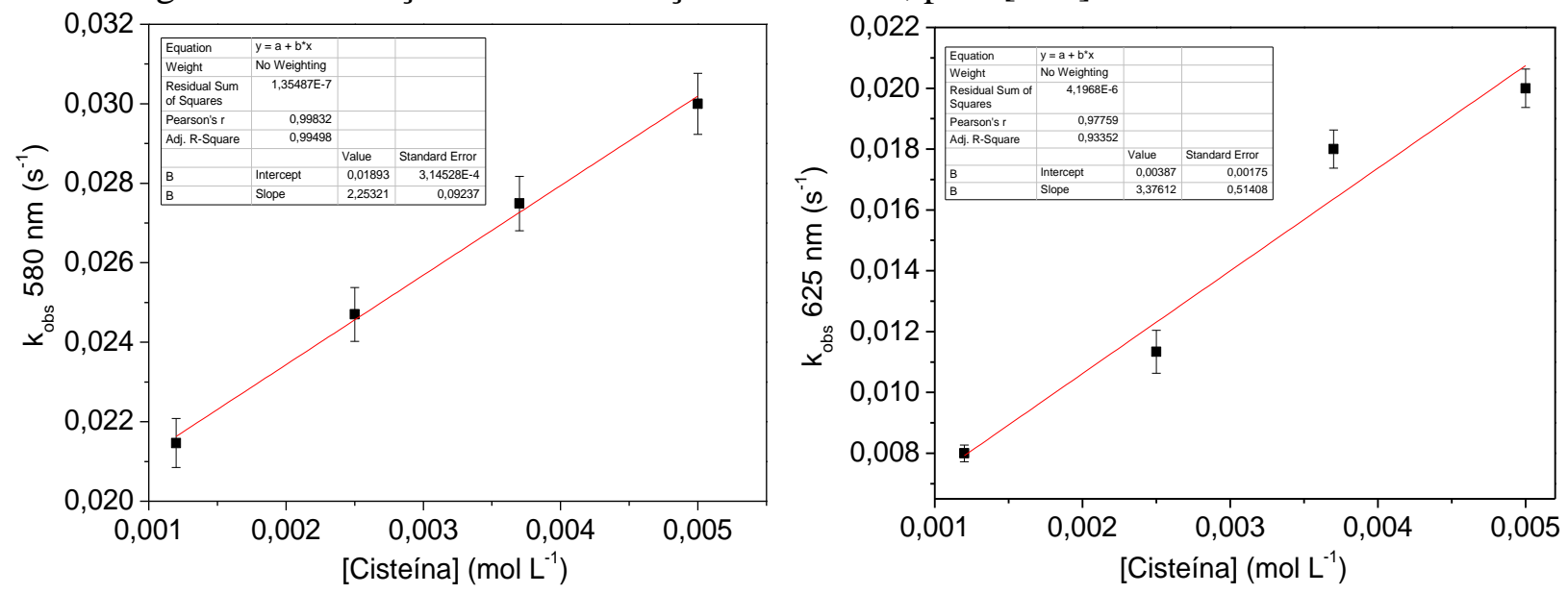

VI. $\left[\mathrm{Zn}^{\mathrm{II}}\right]=1 \times 10^{-3} \mathrm{~mol} \mathrm{~L}^{-1}$
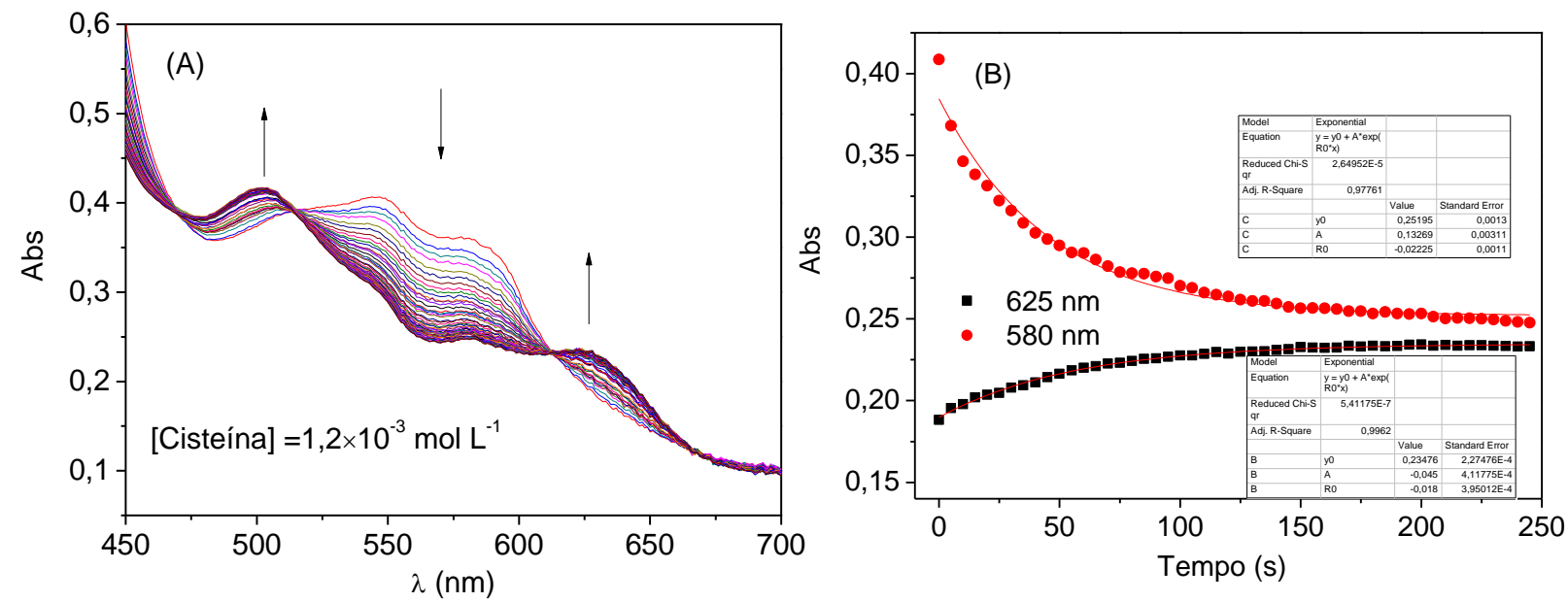

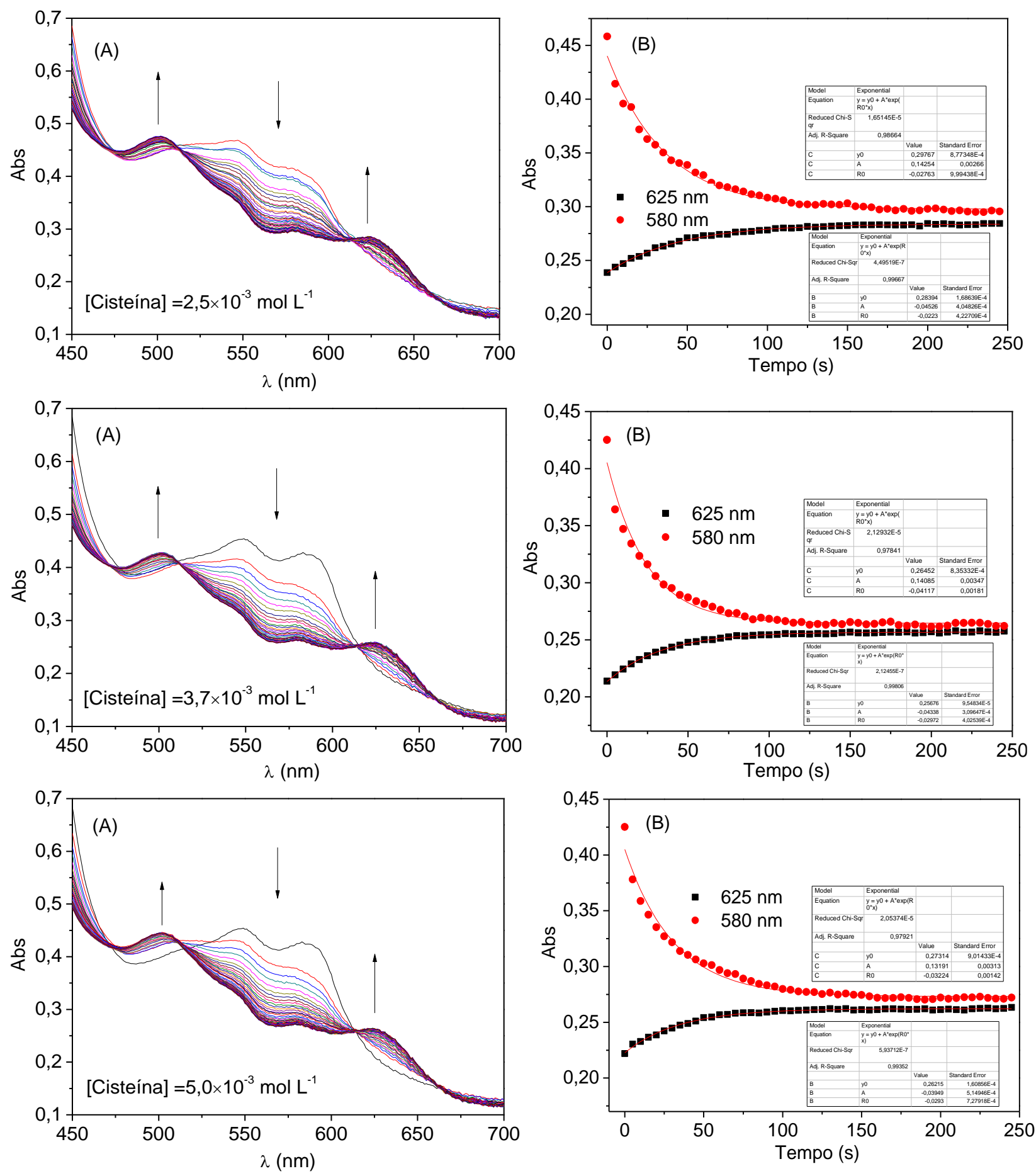
Constantes de segunda ordem $\left(\mathrm{k}_{2}\right)$ em $580 \mathrm{~nm}$ e $625 \mathrm{~nm}$ do processo de redução da espécie ferrilmioglobina em função da concentração de cisteína, para $\left[\mathrm{Zn}^{\mathrm{II}}\right]=1 \times 10^{-3} \mathrm{~mol} \mathrm{~L}^{-1}$.
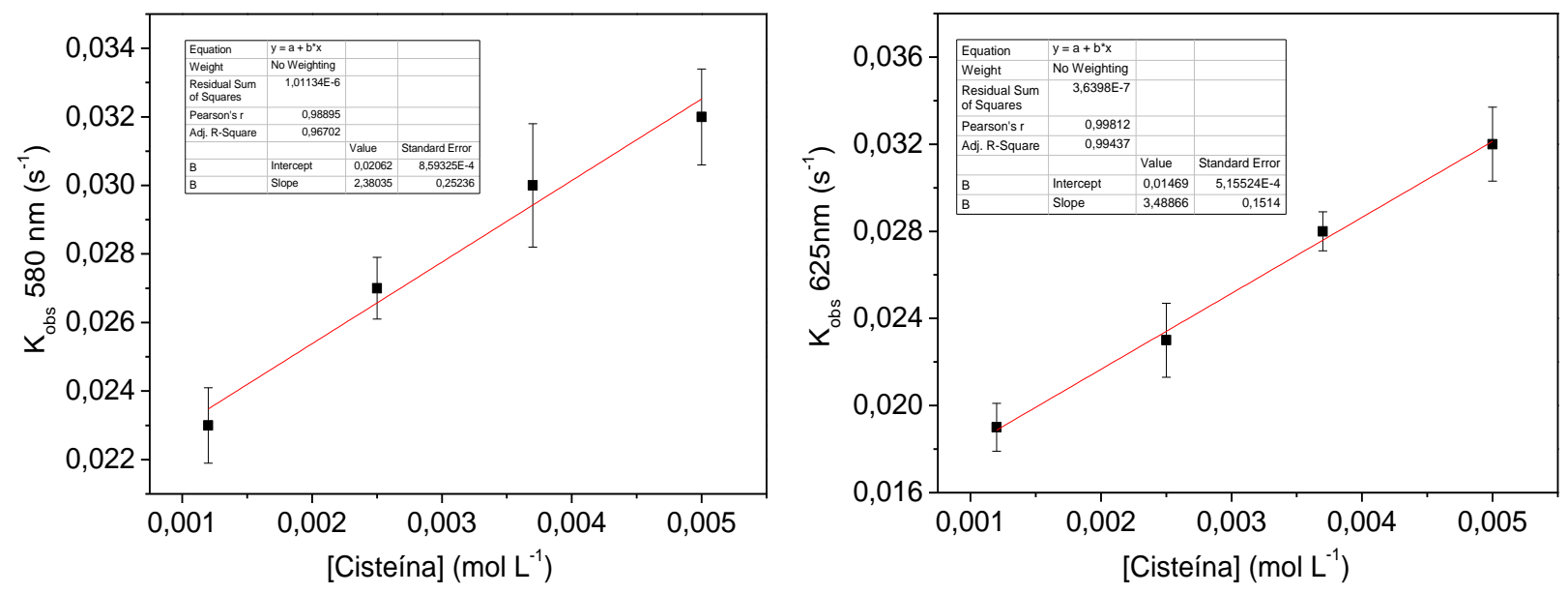